MARCO DEL NEGRO

Federal Reserve Bank of New York

DOMENICO GIANNONE

Federal Reserve Bank of New York
MARC P. GIANNONI

Federal Reserve Bank of New York

ANDREA TAMBALOTTI

Federal Reserve Bank of New York

\title{
Safety, Liquidity, and the Natural Rate of Interest
}

\begin{abstract}
Why are interest rates so low in the Unites States? We find that they are low primarily because the premium for safety and liquidity has increased since the late 1990s, and to a lesser extent because economic growth has slowed. We reach this conclusion using two complementary perspectives: a flexible time series model of trends in Treasury and corporate yields, inflation, and long-term survey expectations; and a medium-scale dynamic stochastic general equilibrium model. We discuss the implications of this finding for the natural rate of interest.
\end{abstract}

\section{A} t least since the Great Recession, interest rates have been persistently at or near historical lows in many advanced economies. In the United States, short-term interest rates have only recently risen above their effective lower bound, while 10-year nominal Treasury bond yields have hovered around 2 percent since mid-2011. In comparison, 10-year yields averaged 6.7 percent in the 1990 s and 4.5 percent in the first decade of the 2000s. The causes and macroeconomic implications of this secular decline in interest rates have been widely discussed, even reawakening the specter of secular stagnation, a chronic economic malaise characterized by low growth and low rates of return (Hansen 1939; Summers 2014). The decline in interest rates poses important challenges for monetary policy, as shown

Conflict of Interest Disclosure: The authors did not receive financial support from any firm or person for this paper or from any firm or person with a financial or political interest in this paper. They are currently not officers, directors, or board members of any organization with an interest in this paper. The analysis and conclusions set forth are those of the authors and do not indicate concurrence by the Federal Reserve Bank of New York or the Federal Reserve Board. 
by Michael Kiley and John Roberts (2017); but it also matters for fiscal policy, and for our understanding of the nature of business cycles.

In this paper, we contribute to the debate on the extent of the secular decline in interest rates, and on its fundamental drivers, from two complementary perspectives. First, we estimate a flexible time series model - a vector autoregression (VAR), with common trends- to extract the permanent component of the real interest rate from data on nominal bond returns, inflation, and their long-run survey expectations. We also use this model to decompose the overall trend in interest rates into some of its fundamental drivers. Second, we estimate a medium-scale dynamic stochastic general equilibrium (DSGE) model that features nominal, real, and financial frictions. This model provides a structural view of the underlying forces driving interest rates, which is complementary to that provided by the less restricted time series model. Remarkably, the two models provide a very consistent view of the low-frequency movements in the real interest rate and of its underlying sources.

The common thread running through these two empirical exercises is that they both focus on recovering the properties of the natural rate of interest, henceforth $r_{t}^{*}$ for short. This concept was originally proposed by Knut Wicksell (1898), and it has been formalized in the context of modern macroeconomics by Michael Woodford (2003). We define $r_{t}^{*}$ as the real return to an asset with the same safety and liquidity attributes as a 3-month U.S. Treasury bill in a counterfactual economy without nominal rigidities. To the extent that these rigidities are the main source of the real effects of monetary policy, as they are in our DSGE model, the natural rate of interest is the counterfactual rate that would be observed "in the absence" of monetary policy. Therefore, it summarizes the real forces driving the movements in interest rates, abstracting from the influence of monetary policy decisions. We emphasize the safety and liquidity properties of $r_{t}^{*}$ because central banks generally target returns on short-term safe and liquid assets. Therefore, for $r_{t}^{*}$ to be a useful benchmark for monetary policy, it should be associated with the return to an asset that possesses such attributes.

Our three main findings can be summarized as follows. First, the VAR and DSGE models recover very similar estimates of the low-frequency component of the natural rate, as shown in figure 1. According to both models, this trend was fairly stable, at about 2 to 2.5 percent, from the early 1960s to the mid-1990s; it reached a peak in the late 1990s; and it has been declining steadily since then. We estimate its current level to be between 1 and 1.5 percent. 
Figure 1. The Low-Frequency Component of $r_{t}^{*}$ in the VAR and DSGE Models, 1960-2016

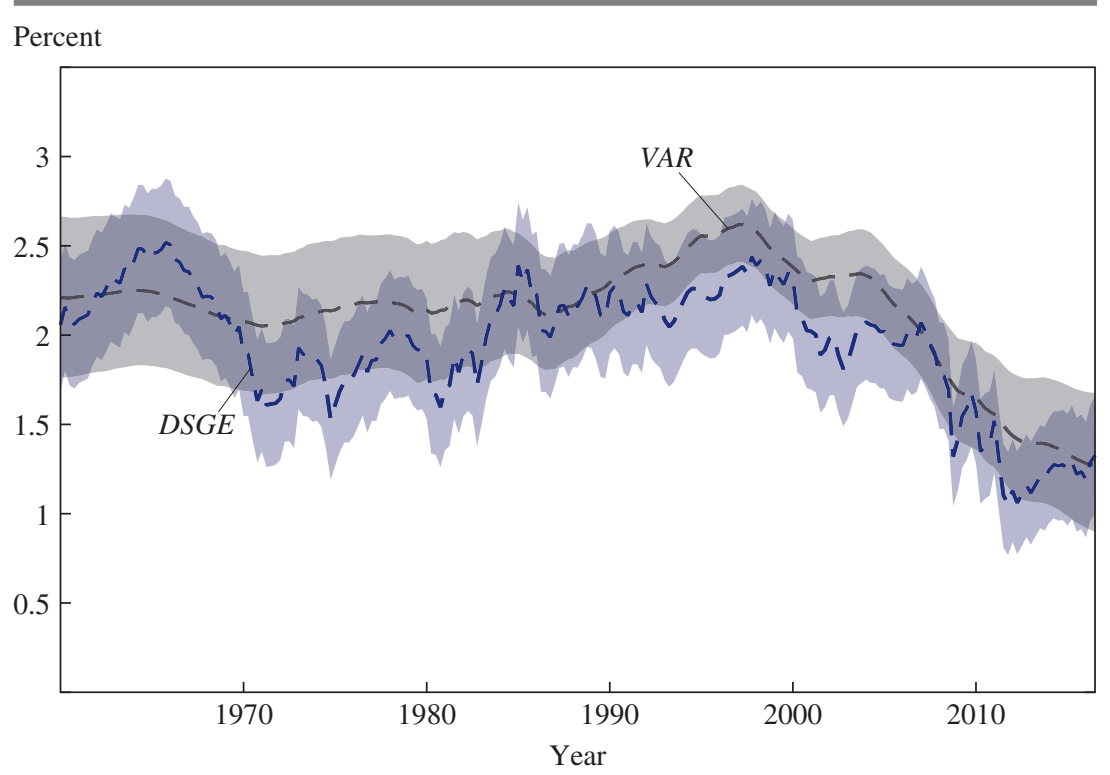

Source: Authors' calculations.

a. For each trend, the dashed line is the posterior median, and the shaded area shows the 68 percent posterior coverage interval for the estimate of the low-frequency component.

Second, the main drivers of this decline are rising premiums for the safety and liquidity of Treasury bonds, what Arvind Krishnamurthy and Annette Vissing-Jorgensen (2012) refer to as the convenience yield, as well as persistently slower economic growth. The rise in the convenience yield explains up to 1 percentage point of the trend decline in the natural rate, and it is precisely estimated. Slower economic growth, as measured by data on either per capita consumption or labor productivity, accounts for up to 60 basis points, or about 40 percent, of the trend decline, although this estimate is subject to sizable statistical uncertainty. The prominent role of the convenience yield as a source of low-frequency fluctuations in real interest rates uncovered by our estimates adds to a growing body of recent evidence suggesting that Treasury bonds are valued not only for their pecuniary return but also for their attributes of safety and liquidity. Following the empirical strategy of Krishnamurthy and Vissing-Jorgensen (2012), we identify these attributes by comparing the trends in the yields of securities that are less safe and less liquid than 
Treasuries, such as Aaa and Baa corporate bonds. This comparison reveals that corporate bonds have experienced less of a secular decline in their yield than Treasuries.

Third and finally, we find that safety and liquidity factors, together with the productivity trend, are also the key drivers of the low-frequency movements in the natural rate of interest in the DSGE model. Moreover, safety and liquidity factors also play a prominent role in its fluctuations at business cycle and other frequencies.

The paper's main novel contribution is identifying the convenience yield as a key driver of the trend in the natural rate of interest. To fix ideas on the relationship between the two, it is useful to start from the Euler equation for investing in a safe, liquid, short-term nominal government security, such as a 3-month U.S. Treasury bill carrying a nominal return $R_{t}$ :

$$
1=E_{t}\left[\frac{1+R_{t}}{1+\pi_{t+1}}\left(1+C Y_{t+1}\right) M_{t+1}\right]
$$

where $\pi_{t}$ is inflation and $M_{t+1}$ is the stochastic discount factor, which in textbook formulations would be the marginal rate of substitution between consumption in two successive periods $\beta u^{\prime}\left(c_{t+1}\right) / u^{\prime}\left(c_{t}\right)$. Equation 1 is a standard Euler equation, except for the presence of the convenience yield term $\left(1+C Y_{t+1}\right)$. This is the premium associated with the special safety and liquidity characteristics of the Treasury security relative to assets with the same pecuniary payoff, but no such special attributes. ${ }^{1}$ Therefore, an increase in the convenience yield depresses the safe real rate of return, for a given stochastic discount factor, because investors will be willing to accept a lower pecuniary return in exchange for the higher convenience. Similarly, in the counterfactual economy without nominal rigidities, an

1. As Greenwood, Hanson, and Stein (2015, p. 1685) put it, the recent literature "documents significant deviations from the predictions of standard asset pricing modelspatterns that can be thought of as reflecting money-like convenience services-in the pricing of Treasury securities generally, and in the pricing of short-term T-bills more specifically." Krishnamurthy and Vissing-Jorgensen (2012) measure the historical convenience yield on Treasuries and show that it has been sizable, averaging 73 basis points per year. From a theoretical point of view, they model the convenience yield as arising from agents deriving direct utility from holding safe and liquid assets. For Kiyotaki and Moore (2012), the liquidityrelated component of the convenience yield arises from so-called liquidity (or resaleability) constraints facing actors in financial markets: Liquid assets are valued as they relax such constraints. In equation 1, we introduce the convenience yield following the specification of Kiyotaki and Moore (2012). 
increase in the convenience yield will depress the natural rate of interest. ${ }^{2}$ In the long run, this implies that trends in the convenience yield may drive trends in $r_{t}^{*}$. This is the main hypothesis we explore quantitatively in this paper.

Our two approaches to estimating $r_{t}^{*}$ are related to the popular model developed by Thomas Laubach and John Williams (2003). Their framework can be viewed both as a restricted version of our VAR and also as a less tightly parameterized version of our DSGE model. As in our VAR, Laubach and Williams (2003) focus on the low-frequency component of the natural rate, which they also model as an $I(1)$ process. However, by assuming that $r_{t}^{*}$ is a linear function of the growth rate of trend output, they impose more restrictions than in our VAR. The main drawback of their framework compared with a fully specified DSGE model is that the latter provides a more precise notion of the counterfactual that defines the natural rate, as detailed in section III below. Laubach and Williams (2016) update their earlier estimates of the natural rate. They find a more dramatic decline in $r_{t}^{*}$ than the long-run rate identified by our VAR model during the Great Recession and in the years that followed it. ${ }^{3}$ However, their estimate relatively closely tracks a shorter-term $r_{t}^{*}$, such as the 5-year forward natural rate implied by our DSGE model, since the early 1980s. We compare their estimated natural rate with the one resulting from our DSGE model in subsection III.B.

The extremely low levels of interest rates since the Great Recession have received a great deal of attention, and various explanations have been proposed. Laubach and Williams (2016) attribute a large fraction of the secular decline in the natural rate to a fall in the growth rate of trend output. ${ }^{4}$ Other authors, however, are more skeptical of such a tight connection. Looking at cross-country data starting in the 19th century, James Hamilton and others (2016) find only a tenuous link between $r_{t}^{*}$ and output growth. For the United States, this relationship can only go so far, given that rates were high in the 1970s and 1980s, when productivity growth was low; and that they started declining in the 1990s, when productivity accelerated.

2. Del Negro and others (2017) discuss the impact on $r_{t}^{*}$ of the liquidity shocks experienced after the Lehman Brothers crisis.

3. Several other recent papers use unobserved component models to estimate a trend in the real interest rate, including Kiley (2015); Pescatori and Turunen (2015); and Johannsen and Mertens (2016).

4. See, for instance, Fernald and others (2017) for a thorough assessment of the decline in trend output growth since the mid-2000s. 
A second class of explanations for the low interest rates has focused on factors that can be expected to shift desired saving and investment. ${ }^{5}$ The most prominent one is arguably the ongoing demographic transition. For instance, Carlos Carvalho, Andrea Ferrero, and Fernanda Nechio (2016) and Etienne Gagnon, Benjamin Johannsen, and David López-Salido (2016) argue that changes in the dependency ratio due to increased life expectancy and slower population growth can have potentially significant repercussions for aggregate saving, while Carlo Favero, Arie Gozluklu, and Haoxi Yang (2016) argue that demographic factors help predict bond yields. Another factor contributing to higher desired saving and hence to lower interest rates is rising inequality, because higher-income households tend to save more out of marginal income. However, Adrien Auclert and Matthew Rognlie (2016) point out that, in general equilibrium, the fall in the interest rate tends to result in a boom in investment and output, which is clearly not a feature of the current environment. Increased uncertainty also has the potential to both increase precautionary saving and to depress investment through the channels emphasized by Nicholas Bloom (2009). Moreover, the decline in the price of capital associated with rapid, investment-specific technical change, by reducing the amount of saving needed to finance each unit of capital, might create an imbalance between desired saving and investment that would put downward pressure on the interest rate (Eichengreen 2015).

A third class of explanations for the prevalence of low rates in the United States and around the world since the financial crisis revolves around the idea of secular stagnation, which presumes permanent aggregate demand deficiency or, equivalently, an imbalance between desired saving and investment, which cannot be cleared by a sufficient fall in the real interest rate. Such a barrier to lower real rates can be connected most naturally to a binding zero lower bound, as found by Gauti Eggertsson, Neil Mehrotra, and Jacob Robbins (2017), where real rates are permanently pushed against this barrier by a deleveraging shock interacted with an overlapping generation structure.

In contrast to all these explanations, our analysis emphasizes the role of spreads between Treasury and corporate bonds. We uncover a prominent role for low-frequency movements in the convenience yield in accounting for the observed decline in real interest rates, which was previously

5. Rachel and Smith (2015) provide a comprehensive overview of this literature. 
largely ignored in the literature on $r_{t}^{*} \cdot{ }^{6}$ Our findings are very much in line with the recent literature discussing the causes and macroeconomic consequences of the shortage of safe assets (Bernanke and others 2011; Caballero and Krishnamurthy 2009; Caballero 2010; Caballero and Farhi 2017; Caballero, Farhi, and Gourinchas 2016; Gourinchas and Rey 2016). ${ }^{7}$ One implication of this shortage is that the yield of safe assets, relative to assets that are less safe, should have seen a secular decline, which is consistent with what we find. ${ }^{8}$ Interestingly, Pierre-Olivier Gourinchas and Hélène Rey (2016) reach very similar conclusions to ours using a very different approach based on the determinants of the consumption-wealth ratio.

This shortage of safe assets is of course related to the saving glut hypothesis first proposed by Ben Bernanke (2005). According to this view, the current account imbalances that grew from the late 1990s to just before the Great Recession, and the globally low rates that accompanied them, were the result of a massive shift in desired saving in developing economies following the Asian crisis of 1997. This glut did not translate into a generic demand for assets, but into a specific one for safe (and liquid) assets. Bernanke and others (2011) provide evidence that from 2003 to 2007, foreign investors acquired substantial amounts of U.S. Treasuries, agency debt, and agency-sponsored mortgage-backed securities. Jeremy Greenwood, Samuel Hanson, and Jeremy Stein (2016) show that foreign holdings of moneylike claims produced in the United States have risen sharply since the early 2000s. In the words of Ricardo Caballero (2010, pp. 17-18), “There is a connection between the safe-assets imbalance and the more visible global imbalances: The latter were caused by the funding countries' demand for

6. Kiley (2015) includes a corporate spread as an exogenous variable in his analysis, because it helps to forecast output. He finds that this modification to the Laubach and Williams (2003) specification reduces the estimated movements in $r_{t}^{*}$ around the Great Recession. Pescatori and Turunen (2015) find that proxies for the demand for safe assets help to explain some of the cyclical movements in their estimate of $r_{t}^{*}$, especially since the late 1990s.

7. See Gorton (2016) for a definition of safe assets and for a broad discussion of their role in economics. Hall (2016) takes a related but slightly different perspective, as he emphasizes heterogeneity in beliefs and risk aversion, and how changes in the wealth distribution in favor of more risk-averse or pessimistic investors can lead to a decline in the real rate on safe securities.

8. Caballero and Farhi (2017) also show that the expected return on stocks is currently much higher than the yield of safe assets, which is consistent with their theory. Our empirical analysis is arguably more direct, in that the safety premium is only one determinant of the stock market risk premium, while we are able to identify the convenience yield more sharply using spreads. 
financial assets in excess of their ability to produce them, but this gap is particularly acute for safe assets since emerging markets have very limited institutional capability to produce them."

Although much of the macroeconomic literature mentioned above emphasizes safety, we also stress the role of liquidity. Liquidity has long played a prominent role in finance. ${ }^{9}$ For instance, Matthias Fleckenstein, Francis Longstaff, and Hanno Lustig (2014) provide evidence of what they call the "TIPS-Treasury bond puzzle," that is, significant differences in prices between Treasury bonds of various maturities and inflation-swapped Treasury inflation-protected securities (TIPS) of the same maturities. ${ }^{10}$ Starting with the work of Nobuhiro Kiyotaki and John Moore (2012), liquidity has also been incorporated into modern macroeconomic models to study its role in business cycles and the Great Recession. ${ }^{11}$ We show that the liquidity convenience yield plays an important role in explaining why interest rates for liquid assets are currently low. We also argue, more broadly, that for both secular trends and cyclical movements in interest rates, liquidity plays a role that is as important as that of safety. ${ }^{12}$

The remainder of the paper proceeds as follows. Section I introduces the empirical model, a VAR with common trends, and section II uses this framework to estimate trends in interest rates. Section III briefly describes the DSGE model and presents the results. Section IV concludes.

\section{A VAR with Common Trends}

The model is given by the measurement equation

$$
y_{t}=\Lambda \bar{y}_{t}+\tilde{y}_{t}
$$

9. See, among many others, Longstaff (2004), Acharya and Pedersen (2005), Longstaff, Mithal, and Neis (2005), Amihud, Mendelson, and Pedersen (2006, 2012), Gârleanu and Pedersen (2011), and Fleckenstein, Longstaff, and Lustig (2014).

10. Specifically, they find that the price of a Treasury bond and an inflation-swapped TIPS issue exactly replicating the cash flows of the Treasury bond can differ by more than $\$ 20$ per \$100 notional-a difference that, they argue, is orders of magnitude larger than the transaction costs of executing the arbitrage strategy.

11. See, for instance, Kurlat (2013), Bigio (2015), Ajello (2016), Del Negro and others (2017), Cui and Radde (2016), and Guerron-Quintana and Jinnai (2015).

12. Our VAR and DSGE models treat safety and liquidity as essentially independent factors, which we try to distinguish empirically by looking at the returns on assets with different characteristics. However, safety and liquidity are clearly interrelated. For instance, for Kurlat (2013), market freezes (illiquidity) take place precisely because agents are uncertain about the safety of the assets in the market. 
where $y_{t}$ is an $n \times 1$ vector of observables, $\bar{y}_{t}$ is a $q \times 1$ vector of trends, $q \leq n, \Lambda(\lambda)$ is an $n \times q$ matrix of loadings that is restricted and depends on the vector of free parameters $\lambda$, and $\tilde{y}_{t}$ is an $n \times 1$ vector of stationary components. The rank of $\Lambda$, which is equal to $q$, determines the number of common trends, and the number of cointegrating relationships is therefore $n-q$. Both $\bar{y}_{t}$ and $\tilde{y}_{t}$ are latent and evolve according to a random walk

$$
\bar{y}_{t}=\bar{y}_{t-1}+e_{t}
$$

and a VAR

$$
\Phi(L) \tilde{y}_{t}=\varepsilon_{t},
$$

respectively, where $\Phi(L)=I-\sum_{l=1}^{p} \Phi_{l} L^{l}$ and the $\Phi_{l}$ s are $n \times n$ matrices. The $(q+n) \times 1$ vector of shocks is independent and identically distributed according to

$$
\left[\begin{array}{l}
e_{t} \\
\varepsilon_{t}
\end{array}\right] \sim \mathcal{N}\left(\left[\begin{array}{c}
0_{q} \\
0_{n}
\end{array}\right],\left[\begin{array}{ll}
\Sigma_{e} & 0 \\
0 & \Sigma_{\varepsilon}
\end{array}\right]\right)
$$

where the $\Sigma$ s are conforming positive definite matrices, and $\mathcal{N}(\cdot, \cdot)$ denotes the multivariate Gaussian distribution. Equations 3 and 4 represent the transition equations in the state-space model. The initial conditions $\bar{y}_{0}$ and $\tilde{y}_{0:-p+1}=\left(\tilde{y}_{0}^{\prime}, \ldots, \tilde{y}_{-p+1}^{\prime}\right)^{\prime}$ are distributed according to

$$
\begin{aligned}
& \bar{y}_{0} \sim \mathcal{N}\left(\underline{y_{0}}, \underline{V_{0}}\right), \\
& \tilde{y}_{0:-p+1} \sim \mathcal{N}\left(0, V\left(\Phi, \Sigma_{\varepsilon}\right)\right),
\end{aligned}
$$

where $V\left(\Phi, \Sigma_{\varepsilon}\right)$ is the unconditional variance of $\tilde{y}_{0:-p+1}$ implied by equation $4 .{ }^{13}$ Constants or deterministic trends can be easily accommodated in this framework. The procedure also straightforwardly accommodates missing observations.

The model above is essentially the VAR model of Mattias Villani (2009), except that his deterministic trend is replaced by the stochastic trend, as shown in equation 3. It also corresponds to the multivariate trend-cycle decomposition described by James Stock and Mark Watson (1988, equation 2.4),

13. We impose stationarity on $\tilde{y}_{t}$, as discussed below, so that $V\left(\Phi, \Sigma_{\varepsilon}\right)$ is always well defined. 
with the important difference that the shocks affecting the trend and the cycle are orthogonal to one another-in the parlance of Watson (1986), our model is an "independent trend/cycle decomposition." In a nutshell, the model is a multivariate extension of a standard unobserved component model (Watson 1986; Stock and Watson 2007; Kozicki and Tinsley 2012). Recently, Richard Crump, Stefano Eusepi, and Emanuel Moench (2017) and Benjamin Johannsen and Elmar Mertens (2016) have also estimated models that are very similar to ours. ${ }^{14}$

The priors for the VAR coefficients $\Phi=\left(\Phi_{1}, \ldots, \Phi_{p}\right)^{\prime}$ and the covariance matrices $\Sigma_{\varepsilon}$ and $\Sigma_{e}$ have a standard form, namely,

$$
\begin{aligned}
p\left(\varphi \mid \Sigma_{\varepsilon}\right) & =\mathcal{N}\left(\operatorname{vec}(\underline{\Phi}), \Sigma_{\varepsilon} \otimes \underline{\Omega}\right) I(\varphi), \\
p\left(\Sigma_{\varepsilon}\right) & =\operatorname{IW}\left(\kappa_{\varepsilon},\left(\kappa_{\varepsilon}+n+1\right) \underline{\Sigma_{\varepsilon}}\right), \\
p\left(\Sigma_{e}\right) & =\operatorname{IW}\left(\kappa_{e},\left(\kappa_{e}+q+1\right) \underline{\Sigma_{e}}\right),
\end{aligned}
$$

where $\varphi=\operatorname{vec}(\Phi), I \mathcal{W}(\kappa,(\kappa+m+1) \underline{\Sigma})$ denotes the inverse Wishart distribution with mode $\underline{\Sigma}$ and $\kappa$ degrees of freedom, and $I(\varphi)$ is an indicator function that is equal to 0 if the VAR is explosive-some of the roots of $\Phi(L)$ are less than 1 -and to 1 otherwise. ${ }^{15}$ The prior for $\lambda$ is given by $p(\lambda)$, the product of independent beta, gamma, or Gaussian distributions for each element of the vector $\lambda$ (all the details, as well as the actual values used in the prior, are given below, where we discuss the application).

The model given in equations 2 through 6 is a linear, Gaussian, statespace model. Therefore, it is straightforward to estimate efficiently, in spite of the large size of the state space, using modern simulation smoothing

14. Crump, Eusepi, and Moench (2017) estimate the parameters by maximizing the likelihood. Johannsen and Mertens (2016) use a Gibbs sampler, like we do, but impose that the elements of the matrix $\Lambda$ are known. The sophisticated model used by Johannsen and Mertens (2016) allows for stochastic volatility in the shocks distribution and for explicit treatment of the zero lower bound on nominal rates. Our model can certainly be amended to accommodate the former, along the lines of Del Negro and Primiceri (2015), and in principle also the latter, following the approach of Johannsen and Mertens (2016).

15. The inverse Wishart distribution with parameters $\kappa$ and $(\kappa+m+1) \underline{\Sigma}$ is given by

$$
p(\Sigma ; \kappa,(\kappa+m+1) \underline{\Sigma})=\frac{|(\kappa+m+1) \underline{\Sigma}|^{\kappa / 2}}{2^{m \kappa / 2} \Gamma(\kappa / 2)}|\Sigma|^{-(\kappa+m+1) / 2} \exp \left(-\frac{\kappa+m+1}{2} \operatorname{tr}\left(\Sigma^{-1} \underline{\Sigma}\right)\right),
$$

where $m$ is the size of $\Sigma$. Under this parameterization, $\underline{\Sigma}$ is the mode and $\kappa$ gives the degrees of freedom. 
techniques (Carter and Kohn 1994; Durbin and Koopman 2002). Section A of the online appendix describes the Gibbs sampler, which accommodates VARs of any size and with any estimated cointegrating relationship. ${ }^{16}$

\section{Estimating and Decomposing the Trend in $\boldsymbol{r}_{t}$}

In this section, we estimate the trend in the return to safe and liquid assets $r_{t}$ and analyze its determinants. We do so using the VAR discussed in section I with data on nominal Treasury yields at different maturities, as well as inflation, inflation expectations, and measures of credit spreads associated with safety and liquidity. Under the generally accepted assumption that the gap between the observed real rate $r_{t}$ and the natural rate $r_{t}^{*}$ is stationary, we can learn about the trend in the latter-which we denote by $\bar{r}_{t}^{*}$-by conducting inference on $\bar{r}_{t}$. This is the strategy pursued in this section. As we will show in section III, the trend in $\bar{r}_{t}$ estimated using the VAR nearly coincides with the low-frequency component of the natural rate of interest obtained from the DSGE model, corroborating this assumption. ${ }^{17}$

We start the exposition in subsection II.A with a very simple specification that only includes data on nominal yields for Treasuries with short (3-month) and long (20-year) maturity, and on inflation and its expectations. This is the minimum amount of information needed to identify the trend in the real interest rate separately from that in inflation. We use both short- and long-term bond yields because we are interested in a trend that is common across maturities, and because the long-term yield continues to provide information on that trend, even during the years in which the short-term rate is constrained by the zero lower bound (ZLB).$^{18}$ The trend in the real interest rate estimated in this simple model falls by about 1.25 percentage points from the late 1990s to the end of 2016. This

16. The online appendixes for this and all other papers in this volume may be found at the Brookings Papers web page, www.brookings.edu/bpea, under "Past BPEA Editions."

17. Although very common, the assumption of a stationary interest rate gap, or that monetary policy cannot affect the growth rate of the economy in the long run, is not entirely uncontroversial. For instance, it is violated in models featuring endogenous growth with nominal rigidities (Benigno and Fornaro 2017). Perhaps more important, equation 3 implies that trends evolve smoothly over time. Therefore, our approach cannot capture abrupt shifts from one long-run regime to another, as envisioned, for example, in the theory of secular stagnation (Summers 2014; Eggertsson, Mehrotra, and Robbins 2017).

18. In principle, we could use many more maturities, but doing so would require taking a stance on the possible presence of different trends at different maturities, a task that is beyond the scope of this paper. 
Table 1. Changes in Trends, 1998-2016

\begin{tabular}{|c|c|c|c|c|c|}
\hline & (1) & (2) & (3) & (4) & (5) \\
\hline Trend & Baseline & $\begin{array}{l}\text { Convenience } \\
\text { yield }\end{array}$ & $\begin{array}{c}\text { Safety and } \\
\text { liquidity }\end{array}$ & Consumption & $D S G E$ \\
\hline \multirow[t]{2}{*}{$\bar{r}_{t}$} & $-1.29 * *$ & $-1.27 * *$ & $-1.30 * *$ & $-1.40 * *$ & $-1.05^{* *}$ \\
\hline & $\begin{array}{l}{[-1.70,-0.85]} \\
(-2.07,-0.43)\end{array}$ & $\begin{array}{l}{[-1.60,-0.92]} \\
(-1.91,-0.56)\end{array}$ & $\begin{array}{l}{[-1.63,-0.95]} \\
(-1.95,-0.60)\end{array}$ & $\begin{array}{l}{[-1.84,-0.92]} \\
(-2.23,-0.43)\end{array}$ & $\begin{array}{l}{[-1.15,-0.95]} \\
(-1.39,-0.69)\end{array}$ \\
\hline $\bar{m}_{t}$ & & $\begin{array}{c}-0.34 \\
{[-0.65,-0.02]} \\
(-0.96,0.29)\end{array}$ & $\begin{array}{c}-0.33 \\
{[-0.65,-0.01]} \\
(-0.95,0.31)\end{array}$ & $\begin{array}{c}-0.61 \\
{[-1.04,-0.15]} \\
(-1.45,0.30)\end{array}$ & $\begin{array}{c}-0.38 * * \\
{[-0.44,-0.32]} \\
(-0.60,-0.18)\end{array}$ \\
\hline $\bar{g}_{t}$ & & & & $\begin{array}{c}-0.56 \\
{[-0.98,-0.13]} \\
(-0.37,0.29)\end{array}$ & \\
\hline $\bar{\beta}_{t}$ & & & & $\begin{array}{c}-0.04 \\
{[-0.21,0.12]} \\
(-0.37,0.29)\end{array}$ & \\
\hline$-\overline{c y}_{t}$ & & $\begin{array}{c}-0.93^{* *} \\
{[-1.14,-0.71]} \\
(-1.35,-0.49)\end{array}$ & $\begin{array}{c}-0.97 * * \\
{[-1.18,-0.75]} \\
(-1.40,-0.53)\end{array}$ & $\begin{array}{c}-0.78 * * \\
{[-0.99,-0.57]} \\
(-1.20,-0.36)\end{array}$ & $\begin{array}{c}-0.66 * * \\
{[-0.76,-0.57]} \\
(-1.00,-0.34)\end{array}$ \\
\hline$-\overline{c y_{t}^{s}}$ & & & $\begin{array}{c}-0.45 * * \\
{[-0.60,-0.31]} \\
(-0.74,-0.16)\end{array}$ & $\begin{array}{c}-0.33 * * \\
{[-0.47,-0.18]} \\
(-0.61,-0.04)\end{array}$ & $\begin{array}{c}-0.38 * * \\
{[-0.47,-0.28]} \\
(-0.70,-0.06)\end{array}$ \\
\hline$-\overline{c y}_{t}^{l}$ & & & $\begin{array}{c}-0.52 * * \\
{[-0.65,-0.38]} \\
(-0.77,-0.24)\end{array}$ & $\begin{array}{c}-0.45 * * \\
{[-0.58,-0.32]} \\
(-0.71,-0.19)\end{array}$ & $\begin{array}{c}-0.29 * * \\
{[-0.32,-0.25]} \\
(-0.40,-0.17)\end{array}$ \\
\hline $\bar{\Delta} c_{t}$ & & & & $\begin{array}{c}-0.80 \\
{[-1.38,-0.21]} \\
(-1.91,0.39)\end{array}$ & \\
\hline
\end{tabular}

Source: Authors' calculations.

a. For each trend, the table reports the posterior median, with the 68 percent posterior coverage interval in square brackets and the 95 percent posterior coverage interval in parentheses. Statistical significance is indicated with $* *$ if the 95 percent interval does not contain 0 .

estimated decline, reported in table 1 , is very robust across specifications, and is always significant.

Subsection II.B presents a richer model that also includes data on Baa and Aaa corporate bond yields. The spreads between these yields and those of Treasuries of comparable maturity allow us to identify trends in safety and liquidity, and hence in the overall convenience yield on Treasury yields. Our main finding is that these trends account for a large and statistically significant fraction of the trend decline in $r_{t}$-about 90 basis points. In subsection II.C, we also include data on consumption growth to verify the extent to which trends in this variable might account for some of the 
secular movements in the interest rate, as a textbook Euler equation would suggest. We find some evidence of a connection between the two trends, although this relationship is not sharply estimated.

Finally, subsection II.D explores the robustness of the main results to several alternative specifications. The prominent role of the convenience yield in driving the real interest rate lower during the last two decades remains a robust finding across all these specifications.

\section{II.A. Extracting $\bar{r}_{t}$ from Nominal Treasury Yields and Inflation}

MODEL SPECIFICATION Call $R_{\tau, t}$ the net yield on a nominal Treasury of maturity $\tau$ (with $\tau$ expressed in quarters). Following the VAR of section I (equation 2), we decompose the term structure as the sum of a trend $\bar{R}_{\tau, t}$ and a stationary component $\widetilde{R}_{\tau, t}$ :

$$
R_{\tau, t}=\bar{R}_{\tau, t}+\tilde{R}_{\tau, t} .
$$

We define $r_{t}$ as the net real return on an asset that is as safe and liquid as a 3-month Treasury bill, and that therefore satisfies the condition

$$
E_{t}\left[\left(1+r_{t}\right)\left(1+C Y_{t+1}\right) M_{t+1}\right]=1,
$$

where $M_{t+1}$ is the stochastic discount factor. Assuming that the Fisher equation holds in the long run, we can decompose the trend in the nominal short-term rate as

$$
\bar{R}_{1, t}=\bar{r}_{t}+\bar{\pi}_{t},
$$

where $\bar{r}_{t}$ and $\bar{\pi}_{t}$ are the trends in the real interest rate and in inflation, respectively. For a nominal 3-month bill $(\tau=1)$, we can therefore rewrite equation 8 as

$$
R_{1, t}=\bar{r}_{t}+\bar{\pi}_{t}+\tilde{R}_{1, t} .
$$

From equation 10, we cannot separately disentangle movements in $\bar{r}_{t}$ and $\bar{\pi}_{t \cdot}{ }^{19}$ We address this problem by extracting the nominal trend $\bar{\pi}_{t}$ from inflation $\pi_{t}$ (measured as log changes in the GDP deflator) and, whenever

19. Cieslak and Povala (2015) also allow for a persistent inflation component in an empirical model of nominal Treasury yields. 
available, inflation expectations obtained from surveys $\pi_{t}^{e}$ using an unobserved component model, à la Stock and Watson (1999):

$$
\begin{aligned}
& \pi_{t}=\bar{\pi}_{t}+\tilde{\pi}_{t}, \\
& \pi_{t}^{e}=\bar{\pi}_{t}+\tilde{\pi}_{t}^{e} .
\end{aligned}
$$

In principle, equations 10 and 11 are enough to conduct inference on $\bar{r}_{t}$. However, we do not want to use short rates information for the ZLB period, given the concern that these may distort our inference on the trends. Therefore, we do not use data on $R_{1, t}$ after 2008:Q3. ${ }^{20}$ Moreover, inference on trends can be made sharper by using two additional sources of information: long-maturity Treasury yields, and forecasters' expectations of long-run averages of the short-term rate.

If the expectation hypothesis were correct, long-maturity Treasuries would indeed be the ideal observable for extracting trends, being simply averages of expected short-term rates. Of course, the expectation hypothesis does not hold, and movements in the term premium are key drivers of yields, as has been documented-for example, by Refet Gürkaynak and Jonathan Wright (2012) and by Crump, Eusepi, and Moench (2017). We model possible trends in the nominal term premium by including an exogenous component $\overline{t p_{t}}$. We use the yield on 20-year Treasuries as a measure of long-term yields and model it as

$$
R_{80, t}=\bar{r}_{t}+\bar{\pi}_{t}+\overline{t p}_{t}+\tilde{R}_{80, t},
$$

where $\tilde{R}_{80, t}$ captures stationary movements in long-term yields. ${ }^{21}$ Recall that we allow for a correlation in the innovations to the trend; hence, equations 10 and 12 do not necessarily imply that trends in $\bar{r}_{t}, \bar{\pi}_{t}$, or $\overline{t p}_{t}$ are independent. However, because we impose a fairly strong prior that the correlation matrix is diagonal, subsection II.D explores the possibility that trends in inflation might affect the term premium by introducing a term premium component that is proportional to trends in inflation $\gamma^{t p} \bar{\pi}_{t}$ with $\gamma^{t p}>0$.

20. The robustness section discusses the results when using $R_{1, t}$ data for the entire sample.

21. Several papers (most recently, Johannsen and Mertens 2016) assume that the term premium is stationary. We have also considered a constant term premium and found the results to be robust. We use the 20 -year yield because that is the natural counterpart in terms of maturity for the corporate bonds we use in the next section (Krishnamurthy and VissingJorgensen 2012). Results obtained using the 10-year yield are very similar. 
Finally—inspired by Crump, Eusepi, and Moench (2017)—we also use forecasters' expectations of long-run averages of the short-term rate, which we call $R_{1, t}^{e}$, and we model them as

$$
R_{1, t}^{e}=\bar{r}_{t}+\bar{\pi}_{t}+\tilde{R}_{1, t}^{e}
$$

The system of equations 10 through 13 can be expressed as the VAR in equation 2 , where $y_{t}=\left(\pi_{t}, \pi_{t}^{e}, R_{1, t}, R_{80, t}, R_{1, t}^{e}\right)$ and $\bar{y}_{t}=\left(\bar{r}_{t}, \bar{\pi}_{t}, \overline{t p}_{t}\right)$ evolve according to equation 3 , and the stationary components $\left(\tilde{\pi}_{t}, \tilde{\pi}_{t}^{e}, \tilde{R}_{1, t}, \tilde{R}_{80, t}, \tilde{R}_{1, t}^{e}\right)$ evolve according to equation 4 . Note that we impose only two, arguably quite natural, cointegrating restrictions: one between inflation and inflation expectations, and the other between short-term interest rates and their expectations. We estimate this model using the following as observables: annualized personal consumption expenditures (PCE) inflation; long-run (10-year average) PCE inflation expectations; the 3-month Treasury bill rate; the long-run (10-year average) expectations for the 3-month Treasury bill rate; and the 20-year Treasury constant maturity rate. ${ }^{22}$ With the exception of long-run expectations, all the data are available from 1954:Q1 to 2016:Q4. We use the period 1954:Q1-1959:Q4 as the presample, and we estimate the model over the sample 1960:Q1-2016:Q4. Because of the ZLB on interest rates, we treat the short-term rate as unobservable from 2008:Q4 onward.

The prior for $\Sigma_{e}$, the variance-covariance matrix of the innovations to the trends $\bar{y}_{t}$, is very conservative, in the sense of limiting the amount of variation that it attributes to the trends. The matrix $\Sigma_{\varepsilon}$ is therefore diagonal, with elements equal to $1 / 400$ - which, a priori, implies that the standard deviation of the expected change in the trend over one century is only

22. Annualized PCE inflation, the 3-month Treasury bill rate, and the 20-year Treasury constant maturity rate are available from the FRED database; their mnemonics are, respectively, DPCERD3Q086SBEA, TB3MS, and GS20. The long-run PCE inflation expectations are obtained from the Survey of Professional Forecasters from 2007 onward, while for the period from 1970 to 2006, we use the survey-based long-run (5- to 10-years ahead) PCE inflation expectations series of the Federal Reserve Board's FRB/US econometric model. This same data set is employed by Clark and Doh (2014), and we are grateful to Todd Clark for making the data available. The long-run expectations for the 3-month Treasury bill rate are also obtained from the Survey of Professional Forecasters and are available once a year, starting in 1992:Q1. The 20-year Treasury constant maturity rate is not available from 1987:Q1 to 1993:Q3. For this period, following Haver Analytics, we use instead an average of the 10- and 30-year Treasury constant maturity rates (GS10 and GS30, respectively). We use quarterly averages for all variables that are available at a higher frequency than quarterly. 
1 percentage point. For the trend in inflation, we use a higher, but still conservative, prior of 1/200 ( 1 percentage point in 50 years). ${ }^{23}$ In addition, these priors are quite tight, as we set $\kappa_{e}=100$. As shown below, these conservative priors do not prevent us from finding trends where these are clearly present, such as trends in inflation or in the convenience yield. Moreover, the robustness section shows that with a looser prior, we simply let $\bar{y}_{t}$ capture some higher-frequency movements, with not much impact on the substantive results.

The prior for the VAR parameters describing the components $\tilde{y}_{t}$ is a standard Minnesota prior, with the hyperparameter for the overall tightness equal to the commonly used value of 0.2 (Giannone, Lenza, and Primiceri 2015), except, of course, that the prior for the "own-lag" parameter is centered at 0 rather than 1 , as we are describing stationary processes. ${ }^{24}$ The initial conditions $\underline{y_{0}}$ for the trend components $\bar{y}_{t}$ are set at presample averages for inflation, the real rate, and the term spread (2, 0.5, and 1, for, respectively, $\bar{\pi}_{0}, \bar{r}_{0}$, and $\overline{t p_{0}}$ ), with $\underline{V_{0}}$ being the identity matrix. Finally, the VAR uses five lags $(p=5)$.

RESULTS The left panel of figure 2 shows the estimates of $\bar{r}_{t}$. The dashed line shows the posterior median of $\bar{r}_{t}$, while the shaded areas show the 68 and 95 percent posterior coverage intervals (this convention applies to all the latent variables shown below). The trend in the real interest rate, $\bar{r}_{t}$, rises from the 1960s to the early 1980s, remains roughly constant until the late 1990s, and then begins to decline. This result is consistent with previous findings in the literature. In addition to Laubach and Williams (2003), a number of researchers also find that long-term forward rates have fallen substantially during the past 20 years: Michael Bauer, Rudebusch, and Jing Cynthia Wu $(2012,2014)$ and Jens Christensen and Rudebusch (2017), using a term structure model; Crump, Eusepi, and Moench (2017), using data on survey expectations; and Thomas Lubik and Christian Matthes (2015), using a time-varying parameter VAR. The median decline in $\bar{r}_{t}$ from 1998:Q1 to 2016:Q4 is about 1.3 percentage points, as shown

23. Results with a tighter prior of $1 / 400$ for the variance of the inflation trend only change in that the trend in inflation does not rise as much as long-run inflation expectations in the mid-1970s, but are otherwise very similar to the ones shown here.

24. Our prior for the variance $\Sigma_{\varepsilon}$ is a very uninformative inverse Wishart distribution centered at a diagonal matrix of $1 \mathrm{~s}$ (except for inflation, for which the diagonal element is 2 ; and expectations, for which the variance is 0.5 ; these numbers reflect presample variances, except for expectations that are not available), with just enough degrees of freedom $(n+2)$ to have a well-defined prior mean. We do not use the "co-persistence" or "sum-of-coefficients" priors of Sims and Zha (1998). 
in the first column of table 1 , from 2.36 to 1.06 percent. This decrease is significant, in that the 95 percent credible intervals range from -2.07 to -0.43 percent. The left panel of figure 2 also shows the short-term rate $R_{1, t}$ and the long-run expectations for the short-term rate $R_{1, t}^{e}$, both expressed in deviations from long-run inflation expectations $\pi_{t}^{e}$, so that trends in the real variables become more apparent. ${ }^{25}$ The trend $\bar{r}_{t}$ declines starting in the late 1990 s, along with the decline in long-term expectations for the short-term real rate $R_{1, t}^{e}-\pi_{t}^{e}$. Toward the end of the sample, the trend remains above the data for $R_{1, t}^{e}-\pi_{t}^{e}$, which is arguably reasonable, in light of the fact that these 10-year averages partly reflect cyclical movements-for example, the slow renormalization of real rates in the aftermath of the crisis. It is also apparent from figure 2 that the use of long-run, short-rate expectations helps in terms of the inference on the trend, because the bands for $\bar{r}_{t}$ get considerably narrower when these data become available (the bands become somewhat wider again in the ZLB period, as we are not using data on the short-term rate during this period).

The right panel of figure 2 shows the data, $\pi_{t}$ (the dotted line), and $\pi_{t}^{e}$ (the solid line), together with the trend $\bar{\pi}_{t}$. We find that $\bar{\pi}_{t}$ appears to capture well the trend in inflation and essentially coincides with long-run inflation expectations, whenever these are available, even though the model only imposes that $\pi_{t}$ and $\pi_{t}^{e}$ share a common trend.

\section{II.B. Drivers of $\bar{r}_{t}$ : The Role of the Convenience Yield}

\section{TRENDS IN THE CONVENIENCE YIELD}

Model specification. In this subsection, we refine the approach outlined above with the goal of assessing the component of long-term movements in $r_{t}$ due to changes in the convenience yield. In order to do this, we bring into the analysis assets whose safety and liquidity attributes are not the same as those of nominal Treasuries.

25. The time series for $R_{1, t}^{e}-\pi_{t}^{e}$ begins in 1970 simply because long-run inflation expectations were not available before then. Figure A1 in the online appendix shows the estimated trends in the term premium together with the term spread $R_{80, t}-R_{1, t}$. Figure A2 shows all the data $y_{t}$ used in the estimation, together with $\Lambda \bar{y}_{t}$ and $\tilde{y}_{t}$, the nonstationary and stationary components, respectively. The figure shows that the model fits the trend in the data reasonably well, including that in the 20 -year yield, in that the $\tilde{y}_{t}$ s do indeed look stationary. In the aftermath of the Great Recession, however, all the stationary components are persistently negative, including those for inflation and long-run expectations. The model suggests that the Great Recession has had a persistently negative effect on the cyclical component of inflation and interest rates, possibly capturing headwinds to the recovery. 
Figure 2. Trends and Observables in the Baseline Model, 1960-2016

$$
\bar{r}_{t}, R_{1, t}-\pi_{t}^{e}, \text { and } R_{1, t}^{e}-\pi_{t}^{e}
$$

Percent

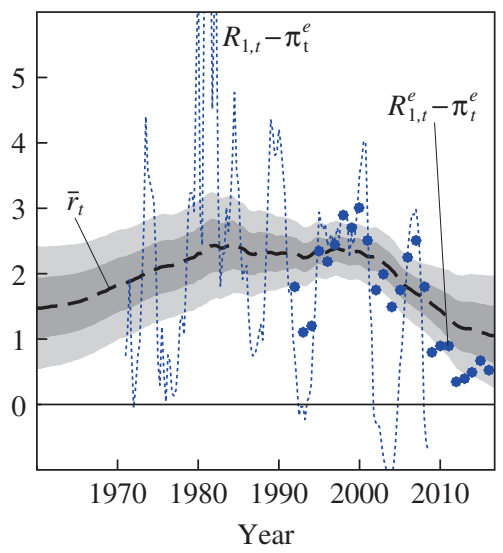

$\bar{\pi}_{t}, \pi_{t}$, and $\pi_{t}^{e}$

Percent

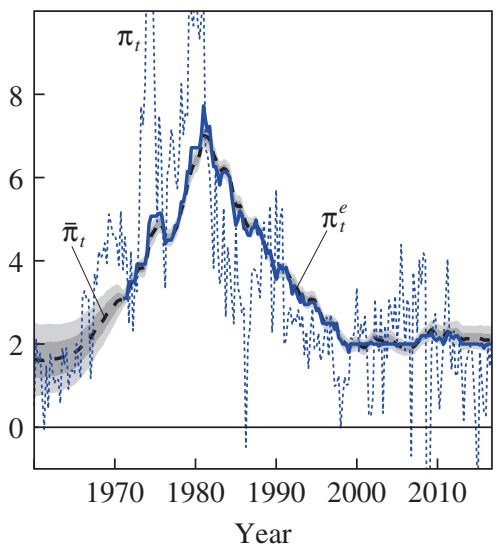

Sources: FRED; Survey of Professional Forecasters; Clark and Doh (2014); authors' calculations.

a. For each trend, the dashed line is the posterior median, the dark shaded area shows the 68 percent posterior coverage interval, and the light shaded area shows the 95 percent posterior coverage interval.

Equation 9 above-the Euler equation-implies that trends in $r_{t}$ are driven by trends in the convenience yield $C Y_{t}$ and in the stochastic discount factor $M_{t}$. In order to proceed, we make the assumption that the covariance between $C Y_{t}$ and $M_{t}$ is stationary, and we write:

$$
\bar{r}_{t}=\bar{m}_{t}-\overline{c y}_{t},
$$

where $c y_{t}=\log \left(1+C Y_{t}\right)$ and $m_{t}=-\log \left(M_{t}\right)$. In addition, the trends $\overline{c y_{t}}$ and $\bar{m}_{t}$ evolve as random walks (as in equation 3 ), although shocks to the trends are allowed to be correlated.

Using the decomposition given above, we can replace $\bar{r}_{t}$ with $\bar{m}_{t}-\overline{c y}_{t}$ in equations 10,12 , and 13. Implicitly, this amounts to assuming that in the long run, all Treasuries - regardless of maturity — benefit in equal measure from the same safety and liquidity attributes as 3-month bills (an assumption we discuss below). This implies that data on $R_{1, t}, R_{80, t}$, or $R_{1, t}^{e}$ are of no use in disentangling $\overline{c y_{t}}$ from $\bar{m}_{t}$. In order to do this, we need to consider assets that carry less of a convenience yield than Treasuries. Krishnamurthy and Vissing-Jorgensen (2012) use the spread between Baa corporate bonds 
and Treasuries to identify the convenience yield. We follow their lead, and thus augment the set of observables with the yield of Baa corporate bonds, which we model as follows:

$$
R_{t}^{B a a}=\bar{m}_{t}-\lambda_{c y}^{\text {Baa }} \overline{c y}_{t}+\bar{d}_{t}+\bar{\pi}_{t}+\overline{t p}_{t}+\tilde{R}_{t}^{B a a},
$$

where $0 \leq \lambda_{c y}^{B a a}<1$, indicating that Baa corporate bonds are less safe and liquid than Treasuries, and where $\bar{d}_{t}$ reflects trends in the actual default probability of corporate bonds. We use the same term premium that we use in Treasuries of equivalent maturity, ${ }^{26}$ which means that we constrain the term premium to be the same, at least in the long run. In the remainder of this section, we ignore $\bar{d}_{t}$, on the grounds that there is no clear secular trend in the average corporate default probability over the sample. In the robustness subsection, we discuss the results of a model that explicitly accounts for $\bar{d}_{t}$, and show that our results are even stronger.

From equations 12 and 15, it follows that the trends in the spread between Baa corporate bond yields and equivalent-maturity Treasuries is given by

$$
\bar{R}_{t}^{B a a}-\bar{R}_{80, t}=\left(1-\lambda_{c y}^{B a a}\right) \overline{c y}_{t},
$$

which implies that trends in the spread reflect trends in the convenience yield. We assume that $\lambda_{c y}^{B a a}=0$, that is, that Baa corporate bonds do not have any convenience yield whatsoever. Given the measured difference in trends $\bar{R}_{t}^{\text {Baa }}-\bar{R}_{80, t}$ between Baa corporate bond yields and equivalentmaturity Treasuries, this assumption is the most conservative in terms of extracting $\overline{c y}$. We should also stress that our results focus on the secular changes in the convenience yield, as opposed to its level. The level of the Baa-Treasury spread may be affected by factors other than safety and liquidity premiums (for example, the average default probability of corporate bonds). The key identifying assumption we use is that secular changes in the spread primarily reflect secular changes in the convenience yield.

Equation 16 deserves additional comments. First, as explained very clearly by Krishnamurthy and Vissing-Jorgensen (2012), the spread $\bar{R}_{t}^{\text {Baa }}-\bar{R}_{80, t}$

26. Following Krishnamurthy and Vissing-Jorgensen (2012), we use 20-year Treasury yields as the reference. 
captures not just the current value of the convenience yield but also the expected average convenience yield throughout the remaining maturity of the bond. But this is precisely what we need, because we are after trends in the convenience yield. Second, we assume that long-term Treasuries benefit from the same convenience yield as short-term Treasuries. In making this assumption, we are arguably underestimating the convenience yield on short-term Treasuries, which is what we are after. All Treasuries are equally safe, irrespective of their maturity; hence, it is reasonable to assume that the component of the convenience yield deriving from safety applies evenly across maturities. As for the component associated with liquidity, Greenwood, Hanson, and Stein (2015) provide some evidence that the liquidity premium is a decreasing function of maturity. They compute what they call $z$-spreads, which capture deviations in the pricing of Treasury bills from an extrapolation based on the rest of the yield curve, and argue that these $z$-spreads, which are sizable, "reflect a money-like premium on short-term T-bills, above and beyond the liquidity and safety premia embedded in longer term Treasury yields" (Greenwood, Hanson, and Stein 2015, p. 1687). In conclusion, for these reasons we think our assumption - that the convenience yields extracted from long-term Treasuries apply in the same measure to Treasury bills-is conservative; but it is nonetheless an assumption, and one should bear this in mind in interpreting our results.

The system formed by equations 10 through 13 and 15 can be expressed as a VAR for $y_{t}=\left(\pi_{t}, \pi_{t}^{e}, R_{1, t}, R_{80, t}, R_{1, t}^{e}, R_{t}^{B a a}\right)$, with common trends $\bar{y}=\left(\bar{m}_{t}, \bar{\pi}_{t}\right.$, $\left.\overline{c y_{t}}, \overline{t p}_{t}\right){ }^{27}$ We use exactly the same priors as described in subsection II.A, except that because we decompose the trend $\bar{r}_{t}$ into two components, $\bar{m}_{t}$ and $\overline{c y_{t}}$, we center the corresponding diagonal value of $\sum_{\varepsilon}$ to a number that is half the value chosen for $\bar{r}_{t}$ (we use 1/800, as opposed to 1/400). ${ }^{28}$

Results. The top-left panel of figure 3 shows $\bar{r}_{t}$ together with the shortterm rate $R_{1, t}$ and the long-run expectations for the short-term rate $R_{1, t}^{e}$, both expressed as deviations from long-run inflation expectations $\pi_{t}^{e}$, similarly to the right panel of figure 2 . The time series of $\bar{r}_{t}$ is very similar to that shown in figure 2, albeit not identical at the beginning of the sample (recall that

27. The Baa yield is available from FRED (mnemonic BAA). As described by Krishnamurthy and Vissing-Jorgensen (2012, p 262), "The Moody's Baa index is constructed from a sample of long-maturity ( $\geq 20$ years) industrial and utility bonds (industrial only from 2002 onward)." This series is available throughout the whole sample, but ends in 2016:Q3.

28. The initial condition $\overline{c y}_{0}$ is set at 1 , using presample averages for the Baa-Treasury spread; and correspondingly, $\bar{m}_{0}$ is set to $1.5\left(\bar{r}_{0}+\overline{c y}_{0}\right)$. The variance of the initial conditions is 1 , as is the case for all other trends. 
we are now using a larger cross section of yields to pin down $\bar{r}_{t}$ ). In terms of the question this paper addresses, the decline in $\bar{r}_{t}$ from the late $1990 \mathrm{~s}$ to the present is 1.27 percentage points, the same as estimated above, as shown in the second column of table 1 . The other two panels of figure 3 show that much of this decline is attributable to an increase in the convenience yield, rather than to a fall in $\bar{m}_{t}$. The top-right panel shows $\overline{c y}_{t}$, and the spread between Baa securities and comparable Treasuries, $R_{t}^{\text {Baa }}-R_{80, t^{*}}$. This spread has a clear upward trend, especially starting right before the turn of the century, which is picked up by the estimate of $\overline{c y}$. Table 1 shows that the convenience yield increases by 93 basis points from 1998:Q1 to 2016:Q4, with 95 percent credible intervals ranging from 49 to 135 basis points. The bottom panel of figure 3 shows the "real rate" $R_{1, t}-\pi_{t}^{e}$ plus the spread $R_{t}^{B a a}-R_{80, t}$. It shows that there is a fall in $\bar{m}_{t}$ (the median decline is about 35 basis points) but is imprecisely estimated, as the upper bound of the 68 percent credible interval is essentially 0 . We should stress once again that the reader should not focus on the levels of $\bar{m}_{t}$ and $\overline{c y}$, but on their changes. Our statement is not, "Were it not for the convenience yield from safety and liquidity, the secular components of real rates would be $x$ percent," but rather, "Much of the decline in rates over the past 20 years is due to the convenience yield." This is because the level of the spread $R_{t}^{B a a}-R_{80, t}$ is affected by factors-mostly the probability of default-other than the convenience yield. ${ }^{29}$

Another perspective on what we find is that the secular decline in real rates for unsafe and illiquid securities has been much less pronounced, if it has taken place at all, than that for safe and liquid securities. As discussed in the introduction to this paper, the trend increase in the safety and liquidity convenience yield since the late 1990s is very much in line with the narrative put forth by Caballero (2010) and the "safe assets" literature more broadly. The Asian crisis first resulted in excess supply of savings, which, being institutional (that is, intermediated via central banks), was naturally directed toward safe and liquid assets. The Nasdaq crash further rendered safe assets more attractive. The housing boom and the related creation of allegedly safe securities partly met this increased demand, but this suddenly came to a halt with the housing crisis and the Great Recession, which resulted in increased demand for, and reduced supply of, safe and liquid assets.

29. Figure $\mathrm{A} 3$ in the online appendix shows the remaining estimated trends $\left(\bar{\pi}_{t}\right.$ and $\left.\overline{t p}_{t}\right)$, along with the relevant data. Figure A4 shows all the data $y_{t}$ used in the estimation, together with $\Lambda \bar{y}_{t}$ and $\tilde{y}_{t}$, the nonstationary and stationary components, respectively. 
Figure 3. Trends and Observables in the Convenience Yield Model, 1960-2016

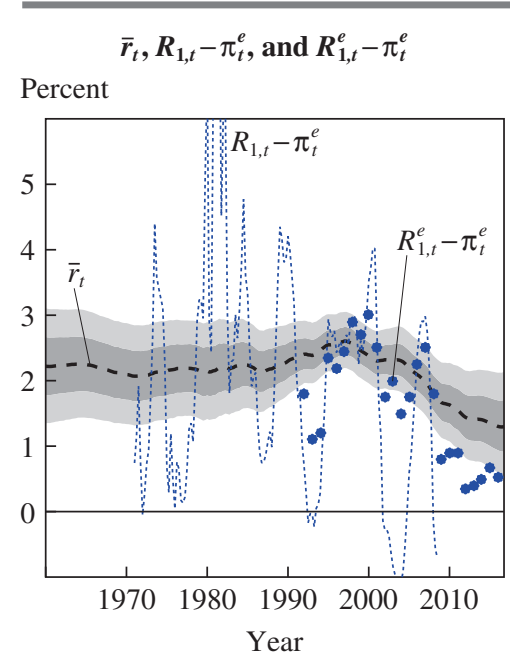

$\overline{c y}_{t}$ and $\boldsymbol{R}_{t}^{B a a}-R_{80, t}$

Percent

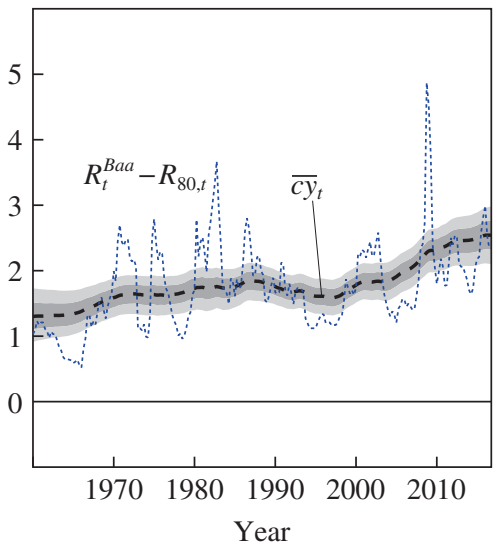

$\bar{m}_{t}$ and $R_{1, t}-\pi_{t}^{e}+\left(R_{t}^{B a a}-R_{80, t}\right)$

Percent

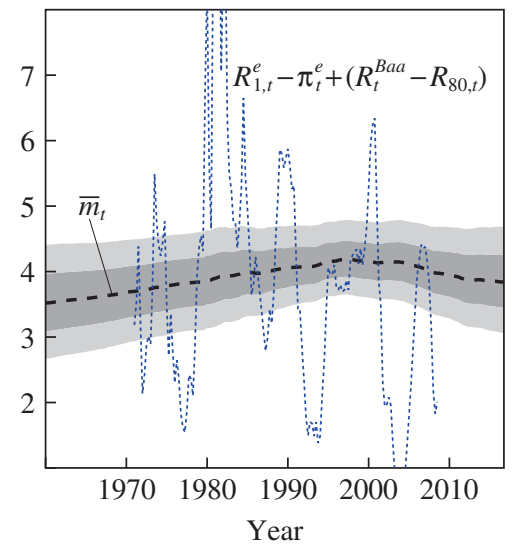

Sources: FRED; Survey of Professional Forecasters; Clark and Doh (2014); authors' calculations.

a. For each trend, the dashed line is the posterior median, the dark shaded area shows the 68 percent posterior coverage interval, and the light shaded area shows the 95 percent posterior coverage interval. 
TRENDS IN THE COMPENSATION FOR SAFETY AND LIQUIDITY

Model specification. Following Krishnamurthy and Vissing-Jorgensen (2012), we decompose the convenience yield $\left(1+C Y_{t}\right)$ into two parts: one due to liquidity $\left(1+C Y_{t}^{l}\right)$ and one to safety $\left(1+C Y_{t}^{s}\right)$. We write the Euler equation for a safe and liquid security as

$$
E_{t}\left[\left(1+r_{t}\right)\left(1+C Y_{t+1}^{l}\right)\left(1+C Y_{t+1}^{S}\right) M_{t+1}\right]=1
$$

Under the assumption that the covariances between $C Y_{t}^{l}, C Y_{t}^{s}$, and $M_{t}$ are stationary, we obtain the following:

$$
\bar{r}_{t}=\bar{m}_{t}-\overline{c y}_{t}^{l}-\overline{c y}_{t}^{s} \text {. }
$$

The distinction between safety and liquidity has two benefits. First, from an economic point of view, it allows us to disentangle the importance of the two components in explaining trends in $r_{t}^{*}$. In order to do so, we need to be able to identify the two trends separately. Once again following Krishnamurthy and Vissing-Jorgensen (2012), we do so by bringing into the analysis the Aaa corporate yield, an index of securities that virtually never default, and hence carry as much of a safety discount as Treasuries but are less liquid than Treasuries, so they enjoy less of a liquidity premium. ${ }^{30}$ We therefore write

$$
\begin{gathered}
R_{t}^{\text {Aaa }}=\bar{m}_{t}-\lambda_{l}^{A a a} \overline{c y}_{t}^{l}-\overline{c y}_{t}^{s}+\bar{\pi}_{t}+\overline{t p}_{t}+\tilde{R}_{t}^{\text {Baa }}, \\
R_{t}^{\text {Baa }}=\bar{m}_{t}-\lambda_{l}^{\text {Aaa }} \overline{c y}_{t}^{l}-\lambda_{s}^{\text {Baa }} \overline{c y}_{t}^{s}+\bar{\pi}_{t}+\overline{t p}_{t}+\tilde{R}_{t}^{\text {Baa }},
\end{gathered}
$$

where $0 \leq \lambda_{l}^{A a a}<1$ and $0 \leq \lambda_{s}^{B a a}<1$, indicating that both Aaa and Baa corporate bonds are less liquid than Treasuries (we assume that their degree of illiquidity is the same; hence, $\lambda_{l}^{B a a}=\lambda_{l}^{A a a}$ ), and that Baa corporate bonds are less safe than Treasuries. From equations 12, 18, and 19, it follows that

$$
\bar{R}_{t}^{A a a}-\bar{R}_{80, t}=\left(1-\lambda_{l}^{A a a}\right) \overline{c y}_{t}^{l},
$$

30. Bao, Pan, and Wang (2011) show that changes in market-level illiquidity explain a substantial part of the time variation in the yield spreads of all high-rated bonds (as measured by Standard \& Poor's A through AAA, which correspond to Moody's A through Aaa), overshadowing the credit risk component. 
and

$$
\bar{R}_{t}^{B a a}-\bar{R}_{t}^{A a a}=\left(1-\lambda_{s}^{B a a}\right) \overline{c y}_{t}^{s} .
$$

As before, we make the conservative assumptions that Baa bonds earn no safety and liquidity premium whatsoever, and that Aaa bonds are safe but completely illiquid. These assumptions are conservative in the sense that they minimize time variation in the trends $\overline{c y}_{t}^{l}$ and $\overline{c y}_{t}^{s}$, given the observed trends in the spreads $\bar{R}_{t}^{\text {Aaa }}-\bar{R}_{80, t}$ and $\bar{R}_{t}^{\text {Baa }}-\bar{R}_{t}^{\text {Aaa }}$.

The system formed by equations 10 through 13,18 , and 19 can be expressed as a VAR for $y_{t}=\left(\pi_{t}, \pi_{t}^{e}, R_{1, t}, R_{80, t}, R_{1, t}^{e}, R_{t}^{\text {Aaa }}, R_{t}^{\text {Baa }}\right)$, with common trends $\left(\bar{m}_{t}, \bar{\pi}_{t}, \overline{c y}_{t}^{s}, \overline{c y}_{t}^{l}, \overline{t p}_{t}\right) .{ }^{31}$ We use exactly the same priors as described above, except that because we decompose the trend $\overline{c y}_{t}$ into two components, $\overline{c y}_{t}^{s}$ and $\overline{c y}_{t}^{l}$, we center the corresponding diagonal values of $\sum_{\varepsilon}$ to a number that is half the value chosen for $\overline{c y}_{t}$ (we use $1 / 1600$, as opposed to $1 / 800) .^{32}$ This obviously makes it harder to find a trend in these convenience yields.

Results. Figure 4 shows the trend $\bar{r}_{t}$ and its decomposition between trends in the convenience yield for safety and liquidity $\overline{c y}_{t}=\overline{c y}_{t}^{l}+\overline{c y}_{t}^{s}$ (note that we are actually plotting $-\overline{c y}_{t}$ ) and the stochastic discount factor $\bar{m}_{t}$. The estimates for $\bar{r}_{t}$ appear in all three panels, and the levels of both $-\overline{c y}_{t}$ and $\bar{m}_{t}$ are normalized, so that in 1998:Q1 the three series coincide (at the posterior median), making the source of the post-1998 decline in $\bar{r}_{t}$ more apparent. The estimates of $\bar{r}_{t}$ are virtually the same as those shown in figure 3, and show $\bar{r}_{t}$ falling by 1.3 percentage points between 1998:Q1 and 2016:Q4 (see column 3 of table 1). Again, this decline is precisely estimated. The top-right panel of figure 4 shows that roughly 1 percentage point of this decline is attributable to an increase in the convenience yield. The converse of the convenience yield $\left(-\overline{c y_{t}}\right)$ falls by 1 percent, and the decrease is very precisely estimated, with the 68 and 95 percent posterior coverage intervals ranging from -1.18 to -0.75 percent and from -1.40 to -0.53 percent, respectively. The term $\bar{m}_{t}$ also declines in the new century, by about 30 basis points, as shown in the bottom panel of figure 4 , but its

31. The Aaa yield is also available from FRED (mnemonic AAA) and has similar characteristics as the Baa index in terms of maturity. This series is available throughout the whole sample, but ends in 2016:Q3.

32. The initial conditions $\overline{c y_{0}^{s}}$ and $\overline{c y}_{0}^{l}$ are set at 0.75 and 0.25 , using presample averages for the Baa-Aaa and the Aaa-Treasury spreads. The variance of the initial conditions is 1, as is the case for all other trends. 
Figure 4. $\bar{r}_{t},-\overline{c y}_{t}$, and $\bar{m}_{t}, 1960-2016^{\mathrm{a}}$

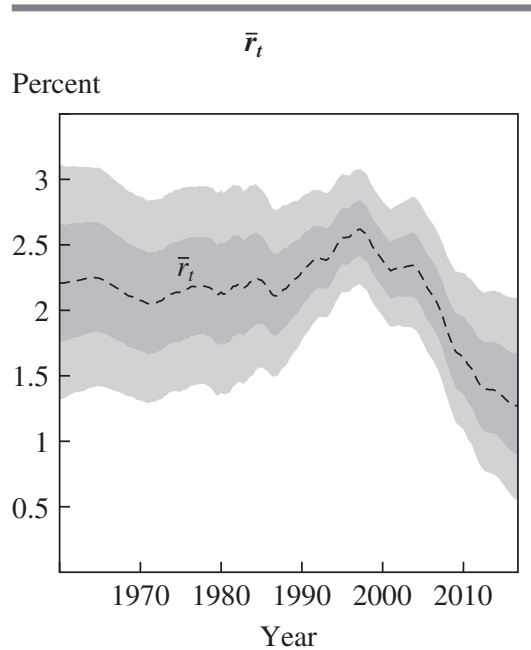

$-\overline{c y}_{t}$

\section{Percent}

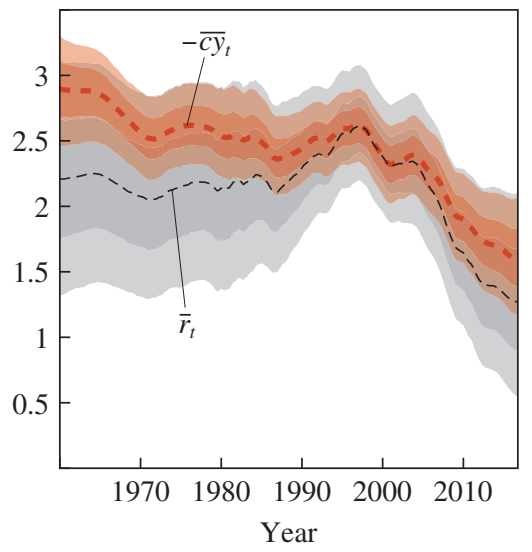

$\overline{\boldsymbol{m}}_{t}$

Percent

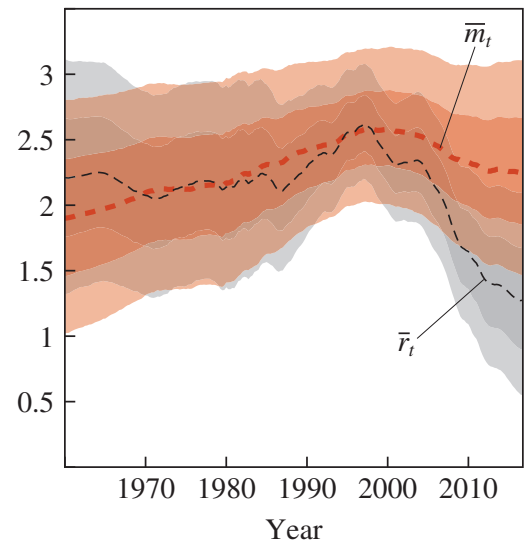

Source: Authors' calculations.

a. For each trend, the dashed line is the posterior median, the dark shaded area shows the 68 percent posterior coverage interval, and the light shaded area shows the 95 percent posterior coverage interval. 
estimates are much more uncertain: The 68 percent intervals of the estimated fall in $\bar{m}_{t}$ range from -0.65 to -0.02 percent.

Figure 5 shows the estimated trends in the overall convenience yield $\overline{c y}$, and the convenience yields attributed to safety $\left(\overline{c y}_{t}^{s}\right)$ and liquidity $\left(\overline{c y}_{t}^{l}\right)$, along with the information that the model uses to extract these trends. ${ }^{33}$ The top-left panel shows $\overline{c y_{t}}=\overline{c y}_{t}^{s}+\overline{c y}_{t}^{l}$, and the spread between Baa securities and Treasuries, $R_{t}^{B a a}-R_{80, t}$ Again, in spite of the fact that the trends $\overline{c y}_{t}^{s}$ and $\overline{c y}_{t}^{l}$ are now separately estimated, the inference for $\overline{c y}_{t}$ is broadly similar to that shown in figure 3. The top-right panel shows $\overline{c y_{t}^{s}}$ and the spread between Baa and Aaa bonds $R_{t}^{\text {Baa }}-R_{t}^{\text {Aaa }}$. The trend in this spread, according to the model, has less of a secular increase in the overall sample than the overall convenience yield. The trend in the safety premium increases in the 1970s, reaches a peak in the early 1980s, declines progressively until the Nasdaq crash, and finally increases by a little less than 50 basis points until the end of the sample. The estimated increase in the safety convenience yield between 1998:Q1 and 2016:Q4 is 45 basis points, and is very significantly different from zero.

The bottom panel of figure 5 shows $\overline{c y_{t}^{l}}$, and the spread between Aaa securities and Treasuries $R_{t}^{\text {Aaa }}-R_{80, t}$. The trend $\overline{c y_{t}^{l}}$ has had a more pronounced secular increase since the early $1980 \mathrm{~s} .{ }^{34}$ From the perspective of the focus of the paper-the sources of the decline in real rates since the 1990s-the bottom panel shows an increase in $\overline{c y_{t}}{ }_{t}$ by about 50 basis points since 1998 (see column 3 of table 1). ${ }^{35}$ Much of this increase occurred during and after the financial crisis. This is not surprising, because the liquidity shock in the aftermath of the Lehman Brothers

33. Figure A5 in the online appendix shows the remaining estimated trends $\left(\bar{\pi}_{t}, \bar{r}_{t}, \bar{m}_{t}\right.$, and $\overline{t p_{t}}$ ), along with the relevant data. Figure A6 in the online appendix shows the prior and posterior distributions of the standard deviations of the shocks to the trend components- the diagonal elements of the matrix $\Sigma_{e}$. Figure A7 in the online appendix shows all the data $y_{t}$ used in the estimation, together with $\Lambda \bar{y}_{t}$ and $\tilde{y}_{t}$, the nonstationary and stationary components, respectively.

34. Although the transitory spikes in the convenience yield for liquidity are easily explained by financial events (for example, the stock market crash of 1987; the burst of the 1990s stock market bubble; 9/11; and the Lehman Brothers crisis), this secular increase is for us not straightforward to explain, but we find it an interesting question for future research. One possibility is that it is related to the growth of the shadow banking system documented by Adrian and Shin $(2009,2010)$.

35. Note that the high-frequency spike in illiquidity that occurred during the financial crisis does not seem to play an important role in the extraction of the trend; in other words, the increase in the compensation for liquidity appears to be mostly driven by the low-frequency movements in the spreads. 
Figure 5. Trends in Compensation for Safety and Liquidity, and Observables, $1960-2016^{\mathrm{a}}$
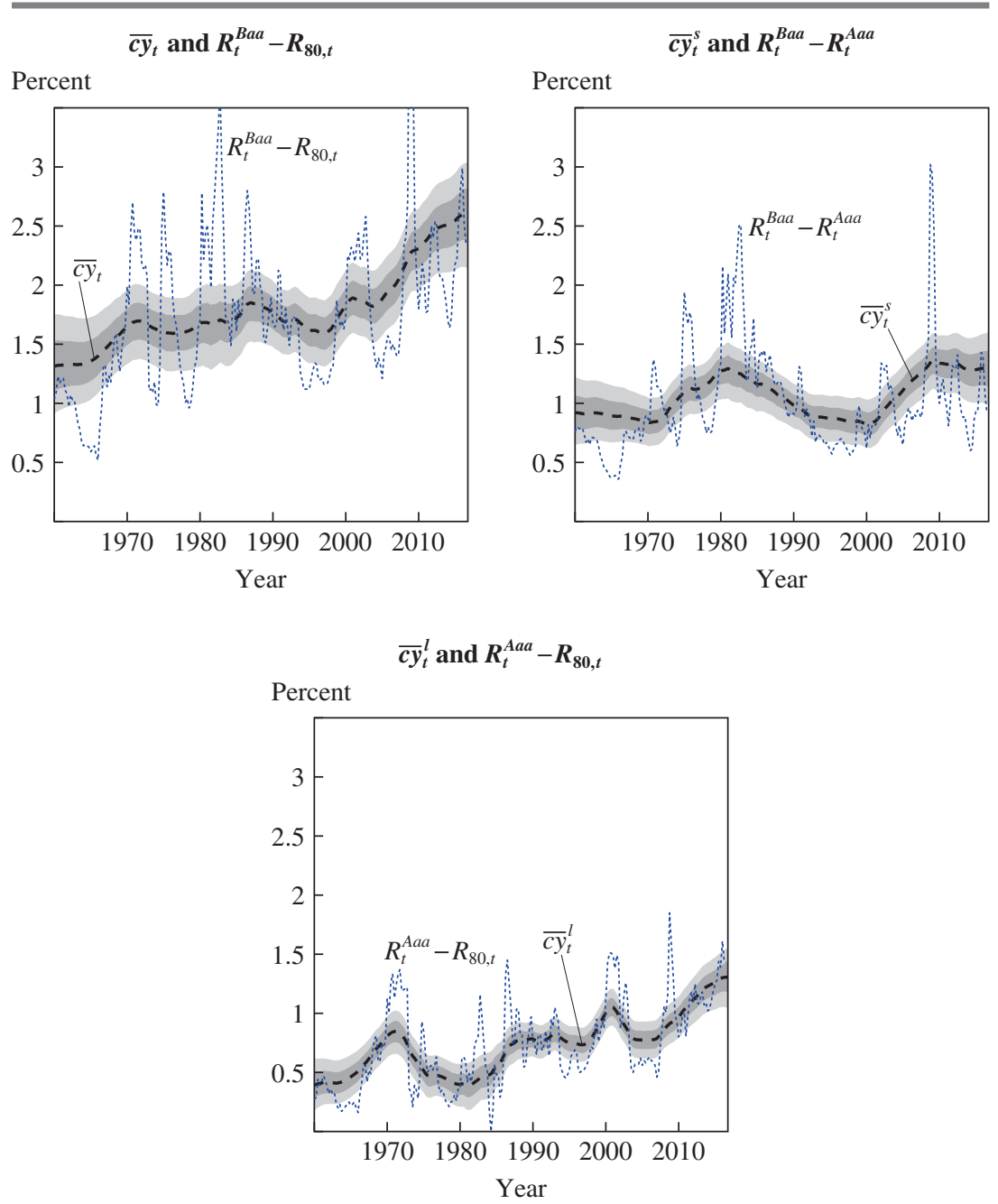

Sources: FRED; authors' calculations.

a. For each trend, the dashed line is the posterior median, the dark shaded area shows the 68 percent posterior coverage interval, and the light shaded area shows the 95 percent posterior coverage interval. 
crisis drastically curtailed the supply of liquid assets, as several asset classes became less liquid (Del Negro and others 2017; Gorton and Metrick 2012), and at the same time increased its demand. In addition, the regulatory changes after the crisis also led to an increased demand for liquid assets, as well as a decline in the supply of liquid liabilities from the financial system. ${ }^{36}$ Wenxin Du, Alexander Tepper, and Adrien Verdelhan (2017) show that the postcrisis deterioration of liquidity is evident from persistent and sizable deviations in covered interest rate parity. In conclusion, we find that the increase in the convenience yield since the late 1990s has been roughly evenly split between compensation for safety and liquidity.

\section{II.C. The Role of Consumption}

MODEL SPECIFICATION The VAR specifications that we have considered so far have all been agnostic on the fundamental determinants of the trends in the stochastic discount factor $m_{t}$. We chose this approach because there is no consensus in the literature on how to model this variable. Many asset pricing theories, however, connect the stochastic discount factor to some function of consumption growth. This list includes the consumption Euler equation that holds in the DSGE model of the next section. These theories, in fact, are the basis for the often-discussed relationship between trends in rate of returns and in the economy's growth rate (Laubach and Williams 2003; Hamilton and others 2016).

This subsection explores this relationship by including a measure of per capita consumption growth in the VAR. This model is an extended version of the baseline specification of section II, in which $\bar{m}_{t}$ is decomposed into two factors. The first factor, denoted by $\bar{g}_{t}$, is common between the trends in $m_{t}$ and in the growth rate of per capita consumption, which we call $\overline{\Delta c}_{t}$. Motivated by the fact that trends in $m_{t}$ may in principle be driven by factors

36. See the liquidity requirements for financial institutions under Basel III (Basel Committee on Banking Supervision 2013). There is a rapidly growing body of literature, nicely summarized by Anderson and Stulz (2017), on whether postcrisis regulation affected liquidity provision in financial markets. Its conclusions so far are that for small trades liquidity seems to have improved, partly thanks to technological innovations such as electronic trading, and that price-based metrics generally show little evidence of deterioration in liquidity conditions (Adrian and others 2016). At the same time, these price-based liquidity metrics do not reflect trades that do not take place because of diminished liquidity. Anderson and Stulz (2017) provide ample evidence of a sharp postcrisis decrease in turnover, partly associated with constraints to broker-dealer balance sheets discussed by Adrian, Boyarchenko, and Shachar (2017). 
that are not associated with consumption, we also introduce a residual factor, $\bar{\beta}_{t}$, so that

$$
\bar{m}_{t}=\bar{g}_{t}+\bar{\beta}_{t}
$$

In addition, we do not impose the condition that $\bar{g}_{t}$ is the same as the trend in overall consumption growth, as would be the case in a textbook version of the Euler equation with log utility. Instead, we allow for another trend in consumption growth, or

$$
\overline{\Delta c}_{t}=\bar{g}_{t}+\bar{\gamma}_{t}
$$

This specification admits the possibility that the relevant consumption pricing factor for interest rates is not aggregate consumption, but possibly a subset of consumption with a different trend from the aggregate. This would be the case, for instance, in a limited participation model in which only a subset of consumers have access to financial markets and the lowfrequency component of their consumption growth is different from that of nonparticipants (Vissing-Jorgensen 2002). Given the steady growth in inequality during the last few decades, such a persistent divergence in the consumption prospects of richer asset holders and poorer households excluded from financial markets seems plausible.

In sum, we augment the system made up of equations 10 through 13, 18, and 19 with an equation for consumption growth

$$
\Delta c_{t}=\bar{g}_{t}+\bar{\gamma}_{t}+\widetilde{\Delta c_{t}}
$$

and set $\bar{m}_{t}=\bar{g}_{t}+\bar{\beta}_{t}$ in all equations involving $\bar{m}_{t}{ }^{37}$ In terms of priors, we want to allow ample room for the trend in consumption growth $\bar{g}_{t}$ to account for the decline in $\bar{r}_{t}$. Therefore, we assume that the prior standard deviation of the innovations to its trend is four times as large as that of $\overline{c y}_{t}^{s}$ and $\overline{c y}_{t}^{l}$, which implies a value of $1 / 400$ for the corresponding diagonal element of the

37. We use the same measure of real per capita consumption as in the DSGE model, namely, personal consumption expenditures divided by the GDP deflator and a smoothed version of population. See the section in the online appendix on DSGE data for more details. Consumption growth is quarterly, annualized. 
Figure 6. Consumption Growth and Its Trend, 1960-2013

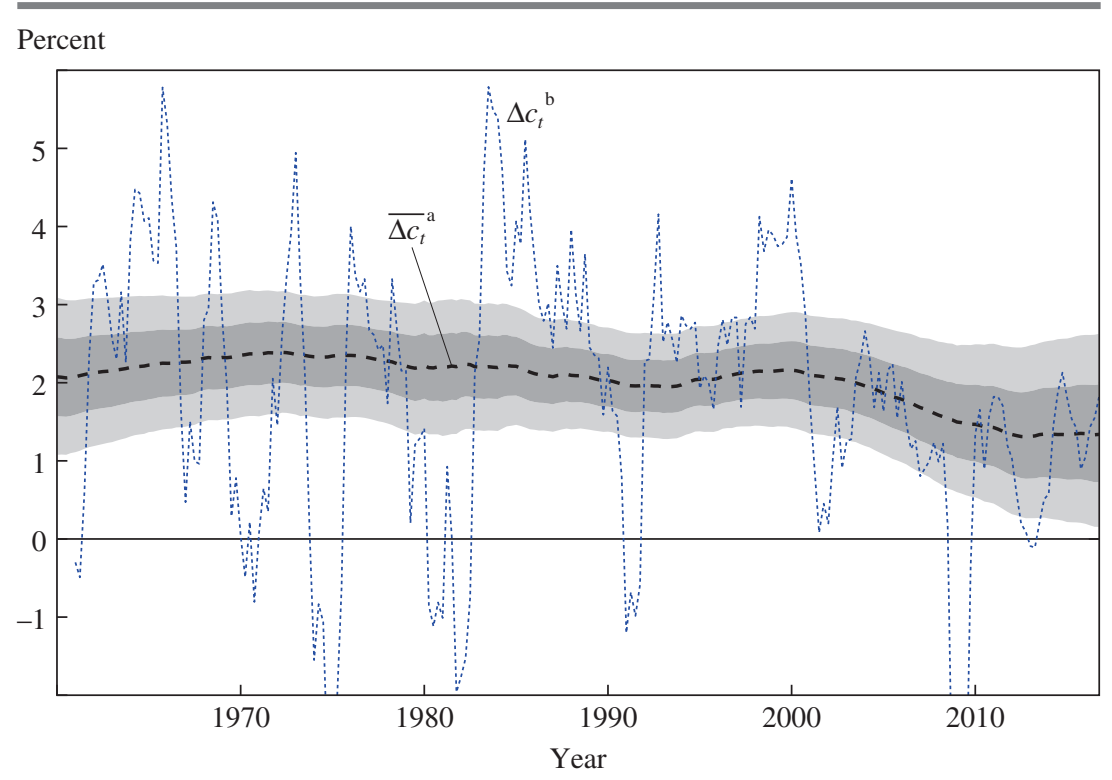

Sources: FRED; authors' calculations.

a. This line is the posterior median for the consumption trend $\overline{\Delta c_{t}}=\bar{g}_{t}+\bar{\gamma}_{t}$, the dark shaded area shows the 68 percent posterior coverage interval, and the light shaded area shows the 95 percent posterior coverage interval.

b. This line is the four-quarter moving average of the growth rate of per capita consumption.

matrix $\sum_{\varepsilon}$. We also assume the same prior for $\bar{\gamma}_{t}$, while the standard deviation of $\bar{\beta}_{t}$ is set to $1 / 8$ of that of $\bar{g}_{t}{ }^{38}$ All other priors are the same as in the baseline model.

RESULTS Figure 6 shows the four-quarter average of the growth rate of per capita consumption together with its trend, $\overline{\Delta c}_{t}=\bar{g}_{t}+\bar{\gamma}_{t}$. The figure shows that the estimated trend in consumption growth has fallen over the past 20 years. This decline has been notable, as shown in column 4 of table 1 . The median estimate is 0.80 percentage point, although it is imprecisely estimated. Table 1 also shows that the component attributable to $\bar{g}_{t}$, which is the part of the trend in consumption growth that affects the interest rate, is about 56 basis points at the posterior median, and it is also surrounded by significant uncertainty. Nonetheless, the estimated decline in $\bar{r}_{t}$ of 1.40 percentage points and the increase in the convenience yield of 0.78 percentage point are close to the figures shown before, and are still

38. The initial conditions $\bar{\gamma}_{0}$ and $\bar{\beta}_{0}$ are set to 0 . As in the previous cases, the initial condition $\bar{m}_{0}$ is set to $1.5\left(\bar{g}_{0}+\bar{\beta}_{0}\right)$. 
precisely estimated..$^{39}$ In sum, the increase in the convenience yield still accounts for the majority of the overall secular trend decline in $r_{t}{ }^{40}$

The results were very similar in a model where we substituted the growth rate of consumption with that of labor productivity among the observables. The motivation for also experimenting with this specification comes from the neoclassical growth model, where the interest rate, productivity growth, and consumption growth are all tied together along the balanced growth path. Therefore, productivity growth provides an alternative source of information on the trend growth rate of the economy. The two trends might not coincide for several reasons-including persistent movements in the current account in an open economy, trends in the labor force participation rate that drive a wedge between the growth rates of the population (in the denominator of per capita consumption), and number of hours worked (in the denominator of labor productivity). Both these phenomena have been observed in the United States since the 1990s, and they are often mentioned as possible secular drivers of the decline in interest rates that has occurred over the same period. As shown in column 4 of table A2 in the online appendix, the estimated trend decline in the real interest rate in this model is centered on 1.61 percentage points, the highest value of all the models we estimated. Of this decline, 84 basis points are accounted for by the increase in the convenience yield, and another 72 by the decline in the trend growth rate of productivity. As before, the former contribution is very tightly estimated, while the latter is quite uncertain.

In summary, the results of this augmented model corroborate our conclusion that the increase in the convenience yield has been a crucial factor in the secular decline of Treasury yields. In addition, the model suggests that the concomitant fall in the trend growth rate of economic activitymeasured either in the form of consumption or of labor productivity-also

39. Figure $\mathrm{A} 8$ in the online appendix shows the remaining estimated trends $\left(\bar{\pi}_{t}, \bar{r}_{t}, \bar{m}_{t}, \overline{t p}_{t}\right.$, $\overline{c y}_{t}^{s}$, and $\overline{c y}_{t}^{t}$ ) along with the relevant data. Figure A9 in the online appendix shows all the data $y_{t}$ used in the estimation, together with $\Lambda \bar{y}_{t}$ and $\tilde{y}_{t}$, the nonstationary and stationary components, respectively.

40. We also estimated a more restricted model with a common trend between aggregate consumption and the interest rate- that is, eliminating $\bar{\gamma}_{\text {. }}$. In that model, the trend in consumption moves much less, and the effects on $\bar{m}_{t}$ are smaller, suggesting that the restriction that all of the trend in consumption growth translates into secular changes in the discount factor is at odds with the data. Otherwise, the results are quite similar to those just discussed. We also tried to estimate the intertemporal elasticity of substitution - that is, modifying equation 20 as $\bar{m}_{t}=\sigma^{-1} \bar{g}_{t}+\bar{\beta}_{t}$. This only resulted in more uncertain estimates of the decline in $\bar{m}_{t}$. This possibly reflects the well-known difficulties in pinning down the intertemporal elasticity of substitution. 
played a relevant role, although this conclusion is subject to significant uncertainty.

\section{II.D. Robustness}

This subsection considers variants to our benchmark specification-the model with convenience from both safety and liquidity.

ALTERNATIVE MEASURES OF CORPORATE SPREADS We rely on the spreads between Moody's Baa or Aaa corporate yields and 20-year Treasuries to capture trends in the premiums for safety and liquidity, for two main reasons. First, they are available for a long time period, which is crucial when estimating a trend. Second, these are the proxies used by Krishnamurthy and Vissing-Jorgensen (2012). This section addresses several potential concerns regarding this measurement approach. As a preliminary consideration, recall that in theory the convenience yield is defined as the spread between a Treasury and a security with the same maturity that is completely illiquid and unsafe. In practice, none of the spreads we consider are completely illiquid or unsafe. Therefore, our estimates arguably underestimate the role of the convenience yield.

Accounting for differences in maturity. Moody's Baa and Aaa corporate bond yields are a composite of returns on securities with different maturities. To avoid the potential problems associated with mixing maturities, Simon Gilchrist and Egon Zakrajšek (2012) construct a corporate spread, matching maturities bond by bond. We do not use this spread as our main measure for three reasons: First, because it has a shorter time series; second, and more important, because it does not allow us to disentangle safety from liquidity; and third, because it includes bonds across the credit rating spectrum (from Standard \& Poor's junk-grade D to prime-grade AAA).

To assess how the trends in the convenience yield that we identify compare with trends in the Gilchrist and Zakrajšek (2012) spread, the top-left panel of figure 7 shows the estimated $\overline{c y_{t}}$ from figure 5 and the Baa-Treasury spread (left axis), together with the Gilchrist and Zakrajšek (2012) spread (right axis). Movements in the Gilchrist and Zakrajšek (2012) spread are wider than those in the Baa-Treasury spread, but the trend in the convenience yield describes their low-frequency component quite well. In particular, the Gilchrist and Zakrajšek (2012) spread averaged 1.28 percent in the five years before 1998:Q1, compared with 2.15 percent in the last five years of the sample (2012:Q1-2016:Q4).

Accounting for callability. Many corporate bonds are callable, while Treasuries are not (at least since 1985). Therefore, secular changes in the 
Figure 7. Convenience Yield Trends and Different Spread Measures, 1960-2016a

Gilchrist and Zakrajš̌k (2012) spread

Percent

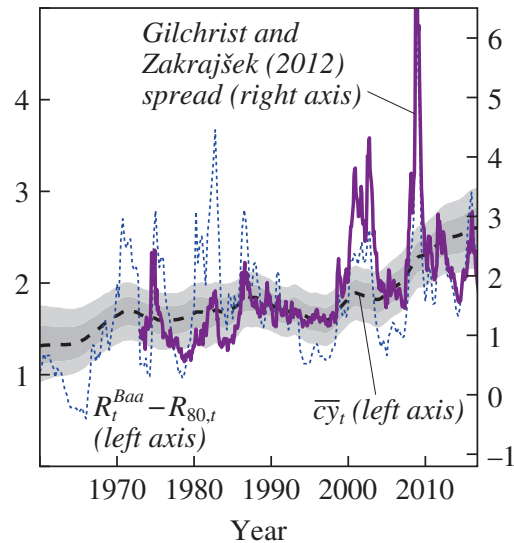

Bloomberg Barclays Industrial BBB spread $^{\mathrm{b}}$

Percent Percent

\section{Bloomberg Barclays Industrial}

\section{A spread}

Percent

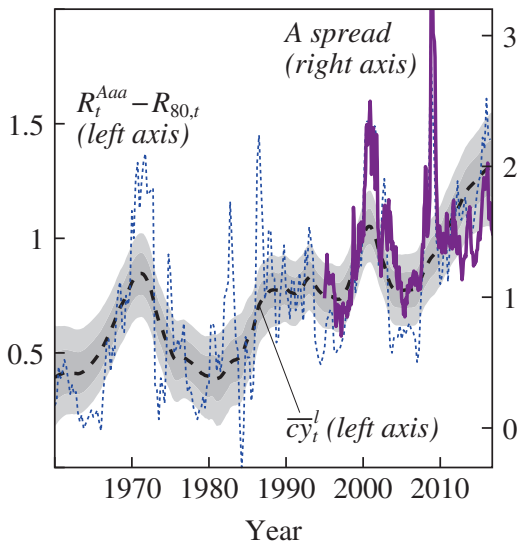

\section{Refcorp spreads ${ }^{\mathrm{d}}$}

Percent Percent

Sources: Gilchrist and Zakrajšek (2012); Bloomberg; FRED; authors' calculations.

a. For each trend, the dashed line is the posterior median, the dark shaded area shows the 68 percent posterior coverage interval, and the light shaded area shows the 95 percent posterior coverage interval.

b. This spread is between the Bloomberg Barclays U.S. Industrial BBB 20-year zero coupon yield and the corresponding Treasury yield.

c. This spread is between the Bloomberg Barclays U.S. Industrial A 20-year zero coupon yield and the corresponding Treasury yield.

d. These spreads are between Refcorp zero-coupon bonds and the corresponding Treasury yield. See note 43 for a description of how these spreads are constructed. 
value of the call option embedded in corporate bonds might drive secular changes in the yield spread. ${ }^{41}$ We address this concern in two ways. First, we use the Bloomberg Barclays credit indexes, which, in addition to the maturity adjustment described above, also control for the bonds' embedded options using Barclays's proprietary model. These series have only been available since 1994:Q4. ${ }^{42}$ The top-right panel of figure 7 shows the spread between the Bloomberg Barclays U.S. Industrial BBB 20-year zero coupon yield and the corresponding Treasury yield (solid line), together with the estimated trend in $\overline{c y}_{t}$ and the Baa-Treasury spread (dotted line). The time series of the Barclays spread is similar to that of the Baa-Treasury spread, except that the latter has increased less over the past few years. Nonetheless, a secular increase in the industrial BBB spread from the late 1990s to today is apparent; this spread averaged 1.36 percent in the first four years of data availability (1994:Q4-1997:Q4), and 1.95 percent in the last four years of the sample (2013:Q1-2016:Q4).

In a similar spirit, the bottom-left panel of figure 7 shows the estimated trend in the liquidity convenience yield $\overline{c y}_{t}^{l}$ and the Aaa-Treasury spread (dotted line), together with the spread between the Bloomberg Barclays U.S. Industrial A 20-year zero coupon yield and the corresponding Treasury yield (solid line). A-rated securities are quite safe; hence, this spread should mainly reflect the convenience yield for liquidity. This spread averaged 0.99 percent in the period 1994:Q4-1997:Q4, and 1.54 percent in the last four years of the sample (2013:Q1-2016:Q4), resulting in an increase of about 55 basis points-roughly our estimate for the increase in $\bar{c} \bar{y}_{t}^{l}$ after 1998 .

Finally, other spreads exist that mainly reflect liquidity, other than that between Aaa corporates and Treasuries. One example is the yield spread between Resolution Funding Corporation (Refcorp) bonds and Treasuries of corresponding maturity. According to Longstaff (2004), the RefcorpTreasury spread is almost entirely attributable to liquidity; because Refcorp bonds are effectively guaranteed by the U.S. government, they are subject

41. Gilchrist and Zakrajšek (2012) address the issue of callability in the construction of their "excess bond premium." They use a panel regression, whereby they regress individual corporate spreads on variables that capture the value of the call option, in addition to bondspecific measures of default probability. However, in order to remove the call option, the spreads are regressed on the level of the interest rate, among other variables, thereby removing the very trends in which we are interested.

42. Bank of America Merrill Lynch also provides similar indexes, but only since 1997, making it hard to infer their post-1998 secular decline. 
to the same taxation and, to the best of our knowledge, they are not callable. Moreover, the spread is calculated using zero-coupon Treasuries with the same maturity as the corresponding Refcorp bond. ${ }^{43}$

The bottom-right panel of figure 7 plots the estimated trend in the liquidity convenience yield $\overline{c y}_{t}^{l}$ from the bottom panel of figure 5, together with daily data from April 16, 1991, to September 6, 2014, on the RefcorpTreasury spreads for maturities of 5, 10, and 20 years collected by Marco Del Negro and others (2017). The trend in liquidity estimated using the Aaa-Treasury spread matches very well the trends in the Refcorp-Treasury spreads, whenever these are available, regardless of maturity. This evidence provides important external validation for our analysis. In addition, it suggests that callability is unlikely to be a key driving force behind secular movements in the Aaa-Treasury spread, because Refcorp bonds are not callable.

ACCOUNTING FOR TRENDS IN CORPORATE DEFAULT Corporate bonds are subject to default. We have not incorporated credit risk trends in our analysis so far. If anything, the distance to default shown in figure 8 displays a secular rise toward the end of the sample. ${ }^{44}$ This evidence suggests that including this factor in our analysis would strengthen the estimated role of the convenience yield since the late 1990s, because corporate spreads should have narrowed on account of a lower aggregate probability of default.

This is indeed what we find when we estimate a model that includes the data on distance to default shown in figure 8 . Including a distance to default trend, $\bar{D}_{t}$, in the equation for the Baa yield produces

$$
R_{t}^{\text {Baa }}=\bar{m}_{t}-\gamma^{d} \bar{D}_{t}+\bar{\pi}_{t}+\overline{t p}_{t}+\tilde{R}_{t}^{\text {Baa }},
$$

43. Refcorp bonds differ from most other agency bonds in that their principal is fully collateralized by Treasury bonds and full payment of coupons is guaranteed by the Treasury under the provisions of the Financial Institutions Reform, Recovery, and Enforcement Act of 1989. Longstaff (2004) does not mention callability as a feature of these bonds. Lehman Brothers' "Guide to Agency and Government-Related Securities" (http://www.investingin bonds.com/assets/files/lehmanagencies.pdf) does not mention callability in reference to Refcorp bonds, while it discusses callability for other agency securities. Following Longstaff (2004), we measure the spread by taking the differences between the constant maturity 10-year points on the Bloomberg fair value curves for Refcorp and Treasury zero-coupon bonds. The Bloomberg mnemonics are C091[X]Y and C079[X]Y, respectively, where $[\mathrm{X}]$ represents the years to maturity.

44. This is the series shown in figure 2 of Gilchrist and Zakrajšek (2012). We are very grateful to Egon Zakrajšek for providing us with an updated data set. 
Figure 8. Distance to Default, 1973-2016

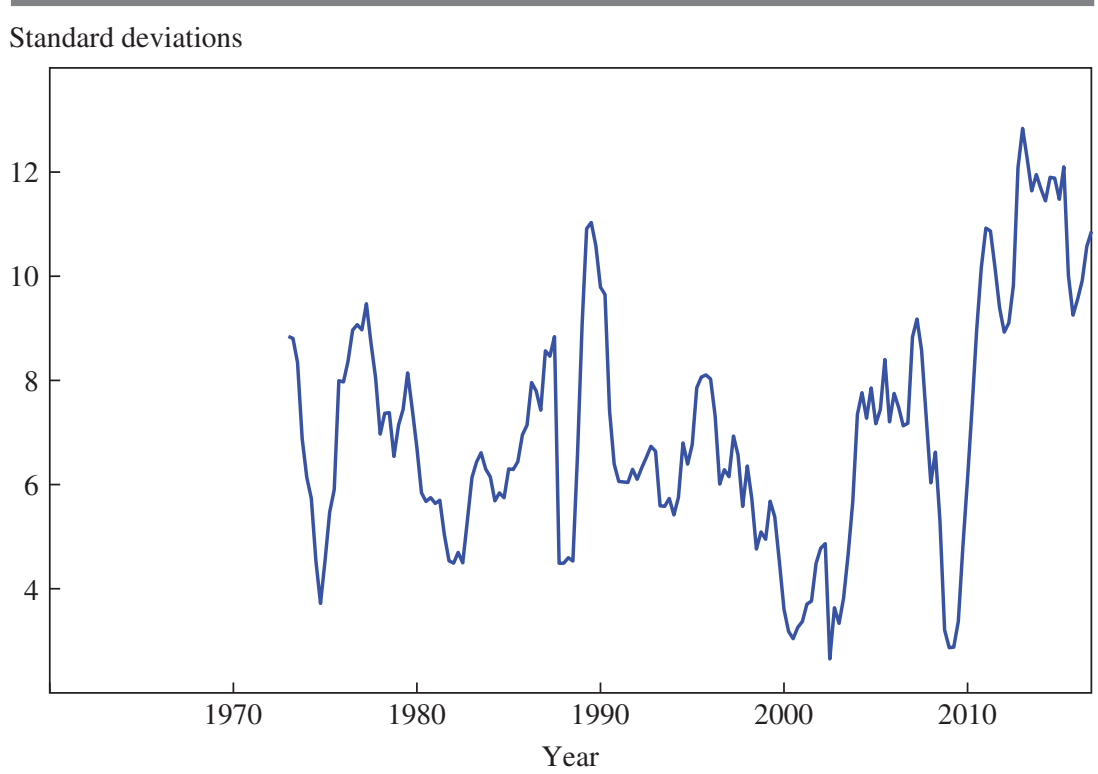

Source: Gilchrist and Zakrajšek (2012).

a. This line is the median distance to default in the nonfinancial corporate sector from figure 2 of Gilchrist and Zakrajšek (2012). Egon Zakrajšek provided us with the most recent data.

where the loading $\gamma^{d}$ is estimated using an exponential distribution with mean $1 / 10$ as the prior. ${ }^{45}$ Table $\mathrm{A} 2$ in the online appendix shows that the estimated increase in the convenience yield since 1998:Q1 is about 1.4 percentage points, larger than in the specifications without default, and it remains precisely estimated.

Gilchrist and Zakrajšek (2012) also construct a spread measure that removes default risk. Unfortunately, this calculation also controls for "bond-specific characteristics that could influence bond yields through either term or liquidity premiums" (Gilchrist and Zakrajšek 2012, p. 1704), and therefore removes precisely the characteristics that are the focus of our paper. Moreover, one of these controls is the bonds' duration, which

45. The prior mean for $\gamma^{d}$ is loosely based on the results of the panel regressions reported by Gilchrist and Zakrajšek (2012), who estimate the effect of the distance to default on corporate spreads. The prior on the variance of the trend $\bar{D}_{t}$ (that is, the corresponding diagonal element of the matrix $\Sigma_{e}$ ) is $1 / 400$, which is the same prior we used for $\bar{r}_{t}$ in the first model. The exponential distribution with parameter $\underline{\gamma}^{-1}$ is $p\left(\gamma ; \underline{\gamma}^{-1}\right)=\underline{\gamma}^{-1} \exp \left(-\underline{\gamma}^{-1} \gamma\right) I(\gamma \geq 0)$, where $I(\cdot)$ is an indicator function. 
correlates with the level of interest rates. Although, for these reasons, we do not use their "excess bond premium" in our analysis, we also believe that using a security-by-security approach similar to that pursued by Gilchrist and Zakrajšek (2012) to provide a cleaner proxy for the convenience yield that we are trying to isolate here should be a priority for future research.

LOOSE PRIOR ON THE TREND Our main result is that trends in the convenience yield account for a large chunk of the decline in $\bar{r}_{t}$, while the effect of changes in the trend of the discount factor $\bar{m}_{t}$ is not as large, and it is quite imprecisely estimated. One possible objection to this conclusion is that our prior on the standard deviation of the innovations to the trends is too conservative, reducing the scope for variation in the trend in $\bar{r}_{t}$ and hence in $\bar{m}_{t}$.

To address this concern, figure 9 shows the outcome of reestimating the model in subsection II.B with the loosest possible prior on the variancecovariance matrix. ${ }^{46}$ The result of this robustness exercise is to add significant high-frequency variation to the estimated trends, but without changing their broad contours. ${ }^{47}$

INFLATION IN THE NOMINAL TERM PREMIUM As anticipated, we also allow for the possibility that trends in inflation affect the nominal term premium by modeling the term premium as the sum of an exogenous component $\overline{t p}_{t}$ and a linear function of the inflation trend, $\gamma^{t p} \bar{\pi}_{t}$. The parameter $\gamma^{t p}$ is estimated using an exponential distribution with mean $1 / 10$ as the prior. This specification is motivated by the work of Wright (2011), who found a positive correlation between the level of the nominal term premium and the volatility of inflation. Instead, we use the level of inflation as a proxy for the latter. We therefore replace $\overline{t p}_{t}$ with $\overline{t p}_{t}+\gamma^{t p} \bar{\pi}_{t}$ in equations 12,18 , and 19. The results under this specification are nearly identical to those of subsection II.B, as shown in figure A11 in the online appendix.

NOMINAL SHORT-TERM RATE OBSERVABLE DURING THE ZLB PERIOD The last robustness exercise we consider consists of using observations on the short-term nominal interest rate, $R_{1, t}$ over the entire sample, as opposed to treating it as missing data during the period when the ZLB was binding. The results from this specification are reported in column 5 of table A2 in the online appendix. They are essentially the same as those in column 3 of table 1 .

46. This looser prior is implemented using 8 degrees of freedom, which are barely enough for the mean to be well defined, as opposed to the 100 used in the baseline specification.

47. Results are similar when we quadruple the variance of the trend innovations, without changing the distribution's degrees of freedom. 
Figure 9. Trends and Observables with the Loosest Possible Prior on the Trend, $1960-2016^{a}$

$$
\bar{r}_{t}, R_{1, t}-\pi_{t}^{e}, \text { and } R_{1, t}^{e}-\pi_{t}^{e}
$$

\section{Percent}

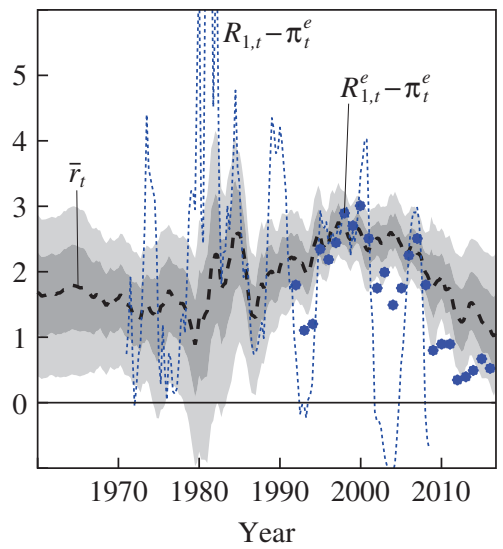

$\overline{c y}_{t}$ and $R_{t}^{B a a}-R_{80, t}$

Percent

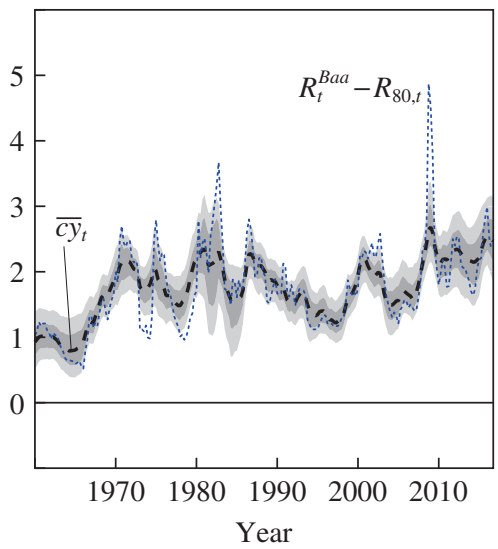

$$
\bar{m}_{t} \text { and } \boldsymbol{R}_{1, t}-\pi_{t}^{e}-\left(\boldsymbol{R}_{t}^{B a a}-\boldsymbol{R}_{80, t}\right)
$$

Percent

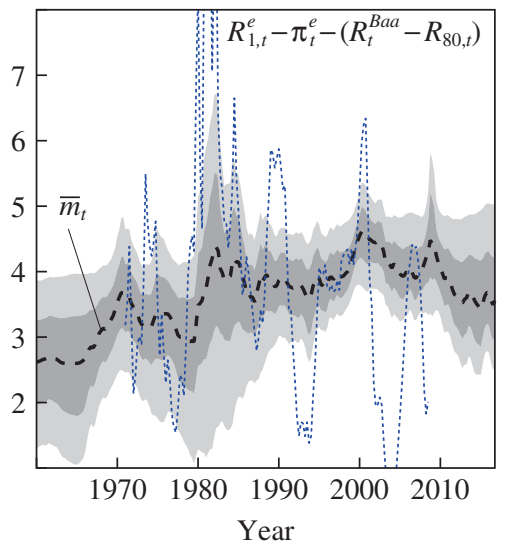

Sources: FRED; Survey of Professional Forecasters; Clark and Doh (2014); authors' calculations.

a. For each trend, the dashed line is the posterior median, the dark shaded area shows the 68 percent posterior coverage interval, and the light shaded area shows the 95 percent posterior coverage interval. 


\title{
III. The Natural Rate of Interest in DSGE Models
}

Our analysis so far has focused on long-run trends in $r_{t}^{*}$ and on the factors that drive them. However, the natural rate of interest also fluctuates over the business cycle. Characterizing these fluctuations, however, requires a structural model. To this end, this section presents estimates of $r_{t}^{*}$ based on an empirical medium-scale DSGE model that features nominal price and wage rigidities, as well as a host of real and financial frictions. Within this New Keynesian environment, we define the natural rate as the real interest rate on a safe and liquid asset that would be observed in equilibrium in the absence of sticky prices and wages, as anticipated in the introduction. ${ }^{48}$

This particular notion of $r_{t}^{*}$ is a useful tool in macroeconomic and monetary analysis for several related reasons. First, the natural rate does not depend on monetary policy. In the equilibrium without nominal rigidities, monetary policy is neutral, in the sense that it does not affect any real variable, including the real interest rate..$^{49}$ Therefore, the natural rate answers the question: What would the real interest rate be "without" monetary policy?

Second, the gap between actual interest rates and their natural level is a more accurate measure of the impetus (or restraint) imparted by monetary policy to aggregate demand than the level of the policy rate itself, as further discussed in subsection III.B. In Wicksell's (1898, p. xxv) own words,

\begin{abstract}
It is not a high or low rate of interest in the absolute sense which must be regarded as influencing the demand for raw materials, labour, and land or other productive resources, and so indirectly as determining the movement of prices. The causative factor is the current rate of interest on loans as compared to what I shall be calling the natural rate of interest on capital.
\end{abstract}

This property of the natural rate does not imply that setting the real policy rate equal to the natural rate is always desirable. This is the case only in extremely simple models that do not feature a trade-off between real and nominal stabilization. In these models, closing the interest rate gap stabilizes the output gap, and at the same time inflation. In larger, more

48. Neiss and Nelson (2003) were the first to evaluate the properties of the natural rate in a calibrated DSGE model. Edge, Kiley, and Laforte (2008), Justiniano and Primiceri (2010), Barsky, Justiniano, and Melosi (2014), and Cúrdia and others (2015) do so in estimated models. De Fiore and Tristani (2011) discuss the concept of the natural rate of interest in a model with financial frictions.

49. This statement holds in the model proposed below, but it might need to be qualified in other environments. Monetary policy might affect real variables even in the absence of nominal rigidities, depending on the exact specification of the financial and real frictions. However, these effects tend to be quantitatively small in empirical models. 
realistic DSGE models, this "divine coincidence" (Blanchard and Galí 2007) between price stability and full employment does not hold. Nonetheless, a monetary policy strategy in which the real policy rate tracks the natural rate generally promotes stable inflation and economic activity, even in those models, providing a more explicitly normative rationale for using estimates of the natural rate as an input into monetary policymaking. ${ }^{50}$

The DSGE perspective on $r_{t}^{*}$ described above is complementary to that explored in the first part of the paper. Although the VAR only provides an estimate of the low-frequency component of $r_{t}$, which only under certain assumptions coincides with the low-frequency components of $r_{t}^{*}$, a fully specified DSGE model gives us the entire time path of the natural rate. This more comprehensive characterization of $r_{t}^{*}$ is especially relevant in a policy context, where its estimates might be used to inform decisions on the appropriate level of the policy rate.

Of course, the flip side of this more general view of the movements in $r_{t}^{*}$ provided by the DSGE approach is that it makes inference conditional on the exact structure of the model, and hence more likely to be affected by misspecification. Nevertheless, our DSGE exercise recovers a trend in the natural rate that is very close to that estimated in the VAR. Moreover, the two approaches also agree on the sources of the persistent decline in $r_{t}^{*}$ since the late 1990s, as illustrated in subsection III.B. Beyond the low frequencies, the DSGE estimation indicates that the natural rate plunged to its historical lows during the Great Recession. This decline in $r_{t}^{*}$ made the lower bound on nominal interest rates bind, impairing the Federal Reserve's ability to stabilize the economy through its conventional policy tool, as we discuss further in subsection III.B. ${ }^{51}$

\section{III.A. The DSGE Model}

We consider a version of the Federal Reserve Bank of New York's DSGE model, as described by Del Negro, Marc Giannoni, and Frank Shorfheide (2015). It builds on the work of Lawrence Christiano, Martin Eichenbaum, and Charles Evans (2005) and Frank Smets and Rafael Wouters (2007), expanded with various features, most notably financial frictions, along the lines of work by Bernanke, Mark Gertler, and Gilchrist

50. For instance, Justiniano, Primiceri, and Tambalotti (2013) find that there is almost no trade-off between nominal and real stabilization in an estimated model similar to the one used here, approximating the divine coincidence that holds exactly in much simpler environments.

51. This finding is common to studies based on a variety of empirical DSGE models, which tend to deliver a fairly consistent view of the business cycle fluctuations in $r_{t}^{*}$, as shown, for instance, in Yellen's (2015) figure 1. 
(1999) and Christiano, Roberto Motto, and Massimo Rostagno (2014). At the core of the model is a frictionless neoclassical structure in which monetary policy has no real effects. This neoclassical core is augmented by frictions, such as the stickiness of nominal prices and wages; by various real frictions, such as the adjustment costs of capital; and by financial frictions that interfere with the flow of funds from savers to borrowers. In addition, the model includes several structural shocks that are the ultimate causes of economic fluctuations, such as shocks to productivity, the marginal efficiency of investment (Greenwood, Hercowitz, and Krusell 1997; Justiniano, Primiceri, and Tambalotti 2010), price and wage markup shocks, and shocks to liquidity and safety premiums. We also allow for anticipated policy shocks, as described by Stefan Laséen and Lars Svensson (2011), to account for the ZLB on nominal interest rates and forward guidance. The equilibrium conditions are approximated around the nonstochastic steady state, and we express all variables in log deviations from that steady state. More details on the model are in the online appendix. Here, we focus the discussion on the parts of the model most closely related to the natural rate of interest and its drivers.

We include two types of wedges between the Treasury rate and the rate at which corporations finance their investments. ${ }^{52}$ The first wedge arises from financial frictions à la Bernanke, Gertler, and Gilchrist (1999), which we model building on the work of Christiano, Motto, and Rostagno (2003, 2014), and Ferre De Graeve (2008). In a nutshell, banks collect deposits from households and lend to entrepreneurs, who use these funds along with their own wealth to acquire physical capital. Entrepreneurs are subject to idiosyncratic disturbances that affect their ability to manage capital. Their revenues may thus turn out to be too low to pay back the loans received by the banks, which protect themselves against this risk by pooling all loans and charging a spread over the deposit rate. The second wedge, which we take as exogenous, captures the convenience yield—the fact that investors prefer to hold Treasuries over alternative assets: ${ }^{53}$

$$
E_{t}\left[\tilde{R}_{t+1}^{k}-R_{t}\right]=c y_{t}+\zeta_{s p, b}\left(q_{t}^{k}+\bar{k}_{t}-n_{t}\right)+\tilde{\sigma}_{\omega, t},
$$

52. Wu and Zhang (2016) also model the spread between corporate and government bonds in a New Keynesian model.

53. We model the convenience yield as a simple transaction cost or subsidy, following Smets and Wouters (2007). These transaction frictions can also be recast as a linear utility benefit from holding Treasuries, as done by Anzoategui and others (2017). In a similar vein, Fisher (2015) includes Treasury bonds in households' utility, as do Krishnamurthy and Vissing-Jorgensen (2012). 
where $E_{t}\left[\tilde{R}_{t+1}^{k}\right]$ is the entrepreneurs' expected return on capital, $R_{t}$ is the 3 -month Treasury bill rate, and $c y_{t}$ is the wedge arising from the convenience yield. The term $q_{t}^{k}+\bar{k}_{t}-n_{t}$ is entrepreneurs' leverage, namely, the value of capital $q_{t}^{k}+\bar{k}_{t}$ relative to net worth $n_{t}$, while $\tilde{\sigma}_{\omega, t}$ represents Christiano, Motto, and Rostagno's (2014) “risk shocks," mean-preserving changes in the cross-sectional dispersion of entrepreneurial ability.

Unlike the models of Pablo Kurlat (2013), Saki Bigio (2015), or Del Negro and others (2017), we assume that the convenience yield is exogenous. Although it is a theoretical limitation of our approach, this assumption is partly justified by the fact that our goal is mostly empirical. We want to use the DSGE model as a tool to map the effects of changes in $c y_{t}$ on the macroeconomy, and on $r_{t}^{*}$ in particular. An important implication of the exogeneity of the convenience yield is that its fluctuations affect the real return on Treasuries in the counterfactual economy without nominal rigidities, but they have no effects on allocations. As a result, monetary policy could completely isolate the model economy from shocks to $c y_{t}$ by adjusting the policy rate appropriately. This is an extreme conclusion, although Del Negro and others (2017) do find that monetary policy can indeed undo most of the effects of changes in the convenience yield in a model where the latter is endogenous.

As in the VAR, we further decompose $c y_{t}$ into a liquidity $\left(c y_{t}^{l}\right)$ and a safety $\left(c y_{t}^{s}\right)$ component, which we identify through the same spreads used in subsection II.B: the spreads between Aaa or Baa corporate bonds and 20-year Treasuries. We assume that the former mainly reflects liquidity:

$$
\text { Aaa-Treasury spread }=c y_{*}^{l}+E_{t}\left[\frac{1}{80} \sum_{j=0}^{79} c y_{t+j}^{l}\right]+e_{t}^{A a a},
$$

while the latter reflects both safety and liquidity, as well as the actual probability of default:

$$
\text { Baa-Treasury spread }=c y_{*}^{l}+c y_{*}^{s}+S P_{*}+E_{t}\left[\frac{1}{80} \sum_{j=0}^{79} \tilde{R}_{t+j+1}^{k}-R_{t+j}\right]+e_{t}^{B a a},
$$

where the terms $E_{t}\left[\tilde{R}_{t+j+1}^{k}-R_{t+j}\right]$ include all the components in equation 23.

The summations in these equations highlight that spreads are measured between long-term yields. Therefore, they capture expectations of future convenience yields, and of other sources of financial wedges, over the entire maturity of the bonds. When estimating the model, we set the 
steady-state premiums for liquidity and safety, $c y_{*}^{l}$ and $c y_{*}^{s}$, to the values found by Krishnamurthy and Vissing-Jorgensen (2012), 46 and 27 basis points, respectively; $e_{t}^{A a a}$ and $e_{t}^{B a a}$ capture measurement error or other possible discrepancies between the data and the corresponding model-implied concepts. ${ }^{54}$

Finally, in parallel with subsection II.B, we model both the liquidity and the safety components of the convenience yield as the sums of two processes: a highly persistent $A R(1)$ process, and a transitory process. We fix the autocorrelation of the persistent components at 0.99 , with the same tight prior on the standard deviation of the innovations as was used in their VAR counterpart. These persistent components capture secular movements in safety and liquidity similar to those described by the unit-root processes in the VAR, while the transitory components capture shocks such as those that hit the economy during the financial crisis. ${ }^{55}$ We also allow for very persistent shocks to the growth rate of total factor productivity (TFP), also with an autocorrelation fixed at 0.99 , along with the stationary shocks to its level featured by Smets and Wouters (2007). These persistent shocks are meant to capture secular changes in the growth rate of TFP, such as those described by John Fernald and others (2017)..$^{56}$

We conclude the model's description by returning to the Euler equation mentioned in the introduction. In the DSGE model, this equation takes the log-linearized form

$$
\begin{aligned}
c_{t}= & -\frac{1-\bar{h}}{\sigma_{c}(1+h)}\left(R_{t}-E_{t}\left[\pi_{t+1}\right]+c y_{t}\right)+\frac{\bar{h}}{1+\bar{h}}\left(c_{t-1}-z_{t}\right) \\
& +\frac{1}{1+\bar{h}} E_{t}\left[c_{t+1}+z_{t+1}\right]+\frac{\left(\sigma_{c}-1\right)}{\sigma_{c}(1+\bar{h})} \frac{w_{*} L_{*}}{c_{*}}\left(L_{t}-E_{t}\left[L_{t+1}\right]\right),
\end{aligned}
$$

54. We fix $c y_{*}^{l}$ and $c y_{*}^{s}$ because they are hard to identify from the initial conditions on the exogenous processes. We also considered versions of the model where the coefficients $c y_{*}^{l}$ and $c y_{*}^{s}$ are estimated, and with no measurement error in the spreads, with very similar results to those shown below.

55. The transitory shocks to the safety factor might capture some of the changes in credit market sentiment emphasized by López-Salido, Stein, and Zakrajšek (2016).

56. The prior on the standard deviation of the persistent TFP shocks is the same as for all the other shocks in the DSGE model. We do not opt for the tight prior used for the trends in the VAR, and for the persistent convenience yield shocks in the VAR, because this choice drastically reduces the impact of TFP shocks on the $r_{t}^{*}$ trend. Therefore, the results shown below should be interpreted as reflecting an upper bound on the contribution of TFP to movements in the natural rate. 
where $c_{t}$ is consumption; $L_{t}$ denotes hours worked, which enter here because utility is nonseparable in consumption and leisure; $\pi_{t}$ is inflation; and $z_{t}$ is productivity growth. ${ }^{57}$ As in equation 1 , this equation contains the convenience yield: As $c y_{t}$ rises (representing, for instance, households' increased desire to hold Treasuries), the real rate drops, holding everything else constant.

The model is estimated with Bayesian methods using several time series over the period 1960:Q1-2016:Q3. In addition to Baa and Aaa spreads, these time series are real output growth (including measures of both gross domestic product and gross domestic income), consumption growth, investment growth, real wage growth, hours worked, inflation (measured by both the core PCE and GDP deflators), the federal funds rate, the 10-year Treasury yield, and Susanto Basu, Fernald, and Miles Kimball's (2006) measure of TFP. ${ }^{58}$ Finally, we also use survey-based, long-run inflation expectations and data on market expectations of the federal funds rates up to six quarters in the future to capture the effects of forward guidance on the policy rate. The online appendix provides more details on data construction and on the prior and posterior distributions for all parameters.

\section{III.B. DSGE Estimates of $r_{t}^{*}$}

This subsection presents the estimates of the natural rate of interest obtained from the DSGE model that we have just described. First, we focus on the low-frequency movements in $r_{t}^{*}$ identified by the DSGE, which we can compare directly with those in the VAR. We then move on to consider the entire time path of the natural rate of interest, including all frequencies.

LONG-RUN $r_{t}^{*}$ We begin our discussion of the DSGE estimates of the natural rate of interest by focusing on its persistent component, because this is the dimension in which the VAR and DSGE approaches are most directly comparable. Remarkably, the two models provide a very similar characterization of this component of interest rates, in terms of both its time series

57. The parameter $\sigma_{c}$ captures the degree of relative risk aversion, while $\bar{h} \equiv h e^{-\gamma}$ depends on the degree of habit persistence in consumption, $h$, and steady-state growth, $\gamma$.

58. We assume that some of the observables equal the model's implied value, plus an $A R(1)$ exogenous process that captures either measurement error or some other source of discrepancy between the model and the data, as in Boivin and Giannoni (2006). For instance, these processes capture discrepancies between the noisy measures of output (real gross domestic product and real gross domestic income) or inflation (based on the core PCE deflator and the GDP deflator) available in the data and the corresponding model concept. For the 10-year Treasury bond yield, instead, such a process represents fluctuations in bond yields that are not captured by changes in the expectations of future short-term rates, such as movements in the term premium. 
Figure 10. The Forward Natural Real Interest Rate $E_{t}\left[r_{t+h}^{*}\right]$ and $\bar{r}_{t}, 1960-2016$

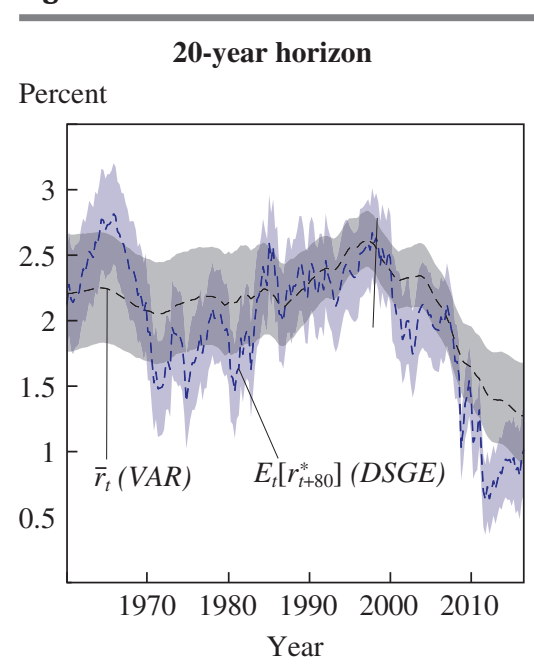

30-year horizon

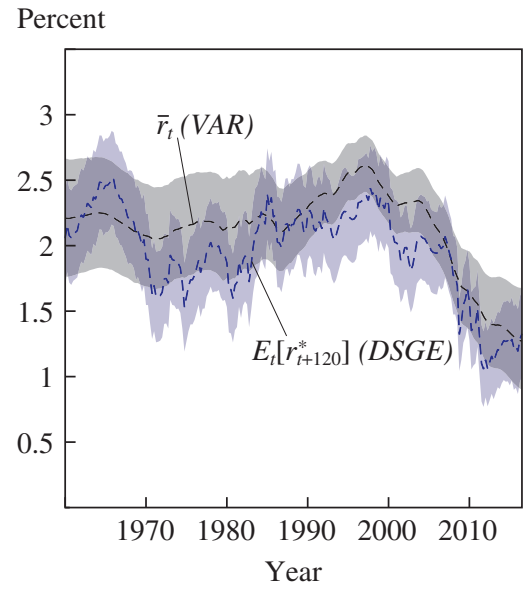

Source: Authors' calculations.

a. For each trend, the dashed line is the posterior median and the shaded area shows the 68 percent posterior coverage interval.

behavior and its fundamental drivers. This consistency between the two models is especially notable, given the significant differences in their specification and in the data used to estimate them.

As a way of isolating persistent movements in real interest rates, figure 10 compares forecasts of the short-term natural rate of interest at the 20- and 30-year horizons for the DSGE model to the VAR estimates of $\bar{r}_{t}$. We refer to these forecasts as (implied) forward rates. The key result highlighted by figure 10 is that these long-horizon forward rates are very similar in the two models. ${ }^{59}$

This result holds whether we use forecasts of either natural or actual interest rates in the DSGE, because the two are almost identical starting at horizons of about 10 years. This similarity is illustrated in figure 11, which compares 5- and 10-year forecasts of the natural and actual real rate of interest implied by the DSGE model. The two rates are close at the shorter horizon, although they can diverge at times by as much as 50 basis points. However, this distance shrinks to just a few basis points at the 10-year horizon. This evidence corroborates the key assumption needed for the VAR to be informative on the persistent component of the natural rate of interest,

59. Comin and Gertler (2006) refer to fluctuations over these horizons as medium-term cycles, in contrast to business cycles that take place at frequencies of two to eight years. 
Figure 11. The Forward Natural Real Interest Rate $E_{t}\left[r_{t+h}^{*}\right]$ and Forward Actual Real Interest Rate $E_{t}\left[r_{t+h}\right], 1960-2016$

5-year horizon

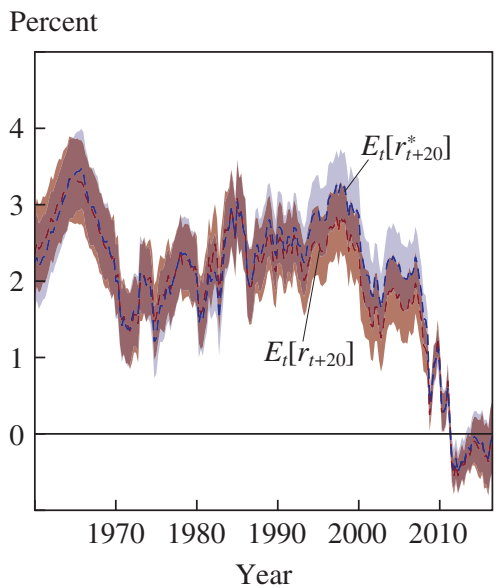

10-year horizon

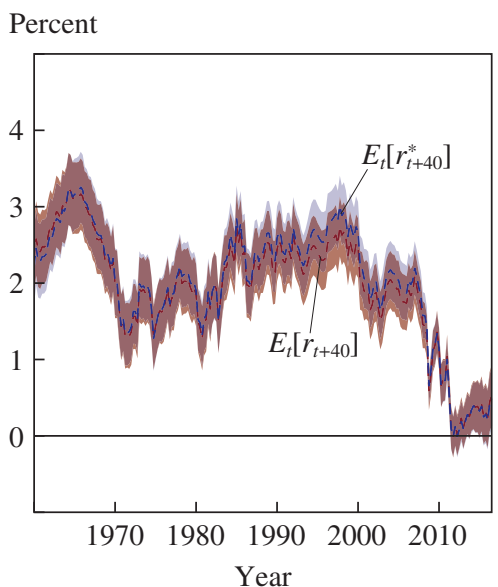

Source: Authors' calculations.

a. For each trend, the dashed line is the posterior median and the shaded area shows the 68 percent posterior coverage interval. Both series were computed using the DSGE model.

namely, that the gap between the actual and the natural economies is less persistent than the natural variables themselves.

The finding that the DSGE model projects sizable fluctuations in the interest rate at very long horizons, and even more that these fluctuations resemble those identified by the VAR, is surprising. The (transformed) DSGE model is stationary around its steady state. Therefore, its infinite horizon forecasts of the interest rate are constant, unlike those of the VAR, which are affected by its permanent shocks ${ }^{60}$ However, we find that the estimated model describes the trend in the real interest rate as well as the VAR, even though it has no power at exactly zero frequency. ${ }^{61}$

Thanks to the flexibility of the estimated DSGE model as a tool to characterize the persistent component of real interest rates, we can

60. Along the model's balanced growth path, the log levels of output, consumption, and investment share a unit root that they inherit from productivity. As a result, their (log) ratios are stationary, and so are all the other variables, including interest rates.

61. The ability of a stationary DSGE model to approximate the low-frequency behavior implied by the VAR is related to the approach of Stock and Watson $(1998,2007)$. They characterize the persistent component of what look like stationary variables, such as GDP growth and inflation, through unit-root processes with a "small" variance. Our results suggest a similarly blurred line between the stationary characterization versus the unit-root characterization of interest rates provided by the DSGE and the VAR. 
Figure 12. The 5-Year Forward Natural Real Interest Rate $E_{t}\left[r_{t+20}^{*}\right]$ and Laubach and Williams's (2016) Estimate of $r_{t}^{*}, 1960-2016$

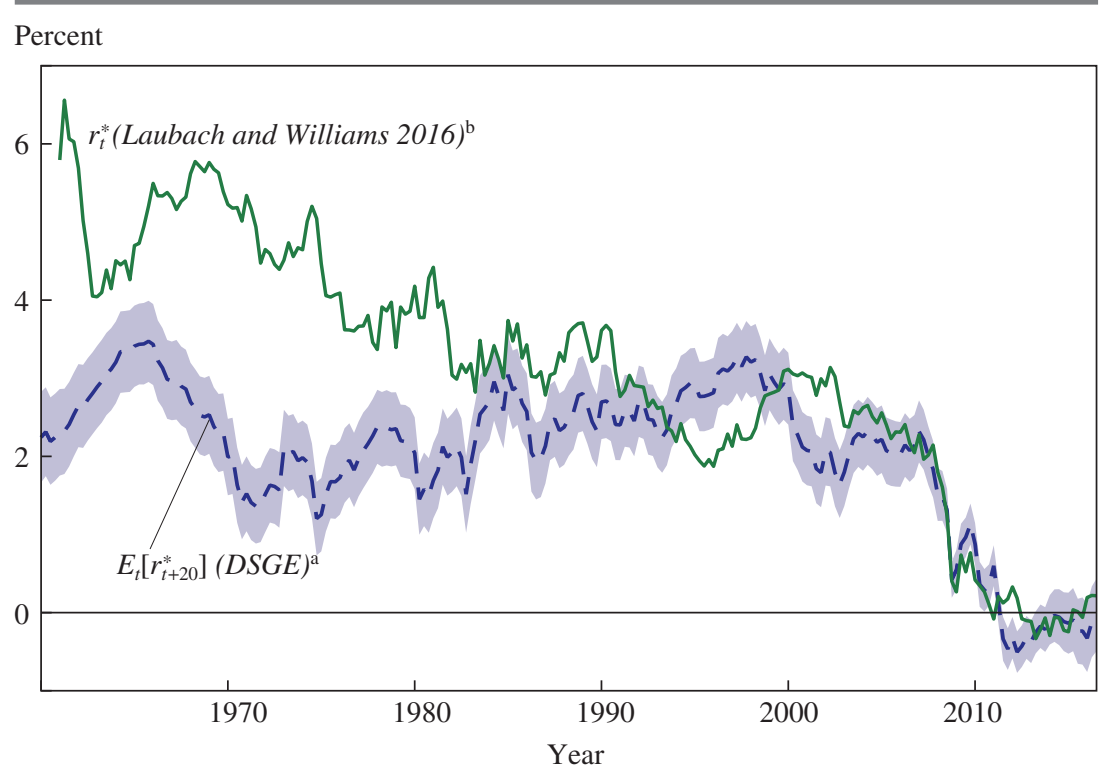

Sources: Laubach and Williams (2016); authors' calculations.

a. The dashed line is the posterior median of the 5-year forward natural real rate computed using the DSGE model. The shaded area shows the 68 percent posterior coverage interval for the estimate of the low-frequency component.

b. This line shows the one-sided estimate of $r_{t}^{*}$ from Laubach and Williams's (2016) figure 5.

address an open question in the literature: How can one integrate socalled longer-run estimates of $r_{t}^{*}$, such as those provided by Laubach and Williams (2016) and by our VAR, with shorter-run estimates derived from DSGE models? The presumption so far has been that the two types of estimates are mostly complementary, because longer-run approaches focus exclusively on permanent movements in $r_{t}^{*}$, while shorter-run approaches assume that $r_{t}^{*}$ is stationary. ${ }^{62}$ In contrast, our results suggest that DSGE models can provide a more comprehensive view of the fluctuations in $r_{t}^{*}$ across frequencies than has generally been assumed until now, therefore encompassing both longer-run and shorter-run measures of $r_{t}^{*}$.

As a further illustration of this point, figure 12 shows that Laubach and Williams's (2016) estimates of the natural rate comove quite closely with the 5-year forward natural rate of interest derived from our DSGE model,

62. Laubach and Williams (2016, section 6) discuss this point at length. 
at least since the early 1980s. This similarity with a relatively short-horizon forward rate suggests that Laubach and Williams's model includes a fair amount of transitory variation in its estimates of $r_{t}^{*}$, even if the latter is assumed to follow an $I(1)$ process. Before the early 1980s, the two estimates are far from each other. Laubach and Williams's measure is as high as 6 percent in the early 1960s, while the DSGE's measure fluctuates around levels similar to those that prevail in subsequent decades. The source of this discrepancy early in the sample is difficult to pin down exactly. Our best guess is that it might be related to how the trends in inflation and economic growth present in the data interact through the Phillips curve that Laubach and Williams use to translate observations on inflation into information on the output gap, and hence on the growth rate of potential output and on $r_{t}^{*}$. This interaction is part of the reason why we allow for a flexible inflation trend in both the VAR and DSGE models.

The consistency of the long-horizon forecasts of the real interest rate between the VAR and DSGE models strengthens our substantive conclusions, especially given the significant differences between the two empirical approaches. Next, we show that the two models also agree on the main sources of persistent fluctuations in the natural rate of interest. This result is illustrated in figure 13, which highlights the contributions of convenience yield and TFP shocks to the estimated movements in the 30-year forward natural real interest rate.$^{63}$ For ease of comparison, figure 14 presents the results of the decomposition of $\bar{r}_{t}$ for the VAR model with consumption from subsection II.C. Specifically, figure 14 shows movements in the posterior median of $\bar{r}_{t}$ (the heavy line) and its components-the convenience yield $\overline{c y}_{t}$, growth $\bar{g}_{t}$, and the residual factor $\bar{\beta}_{t}$, all normalized so that they coincide with $\bar{r}_{t}$ in 1998:Q1, as in figure 4 . As in the VAR, shocks to safety and liquidity in the DSGE account for a large fraction of the low-frequency movements in the natural rate of interest, with TFP shocks also playing a significant role.

We conclude from this analysis that the view of persistent fluctuations in the natural rate of interest provided by the VAR and DSGE models is surprisingly consistent. With this reassuring consistency in hand, we proceed to derive the entire time path of the natural rate of interest, exploiting the full structure of the DSGE framework.

63. The impact of risk shocks $\tilde{\sigma}_{\omega, t}$ is barely noticeable at this horizon, but it is more pronounced in the short-run estimates shown below. The impact of all other shocks is also quite small. 
Figure 13. The 30 -Year Forward Natural Real Interest Rate $E_{t}\left[r_{t+120}^{*}\right]$ and Its Drivers, 1960-2016

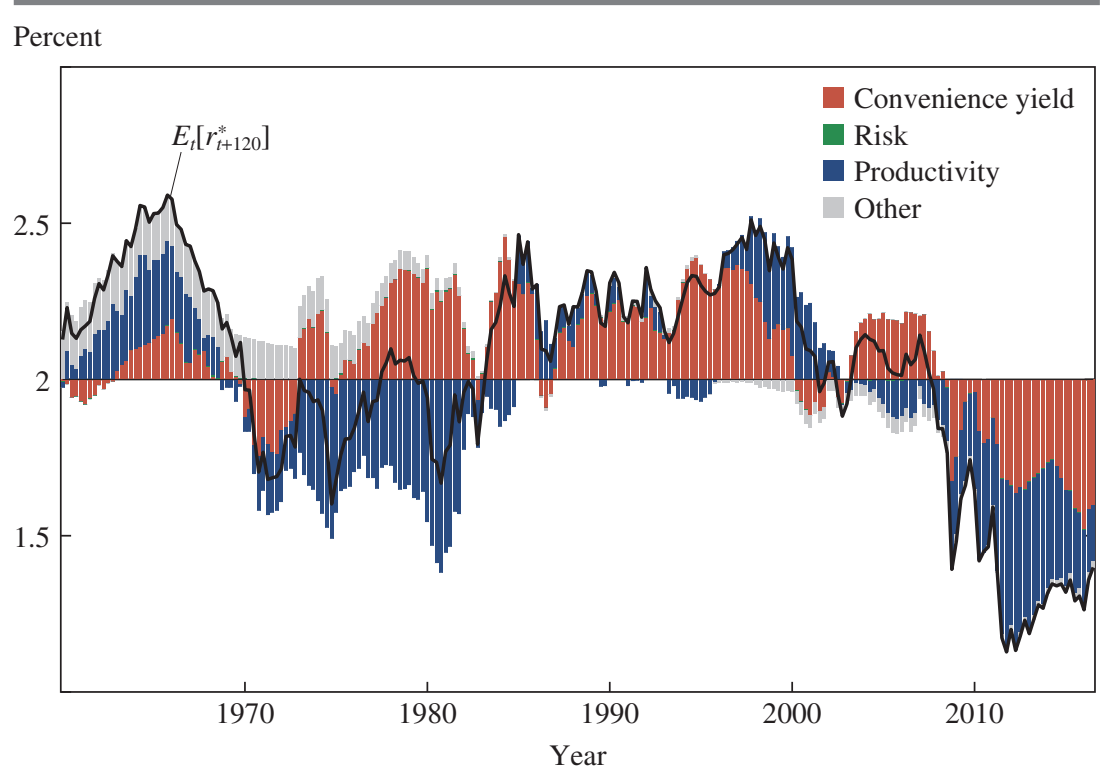

Source: Authors' calculations.

a. The solid line is the posterior median of the 30-year forward natural real rate computed using the DSGE model. The shaded areas are the contributions of the various shocks.

SHORT-RUN $r_{t}^{*}$ Figure 15 shows the estimate of $r_{t}^{*}$ implied by the DSGE model, along with the real federal funds rate, measured as the nominal federal funds rate minus the model-based expected inflation. The first notable feature of the $r_{t}^{*}$ estimate is that it moves considerably over time. This is at odds with the common presumption that $r_{t}^{*}$ should be constant or slow-moving, but it is characteristic of estimates based on DSGE models (Justiniano and Primiceri 2010; Barsky, Justiniano, and Melosi 2014; Cúrdia and others 2015). Second, part of these movements happen at high frequency. These quarter-to-quarter gyrations reflect the short-run nature of the natural rate of interest, which moves in reaction to all the real shocks buffeting the economy. Finally, $r_{t}^{*}$ displays a clear cyclical pattern; it tends to be high and rising during booms, while it declines quite abruptly in recessions. This cyclical decline in $r_{t}^{*}$ is especially pronounced during the Great Recession, when it falls deep into negative territory. ${ }^{64}$ It then remains

64. Although the DSGE model explicitly imposes the ZLB on nominal interest rates, as in Laséen and Svensson (2011), it does not impose such a constraint on $r_{t}^{*}$. 
Figure 14. $\bar{r}_{t}$ in the VAR Model with Consumption and Its Drivers, 1960-2016

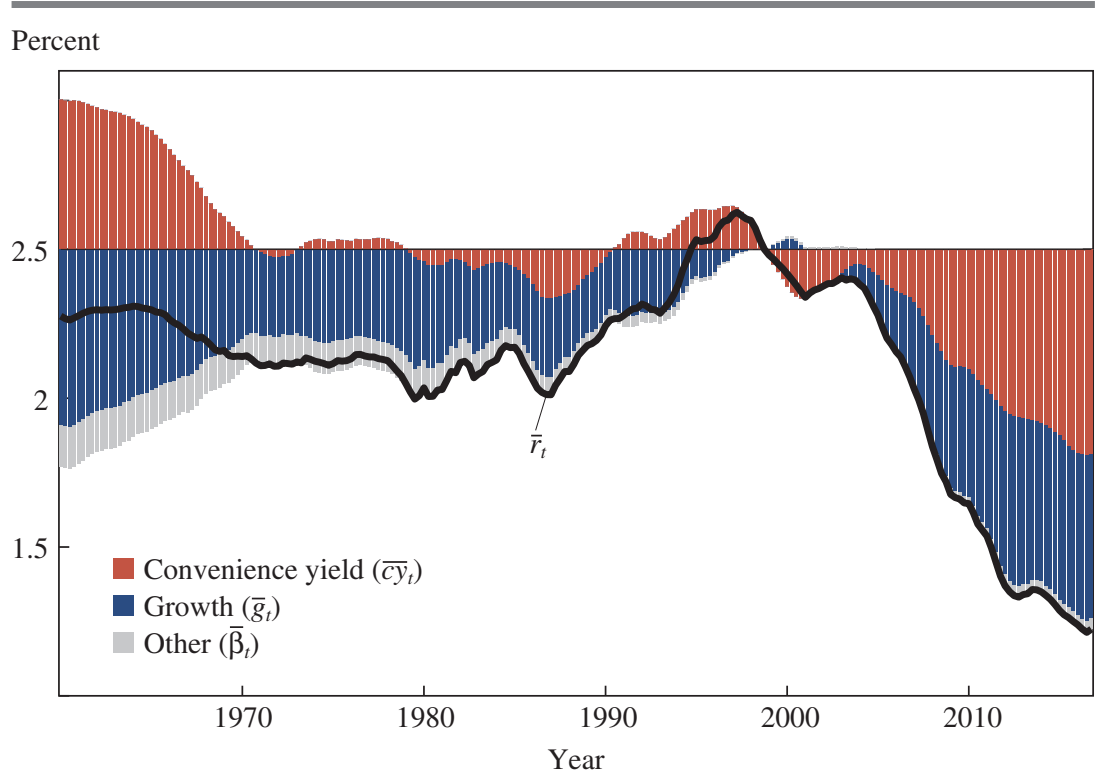

Source: Authors' calculations.

a. The solid line is the posterior median of $\bar{r}_{t}$ computed using the VAR model with consumption. The shaded areas are the posterior median estimates of the contributions of the various trends, normalized to 0 in 1998:Q1.

persistently low through the first phase of the recovery, with some timid increase toward the end of the sample. As a result, the model sees monetary policy as having been constrained by the ZLB over much of this period, providing a rationale for the resort to unconventional monetary policy through large-scale asset purchases and forward guidance.

Fluctuations in $r_{t}^{*}$ are driven by real and financial factors, but not by monetary factors, because in the model monetary policy has no effect in the absence of price and wage rigidities. To understand some of the drivers of the natural rate of interest, consider the consumption Euler equation 24. The same equation holds also in the counterfactual economy, in which prices and wages are fully flexible. Solving this equation for $r_{t}^{*}$, we obtain

$$
\begin{aligned}
r_{t}^{*}= & -c y_{t}+\frac{\sigma_{c}}{1-\bar{h}}\left(E_{t}\left[c_{t+1}^{*}-c_{t}^{*}+z_{t+1}\right]-\bar{h}\left(c_{t}^{*}-c_{t-1}^{*}+z_{t}\right)\right) \\
& -\frac{\left(\sigma_{c}-1\right)}{(1-\bar{h})} \frac{w_{*} L_{*}}{c_{*}} E_{t}\left[L_{t+1}^{*}-L_{t}^{*}\right],
\end{aligned}
$$


Figure 15. The Short-Term Natural Real Interest Rate $r_{t}^{*}$ and Actual Real Interest Rate $r_{t}, 1960-2016^{\mathrm{a}}$

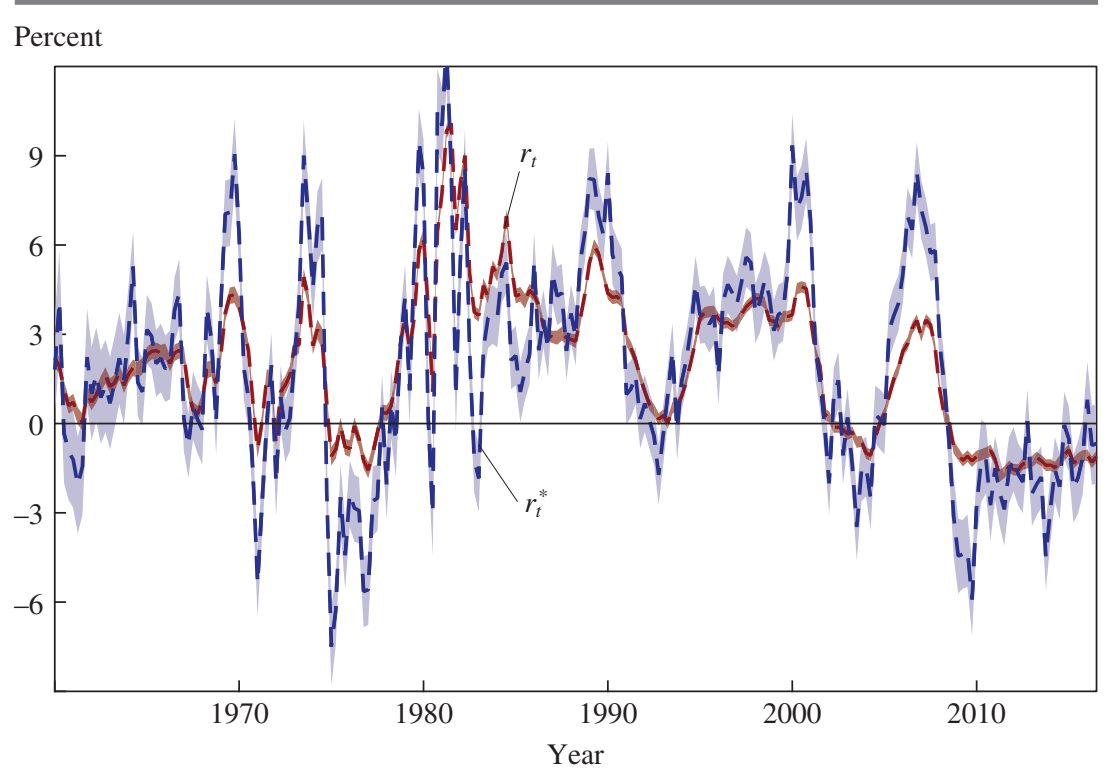

Sources: FRED; authors' calculations.

a. For each trend, the dashed line is the posterior median and the shaded area shows the 68 percent posterior coverage interval. $r_{t}^{*}$ was computed using the DSGE model.

where $c_{t}^{*}$ and $L_{t}^{*}$ denote the level of consumption and hours worked in the flexible-price economy. This equation reveals that $r_{t}^{*}$ falls one-for-one with any increase in the convenience yield $c y_{t}$. The natural rate of interest also depends on consumption growth, as in the VAR specification of subsection II.C, although here it is a combination of future expected and past consumption growth that matters, due to the presence of habits. In addition, the growth rate of hours worked matters as well, because utility is nonseparable between consumption and leisure.

Figure 16 decomposes the $r_{t}^{*}$ estimate shown in figure 15 in terms of the shocks that drive economic fluctuations in the model. As before, we include shocks to the convenience yield $c y_{t}$. Risk shocks $\tilde{\sigma}_{\omega, t}$ reflect the fact that an increase in risk raises the cost of external financing for firms, reducing the demand for investment. TFP shocks also play an important role, as lower expected TFP growth depresses desired consumption and investment, lowering the natural rate of interest. Remaining shocks do not play a significant role. We draw two main lessons from figure 16. First, 
Figure 16. The Short-Term Natural Real Interest Rate $r_{t}^{*}$ and Its Drivers, 1960-2016a

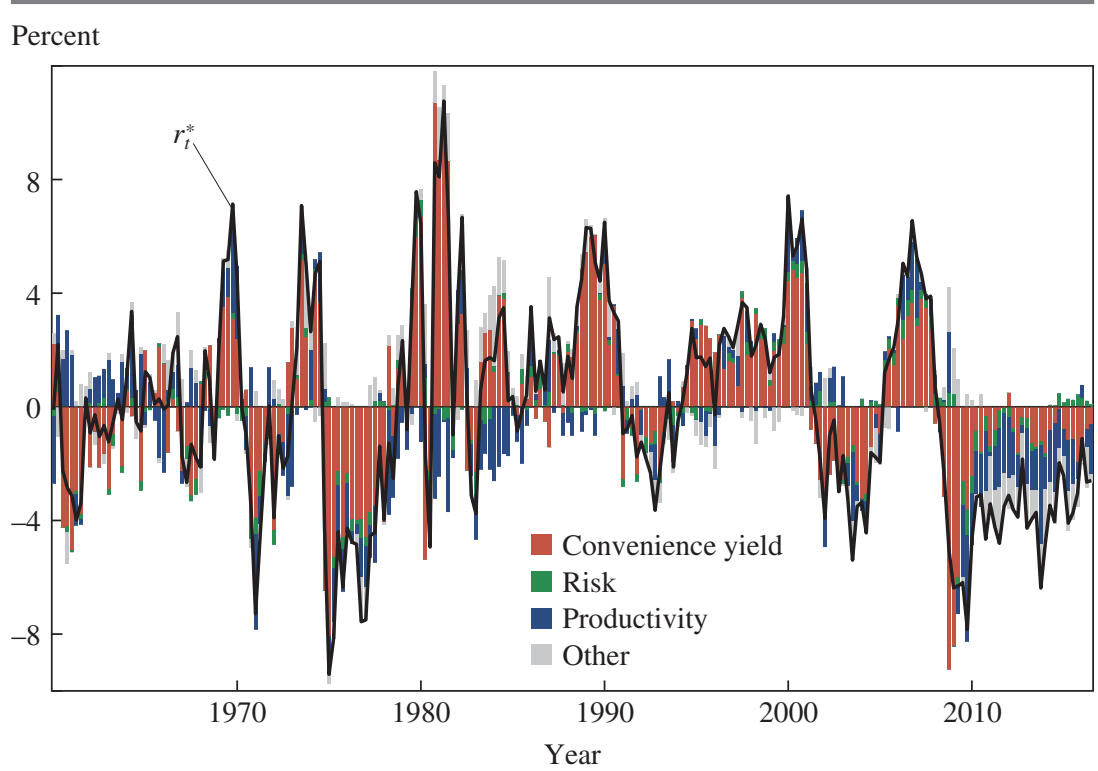

Source: Authors' calculations.

a. The solid line is the posterior median of the natural real rate $r_{t}^{*}$ computed using the DSGE model in deviations from the steady state. The shaded areas are the contributions of the various shocks.

the fall in $r_{t}^{*}$ during the recent financial crisis and the recession that followed was due to an unusual combination of severe financial, risk, and productivity shocks. Second, among these negative contributions, shocks to the convenience yield and negative productivity shocks had particularly pronounced effects.

\section{Conclusion}

We have estimated the natural rate of interest and its fundamental drivers using two very different methodologies. The first one is a flexible, multivariate, unobserved-component model estimated using data on Treasury and corporate bond yields of various maturities, inflation, and survey expectations, which we used to make inference on slow-moving trends in the natural rate of interest. The second is a medium-scale DSGE model with nominal and financial frictions, estimated using the same data on yields, along with a large set of other macroeconomic variables, whose tighter structure allows us to recover the entire time path of the natural rate of interest. 
The two approaches yield remarkably consistent results. First, they both isolate a slow-moving trend in the real interest rate that is fairly flat between 2 and 2.5 percent until the late 1990s, when it starts declining toward a recent trough at about 1 percent. Second, they both attribute most of this decline to an increase in the convenience yield on Treasuries, which they identify as a low-frequency component in the spreads between corporate and Treasury bonds with the same maturity, but different safety and liquidity characteristics. In addition, the DSGE model sees these factors as also playing an important role in the movements of the natural rate of interest at business cycle frequencies. Finally, the DSGE model suggests that the short-term interest rate was severely constrained by the effective lower bound on nominal interest rates starting in late 2008, when the natural rate of interest plunged well into negative territory.

Both our models suggest that the natural rate of interest will likely remain low due to its depressed secular component. But this conclusion is subject to significant uncertainty, because sudden changes in expectations, regulation, market structure, investors' degree of risk aversion, or investors' perceptions of the safety and liquidity attributes of U.S. Treasuries could all be sources of shocks to this trend. Although we have identified a rise in the measured convenience yield as a key driver of the secular decline in the natural rate of interest, we have not investigated the underlying sources of these changes in the premiums commanded by safe and liquid assets. This is something we leave for future research.

ACKNOWLED G M ENTS We are grateful to James Stock, for his guidance as our editor; to Fernando Duarte, Michael Fleming, Refet Gürkaynak, David Lucca, Oreste Tristani, Kenneth West, Jonathan Wright, and especially our discussants, John Williams and Cynthia Wu, for terrific comments; and to Todd Clark and Egon Zakrajšek, for sharing their data. We also thank Brandyn Bok, Daniele Caratelli, Abhi Gupta, Pearl Li, and Erica Moszkowski for excellent research assistance. 


\section{References}

Acharya, Viral V., and Lasse Heje Pedersen. 2005. "Asset Pricing with Liquidity Risk." Journal of Financial Economics 77, no. 2: 375-410.

Adrian, Tobias, Nina Boyarchenko, and Or Shachar. 2017. "Dealer Balance Sheets and Bond Liquidity Provision." Journal of Monetary Economics, forthcoming.

Adrian, Tobias, Michael Fleming, Or Shachar, and Erik Vogt. 2016. "Market Liquidity after the Financial Crisis." Staff Report no. 796. Federal Reserve Bank of New York.

Adrian, Tobias, and Hyun Song Shin. 2009. "Money, Liquidity, and Monetary Policy." American Economic Review 99, no. 2: 600-05.

- 2010. "Financial Intermediaries and Monetary Economics." In Handbook of Monetary Economics, Volume 3A, edited by Benjamin M. Friedman and Michael Woodford. Amsterdam: North-Holland.

Ajello, Andrea. 2016. "Financial Intermediation, Investment Dynamics, and Business Cycle Fluctuations." American Economic Review 106, no. 8: 2256-303.

Amihud, Yakov, Haim Mendelson, and Lasse Heje Pedersen. 2006. "Liquidity and Asset Prices." Foundations and Trends in Finance 1, no. 4: 269-364.

2012. Market Liquidity: Asset Pricing, Risk, and Crises. Cambridge University Press.

Anderson, Mike, and René M. Stulz. 2017. "Is Post-Crisis Bond Liquidity Lower?" Working Paper no. 2017-03-009. Columbus: Ohio State University, Fisher College of Business, Charles A. Dice Center for Research in Financial Economics.

Anzoategui, Diego, Diego Comin, Mark Gertler, and Joseba Martinez. 2017. "Endogenous Technology Adoption and R\&D as Sources of Business Cycle Persistence." Working Paper no. 22005. Cambridge, Mass.: National Bureau of Economic Research.

Auclert, Adrien, and Matthew Rognlie. 2016. "Inequality and Aggregate Demand." Working paper. http://mattrognlie.com/inequad.pdf

Bao, Jack, Jun Pan, and Jiang Wang. 2011. "The Illiquidity of Corporate Bonds." Journal of Finance 66, no. 3: 911-46.

Barsky, Robert, Alejandro Justiniano, and Leonardo Melosi. 2014. "The Natural Rate of Interest and Its Usefulness for Monetary Policy." American Economic Review 104, no. 5: 37-43.

Basel Committee on Banking Supervision. 2013. Basel III: The Liquidity Coverage Ratio and Liquidity Risk Monitoring Tools. Basel: Bank for International Settlements. http://www.bis.org/publ/bcbs238.pdf

Basu, Susanto, John G. Fernald, and Miles S. Kimball. 2006. "Are Technology Improvements Contractionary?” American Economic Review 96, no. 5: 1418-48.

Bauer, Michael D., Glenn D. Rudebusch, and Jing Cynthia Wu. 2012. "Correcting Estimation Bias in Dynamic Term Structure Models." Journal of Business \& Economic Statistics 30, no. 3: 454-67.

2014. "Term Premia and Inflation Uncertainty: Empirical Evidence from an International Panel Dataset: Comment." American Economic Review 104, no. 1: 323-37. 
Benigno, Gianluca, and Luca Fornaro. 2017. "Stagnation Traps." Working Paper no. 2038. European Central Bank.

Bernanke, Ben S. 2005. "The Global Saving Glut and the U.S. Current Account Deficit." Remarks given at the Sandridge Lecture, Virginia Association of Economists, Richmond, March 10.

Bernanke, Ben S., Carol Bertaut, Laurie Pounder DeMarco, and Steven Kamin. 2011. "International Capital Flows and the Return to Safe Assets in the United States, 2003-2007.” International Finance Discussion Paper no. 1014. Washington: Board of Governors of the Federal Reserve System.

Bernanke, Ben S., Mark Gertler, and Simon Gilchrist. 1999. "The Financial Accelerator in a Quantitative Business Cycle Framework." In Handbook of Macroeconomics, Volume 1C, edited by John B. Taylor and Michael Woodford. Amsterdam: North-Holland.

Bigio, Saki. 2015. "Endogenous Liquidity and the Business Cycle." American Economic Review 105, no. 6: 1883-927.

Blanchard, Olivier, and Jordi Galí. 2007. "Real Wage Rigidities and the New Keynesian Model." Journal of Money, Credit and Banking 39, suppl. 1: 35-65.

Bloom, Nicholas. 2009. "The Impact of Uncertainty Shocks." Econometrica 77, no. 3: 623-85.

Boivin, Jean, and Marc Giannoni. 2006. "DSGE Models in a Data-Rich Environment.” Working Paper no. 12772. Cambridge, Mass.: National Bureau of Economic Research.

Caballero, Ricardo J. 2010. "The 'Other' Imbalance and the Financial Crisis.” Working paper no. 15636. Cambridge, Mass.: National Bureau of Economic Research.

Caballero, Ricardo J., and Emmanuel Farhi. 2017. "The Safety Trap." Review of Economic Studies, forthcoming.

Caballero, Ricardo J., Emmanuel Farhi, and Pierre-Olivier Gourinchas. 2016. "Global Imbalances and Currency Wars at the ZLB." Working Paper no. 21670. Cambridge, Mass.: National Bureau of Economic Research.

Caballero, Ricardo J., and Arvind Krishnamurthy. 2009. "Global Imbalances and Financial Fragility." American Economic Review 99, no. 2: 584-88.

Carter, Christopher K., and Robert Kohn. 1994. "On Gibbs Sampling for State Space Models." Biometrika 81, no. 3: 541-53.

Carvalho, Carlos, Andrea Ferrero, and Fernanda Nechio. 2016. "Demographics and Real Interest Rates: Inspecting the Mechanism." European Economic Review 88: 208-26.

Christensen, Jens H.E., and Glenn D. Rudebusch. 2017. "A New Normal for Interest Rates? Evidence from Inflation-Indexed Debt.” Working Paper no. 2017-07. Federal Reserve Bank of San Francisco.

Christiano, Lawrence J., Martin Eichenbaum, and Charles L. Evans. 2005. "Nominal Rigidities and the Dynamic Effects of a Shock to Monetary Policy." Journal of Political Economy 113, no. 1: 1-45.

Christiano, Lawrence J., Roberto Motto, and Massimo Rostagno. 2003. "The Great Depression and the Friedman-Schwartz Hypothesis." Journal of Money, Credit and Banking 35, no. 6, pt. 2: 1119-97. 
2014. "Risk Shocks." American Economic Review 104, no. 1: 27-65.

Cieslak, Anna, and Pavol Povala. 2015. "Expected Returns in Treasury Bonds." Review of Financial Studies 28, no. 10: 2859-901.

Clark, Todd E., and Taeyoung Doh. 2014. "Evaluating Alternative Models of Trend Inflation." International Journal of Forecasting 30, no. 3: 426-48.

Comin, Diego, and Mark Gertler. 2006. "Medium-Term Business Cycles." American Economic Review 96, no. 3: 523-51.

Crump, Richard K., Stefano Eusepi, and Emanuel Moench. 2017. "The Term Structure of Expectations and Bond Yields." Staff Report no. 775. Federal Reserve Bank of New York.

Cui, Wei, and Sören Radde. 2016. "Search-Based Endogenous Asset Liquidity and the Macroeconomy." Working Paper no. 1917. European Central Bank.

Cúrdia, Vasco, Andrea Ferrero, Ging Cee Ng, and Andrea Tambalotti. 2015. "Has U.S. Monetary Policy Tracked the Efficient Interest Rate?" Journal of Monetary Economics 70: 72-83.

De Fiore, Fiorella, and Oreste Tristani. 2011. "Credit and the Natural Rate of Interest.” Journal of Money, Credit and Banking 43, nos. 2-3: 407-40.

De Graeve, Ferre. 2008. "The External Finance Premium and the Macroeconomy: US Post-WWII Evidence." Journal of Economic Dynamics and Control 32, no. 11: 3415-40.

Del Negro, Marco, Gauti Eggertsson, Andrea Ferrero, and Nobuhiro Kiyotaki. 2017. "The Great Escape? A Quantitative Evaluation of the Fed's Liquidity Facilities." American Economic Review 107, no. 3: 824-57.

Del Negro, Marco, Marc P. Giannoni, and Frank Schorfheide. 2015. "Inflation in the Great Recession and New Keynesian Models." American Economic Journal: Macroeconomics 7, no. 1: 168-96.

Del Negro, Marco, and Giorgio E. Primiceri. 2015. “Time Varying Structural Vector Autoregressions and Monetary Policy: A Corrigendum." Review of Economic Studies 82, no. 4: 1342-45.

Du, Wenxin, Alexander Tepper, and Adrien Verdelhan. 2017. "Deviations from Covered Interest Rate Parity." Working Paper no. 23170. Cambridge, Mass.: National Bureau of Economic Research.

Durbin, James, and Siem Jan Koopman. 2002. "A Simple and Efficient Simulation Smoother for State Space Time Series Analysis." Biometrika 89, no. 3: 603-16.

Edge, Rochelle M., Michael T. Kiley, and Jean-Philippe Laforte. 2008. "Natural Rate Measures in an Estimated DSGE Model of the U.S. Economy." Journal of Economic Dynamics and Control 32, no. 8: 2512-35.

Eggertsson, Gauti B., Neil R. Mehrotra, and Jacob A. Robbins. 2017. "A Model of Secular Stagnation: Theory and Quantitative Evaluation.” Working Paper no. 23093. Cambridge, Mass.: National Bureau of Economic Research.

Eichengreen, Barry. 2015. "Secular Stagnation: The Long View." American Economic Review 105, no. 5: 66-70. 
Favero, Carlo A., Arie E. Gozluklu, and Haoxi Yang. 2016. "Demographics and the Behavior of Interest Rates." IMF Economic Review 64, no. 4: 732-76.

Fernald, John G., Robert E. Hall, James H. Stock, and Mark W. Watson. 2017. "The Disappointing Recovery of Output after 2009." In the present volume of Brookings Papers on Economic Activity.

Fisher, Jonas D. M. 2015. "On the Structural Interpretation of the Smets-Wouters 'Risk Premium' Shock." Journal of Money, Credit and Banking 47, nos. 2-3: 511-16.

Fleckenstein, Matthias, Francis A. Longstaff, and Hanno Lustig. 2014. "The TIPSTreasury Bond Puzzle." Journal of Finance 69, no. 5: 2151-97.

Gagnon, Etienne, Benjamin K. Johannsen, and David López-Salido. 2016. “Understanding the New Normal: The Role of Demographics." Finance and Economics Discussion Series no. 2016-080. Washington: Board of Governors of the Federal Reserve System.

Gârleanu, Nicolae, and Lasse Heje Pedersen. 2011. "Margin-Based Asset Pricing and Deviations from the Law of One Price." Review of Financial Studies 24, no. 6: 1980-2022.

Giannone, Domenico, Michele Lenza, and Giorgio E. Primiceri. 2015. "Prior Selection for Vector Autoregressions." Review of Economics and Statistics 97, no. 2: 436-51.

Gilchrist, Simon, and Egon Zakrajšek. 2012. "Credit Spreads and Business Cycle Fluctuations." American Economic Review 102, no. 4: 1692-720.

Gorton, Gary B. 2016. "The History and Economics of Safe Assets." Working Paper no. 22210. Cambridge, Mass.: National Bureau of Economic Research.

Gorton, Gary, and Andrew Metrick. 2012. "Securitized Banking and the Run on Repo.” Journal of Financial Economics 104, no. 3: 425-51.

Gourinchas, Pierre-Olivier, and Hélène Rey. 2016. "Real Interest Rates, Imbalances and the Curse of Regional Safe Asset Providers at the Zero Lower Bound." Working Paper no. 22618. Cambridge, Mass.: National Bureau of Economic Research.

Greenwood, Jeremy, Zvi Hercowitz, and Per Krusell. 1997. "Long-Run Implications of Investment-Specific Technological Change." American Economic Review 87, no. 3: 342-62.

Greenwood, Robin, Samuel G. Hanson, and Jeremy C. Stein. 2015. "A ComparativeAdvantage Approach to Government Debt Maturity." Journal of Finance 70, no. 4: $1683-722$.

. 2016. "The Federal Reserve's Balance Sheet as a Financial-Stability Tool." In Economic Policy Symposium Proceedings: Designing Resilient Monetary Policy Frameworks for the Future. Jackson Hole, Wyo.: Federal Reserve Bank of Kansas City.

Guerron-Quintana, Pablo A., and Ryo Jinnai. 2015. "Liquidity Shocks and Asset Prices." Technical Report no. HIAS-E-17. Tokyo: Hitotsubashi University, Hitotsubashi Institute for Advanced Study.

Gürkaynak, Refet S., and Jonathan H. Wright. 2012. "Macroeconomics and the Term Structure.” Journal of Economic Literature 50, no. 2: 331-67. 
Hall, Robert E. 2016. "Understanding the Decline in the Safe Real Interest Rate." Working Paper no. 22196. Cambridge, Mass.: National Bureau of Economic Research.

Hamilton, James D., Ethan S. Harris, Jan Hatzius, and Kenneth D. West. 2016. "The Equilibrium Real Funds Rate: Past, Present, and Future." IMF Economic Review 64, no. 4: 660-707.

Hansen, Alvin H. 1939. "Economic Progress and Declining Population Growth." American Economic Review 29, no. 1: 1-15.

Johannsen, Benjamin K., and Elmar Mertens. 2016. "A Time Series Model of Interest Rates with the Effective Lower Bound." Finance and Economics Discussion Series no. 2016-033. Washington: Board of Governors of the Federal Reserve System.

Justiniano, Alejandro, and Giorgio E. Primiceri. 2010. "Measuring the Equilibrium Real Interest Rate." Economic Perspectives 34, no. 1: 14-27.

Justiniano, Alejandro, Giorgio E. Primiceri, and Andrea Tambalotti. 2010. "Investment Shocks and Business Cycles.” Journal of Monetary Economics 57, no. 2: $132-45$.

_. 2013. "Is There a Trade-Off between Inflation and Output Stabilization?" American Economic Journal: Macroeconomics 5, no. 2: 1-31.

Kiley, Michael T. 2015. "What Can the Data Tell Us about the Equilibrium Real Interest Rate?" Finance and Economics Discussion Series no. 2015-077. Washington: Board of Governors of the Federal Reserve System.

Kiley, Michael T., and John M. Roberts. 2017. "Monetary Policy in a Low Interest Rate World." In the present volume of Brookings Papers on Economic Activity.

Kiyotaki, Nobuhiro, and John Moore. 2012. "Liquidity, Business Cycles, and Monetary Policy." Working Paper no. 17934. Cambridge, Mass.: National Bureau of Economic Research.

Kozicki, Sharon, and Peter A. Tinsley. 2012. "Effective Use of Survey Information in Estimating the Evolution of Expected Inflation." Journal of Money, Credit and Banking 44, no. 1: 145-69.

Krishnamurthy, Arvind, and Annette Vissing-Jorgensen. 2012. "The Aggregate Demand for Treasury Debt." Journal of Political Economy 120, no. 2: 233-67.

Kurlat, Pablo. 2013. "Lemons Markets and the Transmission of Aggregate Shocks." American Economic Review 103, no. 4: 1463-89.

Laséen, Stefan, and Lars E. O. Svensson. 2011. "Anticipated Alternative Policy Rate Paths in Policy Simulations." International Journal of Central Banking 7, no. 3: 1-35.

Laubach, Thomas, and John C. Williams. 2003. "Measuring the Natural Rate of Interest." Review of Economics and Statistics 85, no. 4: 1063-70.

_. 2016. "Measuring the Natural Rate of Interest Redux." Business Economics 51, no. 2: 57-67. 
Longstaff, Francis A. 2004. "The Flight-to-Liquidity Premium in U.S. Treasury Bond Prices." Journal of Business 77, no. 3: 511-26.

Longstaff, Francis A., Sanjay Mithal, and Eric Neis. 2005. "Corporate Yield Spreads: Default Risk or Liquidity? New Evidence from the Credit Default Swap Market." Journal of Finance 60, no. 5: 2213-53.

López-Salido, David, Jeremy C. Stein, and Egon Zakrajšek. 2016. "Credit-Market Sentiment and the Business Cycle." Working Paper no. 21879. Cambridge, Mass.: National Bureau of Economic Research.

Lubik, Thomas A., and Christian Matthes. 2015. "Calculating the Natural Rate of Interest: A Comparison of Two Alternative Approaches." Economic Brief no. 15-10. Federal Reserve Bank of Richmond.

Neiss, Katharine S., and Edward Nelson. 2003. "The Real-Interest-Rate Gap as an Inflation Indicator." Macroeconomic Dynamics 7, no. 2: 239-62.

Pescatori, Andrea, and Jarkko Turunen. 2015. "Lower for Longer: Neutral Rates in the United States." Working Paper no. 15/135. Washington: International Monetary Fund.

Rachel, Lukasz, and Thomas D. Smith. 2015. "Secular Drivers of the Global Real Interest Rate." Staff Working Paper no. 571. Bank of England.

Sims, Christopher A., and Tao Zha. 1998. "Bayesian Methods for Dynamic Multivariate Models." International Economic Review 39, no. 4: 949-68.

Smets, Frank, and Rafael Wouters. 2007. "Shocks and Frictions in US Business Cycles: A Bayesian DSGE Approach." American Economic Review 97, no. 3: 586-606.

Stock, James H., and Mark W. Watson. 1988. "Testing for Common Trends." Journal of the American Statistical Association 83, no. 404: 1097-107.

1998. "Median Unbiased Estimation of Coefficient Variance in a TimeVarying Parameter Model." Journal of the American Statistical Association 93, no. 441: 349-58.

. 1999. "Forecasting Inflation." Journal of Monetary Economics 44, no. 2: 293-335.

—. 2007. "Why Has U.S. Inflation Become Harder to Forecast?" Journal of Money, Credit and Banking 39, suppl. 1: 3-33.

Summers, Lawrence H. 2014. "Reflections on the 'New Secular Stagnation Hypothesis.'” In Secular Stagnation: Facts, Causes and Cures, edited by Coen Teulings and Richard Baldwin. London: CEPR Press,

Villani, Mattias. 2009. "Steady-State Priors for Vector Autoregressions." Journal of Applied Econometrics 24, no. 4: 630-50.

Vissing-Jorgensen, Annette. 2002. "Limited Asset Market Participation and the Elasticity of Intertemporal Substitution." Journal of Political Economy 110, no. 4: 825-53.

Watson, Mark W. 1986. "Univariate Detrending Methods with Stochastic Trends." Journal of Monetary Economics 18, no. 1: 49-75. 
Wicksell, Knut. 1898. Interest and Prices: A Study of the Causes Regulating the Value of Money. Translated by R. F. Kahn (1936). London: Macmillan.

Woodford, Michael. 2003. Interest and Prices: Foundations of a Theory of Monetary Policy. Princeton University Press.

Wright, Jonathan H. 2011. "Term Premia and Inflation Uncertainty: Empirical Evidence from an International Panel Dataset." American Economic Review 101, no. 4: 1514-34.

Wu, Jing Cynthia, and Ji Zhang. 2016. “A Shadow Rate New Keynesian Model.” Working Paper no. 22856. Cambridge, Mass.: National Bureau of Economic Research.

Yellen, Janet. 2015. "The Economic Outlook and Monetary Policy." Speech given at the Economic Club of Washington, Washington, December 2. 


\section{Comments and Discussion}

\section{COMMENT BY}

JOHN C. WILliAMS This paper by Marco Del Negro, Domenico Giannone, Marc Giannoni, and Andrea Tambalotti sets the ambitious goal of providing a coherent, theoretically founded explanation for why the natural rate of interest, or $r^{*}$, has declined during the past two decades in the United States. The authors present evidence that a sustained rise in the convenience yield - the spread between the return on assets related to the real economy, like corporate bonds, and returns on ultrasafe, highly liquid assets like Treasury securities-combined with a pronounced slowdown in trend productivity growth, have driven down $r^{*}$. By incorporating these medium-term real and financial factors in a dynamic stochastic general equilibrium (DSGE) model, this paper makes an important step in advancing DSGE models' usefulness for studying issues like $r^{*}$ (Williams 2017a). In so doing, it builds a bridge between the existing literature on $r^{*}$, which has primarily used reduced-form models, and the DSGE models used at central banks.

The starting point for this paper is the emerging consensus that $r^{*}$ has declined over the past few decades in the United States (Williams 2017b). The shaded region of my figure 1 shows a range of estimates of $r^{*}$ at each point in time from seven models taken from the literature (Laubach and Willams 2003; Kiley 2015; Lubik and Matthes 2015; Johanssen and Mertens 2016; Holston, Laubach, and Williams 2016; Crump, Eusepi, and Moench 2017; Christensen and Rudebusch 2017). To put these on a consistent basis, in cases where the model uses inflation measured by the consumer price index (CPI), the estimates are increased by 0.23 percentage point to reflect the trend difference in the inflation rates between the CPI and the personal consumption expenditures (PCE) price index (Christensen 
Figure 1. The Range of Existing $r^{*}$ Estimates, 1986-2016

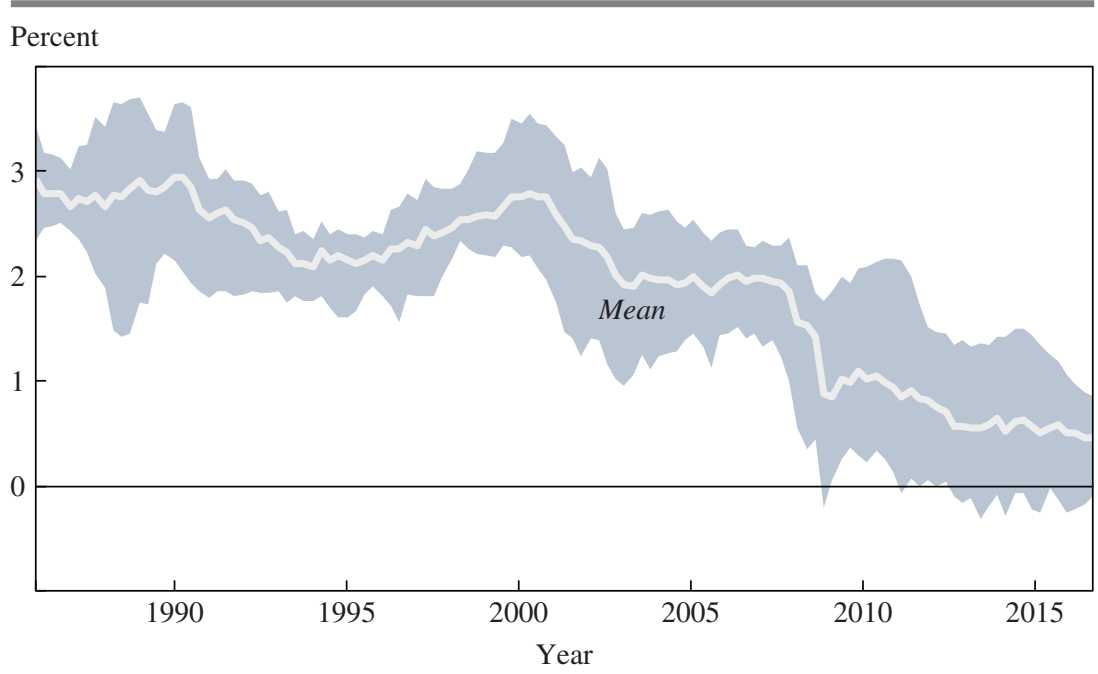

Sources: Laubach and Williams (2003); Kiley (2015); Lubik and Matthes (2015); Johanssen and Mertens (2016); Holston, Laubach, and Williams (2016); Crump, Eusepi, and Moench (2017); Christensen and Rudebusch (2017).

and Rudebusch 2017). The white line shows the mean of the seven estimates at each point in time.

Although these estimates are based on models that differ in terms of specification, methodology, and data, all the estimates reached historically low levels in recent years. As seen in the figure, the mean estimate of $r^{*}$ fluctuated between 2 and 3 percent in the late 1980s and 1990s, fell to about 2 percent in the early $2000 \mathrm{~s}$, and subsequently declined to 0.5 percent in 2016. A striking aspect of these estimates is that they show no signs of moving back to previously normal levels, despite the fact that the U.S. economy has now fully recovered from the Great Recession.

Del Negro and his colleagues add to this literature by estimating a number of vector autoregressive (VAR) models with time-varying intercepts. They use a combination of macroeconomic, survey, and financial market data to estimate these models using Bayesian techniques. This approach builds on the insights, originally due to Sharon Kozicki and P. A. Tinsley (2001), that (i) time variation in intercepts effectively captures most of the instability evident in VAR models, and (ii) survey and financial market data can help pin down these endpoints. In the present paper, the estimates of $r^{*}$ are heavily influenced by the survey and market-based measures. 
Figure 2. The Range of Existing $r^{*}$ Estimates and Estimates Based Solely on Surveys and Bond Yields, 1986-2016

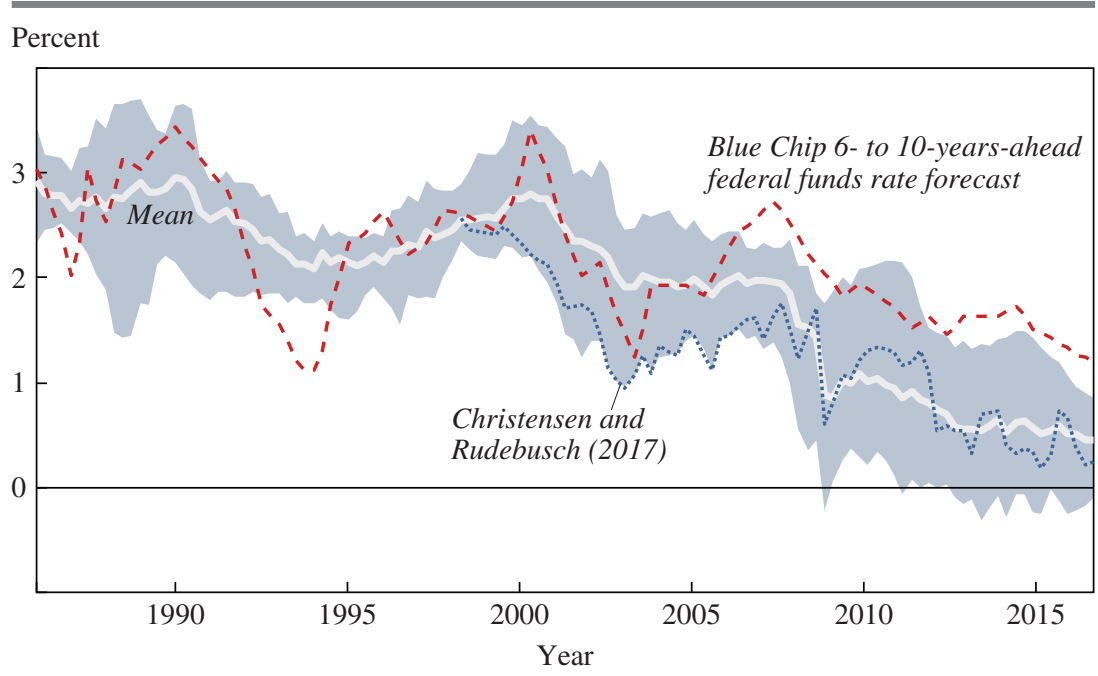

Sources: Laubach and Williams (2003); Kiley (2015); Lubik and Matthes (2015); Johanssen and Mertens (2016); Holston, Laubach, and Williams (2016); Crump, Eusepi, and Moench (2017); Christensen and Rudebusch (2017).

Despite the intuitive appeal of augmenting macroeconomic data with survey and market-based data, it is worth noting that these measures carry with them their own set of issues. First, because they represent the perceptions of market participants, they are indicators of what people think $r^{*}$ is, rather than evidence of structural change inferred directly from economic data. In a world of rational expectations, this is an advantage, because economic agents are efficiently processing all available information to come up with their estimates of $r^{*}$. However, in practice, this search for $r^{*}$ has aspects of a "hall of mirrors," where market participants are trying to discern what the Federal Reserve thinks $r^{*}$ is, while the Federal Reserve's economists are using the views of market participants to estimate $r^{*}$. This may help explain why the estimates of $r^{*}$ reported in this paper are so much more precisely estimated compared with models that do not use survey and market-based indicators (Laubach and Williams 2003; Lubik and Matthes 2015).

Second, market-based indicators often differ from each other by sizable amounts, making estimates based on them sensitive to assumptions and priors used in estimation. My figure 2 illustrates this point. It repeats the range of estimates from my figure 1 and overlays two measures based solely on surveys and bond yields, respectively. The dashed line shows 
Table 1. Estimates of $r^{*}$

\begin{tabular}{lccc}
\hline Source & 1998 & 2016 & Difference \\
\hline Laubach and Williams (2003) & 2.5 & 0.2 & -2.3 \\
Kiley (2015) & 2.5 & 0.9 & -1.7 \\
Lubik and Matthes (2015) & 2.4 & -0.2 & -2.6 \\
Johanssen and Mertens (2016) & 2.5 & 0.8 & -1.7 \\
Holston, Laubach, and Williams (2016) & 3.0 & 0.4 & -2.6 \\
Crump, Eusepi, and Moench (2017) & 2.3 & 0.9 & -1.4 \\
Christensen and Rudebusch (2017) & 2.5 & 0.3 & -2.2 \\
Mean of estimates & 2.5 & 0.5 & -2.1 \\
Del Negro and others' estimates & & & \\
Consumption VAR & 2.6 & 1.2 & -1.3 \\
Productivity VAR & 2.7 & 1.1 & -1.6 \\
10-year forward DSGE & 2.8 & 0.4 & -2.4 \\
\hline
\end{tabular}

a. The estimates from Crump, Eusepi, and Moench (2017) and Christensen and Rudebusch (2017) are adjusted upward by 0.23 percentage point to account for the mean difference between the CPI and the PCE price index.

the biannual consensus forecasts for the real federal funds rate 6 to 10 years in the future taken from the Blue Chip financial forecast (adjusted to reflect the trend difference in the CPI and PCE price index inflation rates mentioned above). The dotted line shows estimates from Jens Christensen and Glenn Rudebusch's (2017) term structure model, which uses indexed Treasury securities to derive expected future real rates. In theory, these two indicators should be measuring close to the same thing. In practice, there are persistent and sizable differences between the two, with the gap nearing a full percentage point in recent years. Clearly, absent other assumptions, survey and financial market indicators alone can assist only so much in pinning down $r^{*}$.

Despite these issues, the present paper's VAR estimates of $r^{*}$ look broadly similar to other estimates made during the past two decades. My table 1 reports the estimated values of $r^{*}$ in 1998 and 2016, along with the difference in estimates between these two dates, for the seven models reported in my figure 1. For comparison, it also reports the estimates from two variants of the VAR model from the present paper. Strikingly, all nine estimates of $r^{*}$ in 1998 are tightly bunched between 2.25 and 3 percent, with a mean estimate of 2.5 percent.

The present paper's VAR model estimates for 2016 are slightly above 1 percent, which is higher than the other seven estimates. The range of estimates for 2016 is -0.2 to 1.2 percent, with a mean of 0.5 percent. Note that all nine estimates display a significant decline since 1998 . The magnitude 
Figure 3. Range of Existing $r^{*}$ Estimates and Del Negro and Others' DSGE Model Estimate, 1986-2016

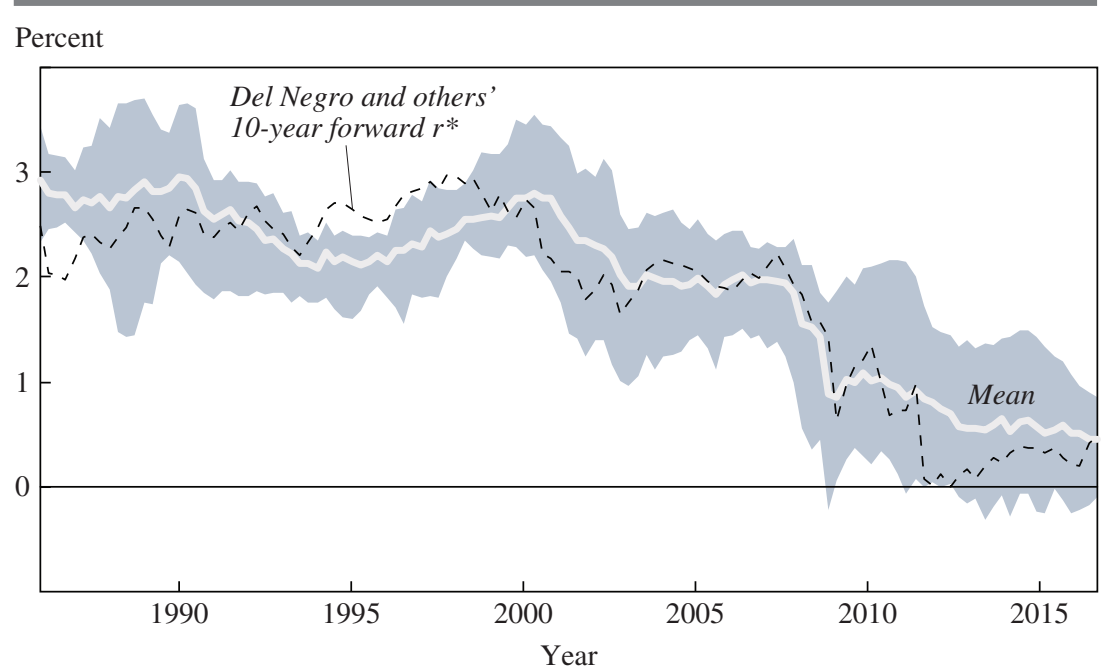

Sources: Laubach and Williams (2003); Kiley (2015); Lubik and Matthes (2015); Johanssen and Mertens (2016); Holston, Laubach, and Williams (2016); Crump, Eusepi, and Moench (2017); Christensen and Rudebusch (2017).

of the decline in the VAR estimates since 1998 is in the lower end of the range, but is similar to the estimates of Richard Crump, Stefano Eusepi, and Emanuel Moench (2017) and Benjamin Johannsen and Elmar Mertens (2016), who, like Del Negro and his colleagues, also combine macroeconomic, survey, and financial data.

Perhaps the most striking result in the paper is the consistency between the DSGE model's estimates of the highly persistent component of $r^{*}$ and estimates taken from the existing literature. My figure 3 again repeats the range of estimates from previous studies, but this time superimposes the DSGE model estimate of the natural rate of interest expected to prevail 10 years in the future (shown by the dashed line in the figure). The DSGE model estimates track the mean of the estimates from the literature remarkably well. Notably, as seen in the final row of my table 1, the recent estimates from the DSGE model are about 0.5 percent, nearly 2.5 percentage points lower than the estimate for 1998.

Del Negro and his colleagues next address the question of why $r^{*}$ has fallen. A litany of potential causes have been identified in the literature (Caballero, Farhi, and Gourinchas 2016; Council of Economic Advisers 2015; Hall 2016; International Monetary Fund 2014; Rachel and Smith 
2015). The present paper narrows the focus to just two leading candidates: a rising convenience yield, and the U.S. productivity slowdown.

Although the paper spends considerably more time on the convenience yield explanation, the growth explanation is equally relevant, both from theory and empirical evidence. For example, the model developed by Thomas Laubach and me (2003) attributes slightly more than half the decline in $r^{*}$ since 1998 to the slowdown in trend growth, leaving the remainder explained by other unspecified factors, potentially including the convenience yield.

The results from both the VAR and DSGE models support the conclusion that the rise in the convenience yield only explains part of the decline in $r^{*}$. Close to half the estimated decline in $r^{*}$ since 1998 in the VAR and DSGE models is explained by the growth slowdown, and the rest is associated with the rise in the convenience yield. The VAR models that incorporate measures of trend productivity or consumption growth show that between 40 and 45 percent of the decline in $r^{*}$ since 1998 is explained by the growth slowdown. ${ }^{1}$ This is seen most clearly in the authors' figure 14 . The DSGE model results are similar, as seen in their figure 13 .

Other evidence supports the notion that real factors like the productivity slowdown have depressed longer-term levels of returns. In its most extreme form, the convenience yield explanation implies that the decline in the return on safe assets is entirely explained by the rise in the convenience yield, leaving the real return to risky assets unchanged. Survey evidence clearly contradicts this prediction (Williams 2017b). The Survey of Professional Forecasters (2017) asks questions about the expected returns to equities, bonds, and Treasury bills over the next 10 years. Comparing the 2017 survey responses with those in 1998, expected medium-term annual real returns to equities and bonds have fallen by 2.7 and 1.7 percentage points, respectively, roughly in line with the 2.2 percentage point decline in expected returns on Treasury bills.

In addition, the evidence in favor of the convenience yield explanation depends on how one measures trends in the convenience yield itself. The authors' figure 7 shows various measures of spreads between yields on narrowly defined groups of bonds and those on Treasury securities having the same duration. Bond spreads rose sharply during the financial crisis, but currently are not at especially elevated levels relative to the precrisis

1. See the authors' table 1, column 4, for VAR results with consumption growth; see their online appendix table A2, column 4, for VAR results with trend productivity. The online appendixes for this and all other papers in this volume may be found at the Brookings Papers web page, www.brookings.edu/bpea, under "Past BPEA Editions." 
Table 2. Median Bond Spreads Precrisis and Postcrisis

\begin{tabular}{lccc}
\hline Source & $1995-2006$ & $2010-16$ & Difference \\
\hline 20-year Refcorp & 0.16 & $0.33^{\mathrm{a}}$ & 0.17 \\
Gilchrist and Zakrajšek (2012) spread & 1.80 & 2.14 & 0.35 \\
Gilchrist and Zakrajšek (2012) excess bond & -0.31 & -0.19 & 0.12 \\
$\quad$ premium & & & \\
Bloomberg Barclays Industrial A 1-year & 0.57 & 0.34 & -0.23 \\
Bloomberg Barclays Industrial A 5-year & 0.75 & 0.70 & -0.05 \\
Bloomberg Barclays Industrial A 10-year & 0.82 & 1.05 & 0.23 \\
Bloomberg Barclays Industrial A 20-year & 1.20 & 1.47 & 0.27 \\
Bloomberg Barclays Industrial BBB 1-year & 0.81 & 0.79 & -0.02 \\
Bloomberg Barclays Industrial BBB 5-year & 1.13 & 1.41 & 0.28 \\
Bloomberg Barclays Industrial BBB 10-year & 1.34 & 1.71 & 0.38 \\
Bloomberg Barclays Industrial BBB 20-year & 1.75 & 1.88 & 0.13 \\
Moody's Aaa Seasoned Corporate & 0.66 & 1.11 & 0.45 \\
Moody's Baa Seasoned Corporate & 1.50 & 2.11 & 0.61 \\
\hline
\end{tabular}

Sources: Gilchrist and Zakrajšek (2012); Bloomberg.

a. The Refcorp spread is through September 2014.

period. Such a calculation is made explicit in my table 2, which compares the medians of various bond spreads during the precrisis period of 1995-2006 with those in the postcrisis period 2010-16. Because spreads are highly asymmetric, the median is used to get a measure of a "normal" spread.

Based on this simple comparison across the two periods, longer-term bond spreads have risen by between 10 and 40 basis points. This comparison suggests that the rise in the convenience yield has played a relatively modest role in the decline in $r^{*}$ over this period. It is particularly important that the current low level of these spreads seen in the authors' figure 7 suggests that any role the elevated convenience yield may have played in recent years is now diminished. This assessment differs markedly from Del Negro and his colleagues' assessment, which uses data that display a larger rise over the two periods, as seen in the last two rows of my table 2, and uses a method of estimating the trend that appears to be overly influenced by the spike in spreads during the financial crisis.

Overall, the paper makes two important contributions to our understanding of the natural rate of interest. The first is the careful incorporation of medium-term real factors that influence $r^{*}$ into a DSGE model. And the second is the inclusion of a meaningful role for financial markets and the convenience yield in the analysis of $r^{*}$. These are important steps, but the paper is best thought of as providing a good start, rather than crossing 
the finish line. In particular, two aspects of the analysis need additional study.

First, further research is needed regarding the measurement of underlying trends in the convenience yield before drawing definitive conclusions regarding its role in the decline in $r^{*}$. Second, the analysis leaves other plausible explanations on the sidelines. In particular, a growing literature highlights the role of demographics, specifically the lengthening of life expectancy, to declining $r^{*}$ (Carvalho, Ferrero, and Nechio 2016; Gagnon, Johannsen, and López-Salido 2016; Eggertsson, Mehrotra, and Robbins 2017). In addition, because the analysis uses a closed-economy model and U.S. data, it abstracts from the global factors that influence $r^{*}$ through channels besides the convenience yield and U.S. productivity growth. Kathryn Holston, Laubach, and I (2016) find that $r^{*}$ has declined in Canada, the United Kingdom, and the euro area as well, suggesting that factors affecting global saving and investment play an important role in the decline of $r^{*}$. Future work can address these open issues, and this paper provides a useful framework for exploring them.

\section{REFERENCES FOR THE WILLIAMS COMMENT}

Caballero, Ricardo J., Emmanuel Farhi, and Pierre-Olivier Gourinchas. 2016. "Global Imbalances and Currency Wars at the ZLB." Working Paper no. 21670. Cambridge, Mass.: National Bureau of Economic Research.

Carvalho, Carlos, Andrea Ferrero, and Fernanda Nechio. 2016. "Demographics and Real Interest Rates: Inspecting the Mechanism." European Economic Review 88: 208-26.

Christensen, Jens H.E., and Glenn D. Rudebusch. 2017. "A New Normal for Interest Rates? Evidence from Inflation-Indexed Debt." Working Paper no. 2017-07. Federal Reserve Bank of San Francisco.

Council of Economic Advisers. 2015. "Long-Term Interest Rates: A Survey." Washington: White House. https://obamawhitehouse.archives.gov/sites/default/ files/docs/interest_rate_report_final.pdf

Crump, Richard K., Stefano Eusepi, and Emanuel Moench. 2017. "The Term Structure of Expectations and Bond Yields." Staff Report no. 775. Federal Reserve Bank of New York.

Eggertsson, Gauti B., Neil R. Mehrotra, and Jacob A. Robbins. 2017. "A Model of Secular Stagnation: Theory and Quantitative Evaluation." Working Paper no. 23093. Cambridge, Mass.: National Bureau of Economic Research.

Gagnon, Etienne, Benjamin K. Johannsen, and David López-Salido. 2016. "Understanding the New Normal: The Role of Demographics." Finance and Economics Discussion Series no. 2016-080. Washington: Board of Governors of the Federal Reserve System. 
Gilchrist, Simon, and Egon Zakrajšek. 2012. "Credit Spreads and Business Cycle Fluctuations.” American Economic Review 102, no. 4: 1692-720.

Hall, Robert E. 2016. "The Role of the Growth of Risk-Averse Wealth in the Decline of the Safe Real Interest Rate.” Working paper. http://web.stanford.edu/ rehall/ DSFIR11032016

Holston, Kathryn, Thomas Laubach, and John C. Williams. 2016. "Measuring the Natural Rate of Interest: International Trends and Determinants." Working Paper no. 2016-11. Federal Reserve Bank of San Francisco.

International Monetary Fund. 2014. World Economic Outlook: Recovery Strengthens, Remains Uneven, April. Washington.

Johannsen, Benjamin K., and Elmar Mertens. 2016. "A Time Series Model of Interest Rates with the Effective Lower Bound." Finance and Economics Discussion Series no. 2016-033. Washington: Board of Governors of the Federal Reserve System.

Kiley, Michael T. 2015. "What Can the Data Tell Us about the Equilibrium Real Interest Rate?" Finance and Economics Discussion Series no. 2015-077. Washington: Board of Governors of the Federal Reserve System.

Kozicki, Sharon, and P. A. Tinsley. 2001. "Shifting Endpoints in the Term Structure of Interest Rates." Journal of Monetary Economics 47, no. 3: 613-52.

Laubach, Thomas, and John C. Williams. 2003. "Measuring the Natural Rate of Interest." Review of Economics and Statistics 85, no. 4: 1063-70.

Lubik, Thomas A., and Christian Matthes. 2015. "Calculating the Natural Rate of Interest: A Comparison of Two Alternative Approaches." Economic Brief no. 15-10. Federal Reserve Bank of Richmond.

Rachel, Lukasz, and Thomas D. Smith. 2015. "Secular Drivers of the Global Real Interest Rate." Staff Working Paper no. 571. Bank of England.

Survey of Professional Forecasters. 2017. "Survey of Professional Forecasters, First Quarter 2017." Federal Reserve Bank of Philadelphia. https://www. philadelphiafed.org/research-and-data/real-time-center/survey-of-professionalforecasters/2017/survq117

Williams, John C. 2017a. "DSGE Models: A Cup Half Full." In DSGE Models in the Conduct of Policy: Use as Intended, edited by Refet S. Gürkaynak and Cédric Tille. London: CEPR Press.

. 2017b. "Three Questions on R-star." Economic Letter no. 2017-05. Federal Reserve Bank of San Francisco.

\section{COMMENT BY}

JING CYNTHIA WU Marco Del Negro, Domenico Gianonne, Marc Giannoni, and Andrea Tambalotti study the natural rate of interest, and examine what contributes to the recent trend of low interest rates in the United States. This topic is interesting and timely, and the authors have done an elaborate analysis. I agree with their conclusion that there is a 
downward trend in interest rates. But they attribute this decline to premiums for safety and liquidity, which I find less convincing.

THE DOWNWARD TREND IN INTEREST RATES I agree with the authors' conclusion of a decline in the trend of interest rates since the late 1990s. I elaborate on this point through the lens of term structure models of interest rates, which is a more popular alternative, for several reasons. First, the no-arbitrage constraint guarantees that the cross section of yields will be internally consistent. Second, this class of models fits the data well, because it does not impose as much structure as dynamic stochastic general equilibrium (DSGE) models. Third, term structure models assume stationarity for nominal yields. Decomposing long-term yields into expectations of the future short-term rate and term premiums is one core question in the term structure literature (Duffee 2002; Wright 2011; Creal and Wu 2016). The expectation component maps into the trend reported by Del Negro and his colleagues. Michael Bauer, Glenn Rudebusch, and I $(2012,2014)$ use a simulation-based method to correct for small sample bias, and show that there is a downward trend in the expectations. Although we use a different methodology, our conclusion about the downward trend confirms one of the main findings of the present paper.

MODEL-IMPLIED $r^{*}$ Del Negro and his colleagues use a DSGE model to extract the natural rate of interest $r^{*}$, where they specify the Euler equation with convenience yield, in line with the work of Arvind Krishnamurthy and Annette Vissing-Jorgensen (2012) and Wu and Ji Zhang (2016). As I mentioned above, I agree with the general conclusion that interest rates have had a downward trend since the late 1990s. However, the estimated natural rate of interest from the DSGE model seems counterintuitive, for two reasons.

First, the $r^{*}$ is implausibly negative. Nominal interest rates are subject to a physical lower bound. Although real interest rates can be arbitrarily negative in theory, the lower bound on nominal rates also constrains real rates, given inflation expectations. The implied nominal $r^{*}$ is as low as -4 percent based on the authors' calculation in a previous version of the paper and my own calculation. Such a large negative number for the nominal interest rate is implausible. First, we do not observe negative interest rates throughout U.S. history. Second, the concept of the natural rate of interest is without interventions by the monetary authority, whereas negative interest rates in Europe and Japan are artificially created by the central banks. Why would agents in an economy without nominal rigidities and a central bank be willing to take a loss by lending money to others when they have the option to store money? Third, even in the cases of Europe and 
Japan, we have observed negative interest rates on the order of magnitude of tens of basis points, which is far from -4 percent. Getting to this point already places significant political pressure on their central banks. ${ }^{1}$

Another counterintuitive implication of the DSGE model is that the natural rate of interest is more volatile than the actual rate (see the authors' figure 15), with the variance of the former being three times that of the latter. This is puzzling, and the opposite of common wisdom. Conceptually, the natural rate of interest removes one source of time variation: nominal rigidities. Therefore, it should be less volatile, unless the nominal rigidities have negative correlations with other factors in the economy. Is there any empirical evidence for such a negative correlation? After all, the natural rate of interest is an unobserved counterfactual object.

Both these aspects invite further investigation and modification of the model. I lay out one potential direction below.

THE ZERO LOWER BOUND AND THE SHADOW RATE The present paper lacks proper treatment for the zero lower bound (ZLB) period. For example, in their reduced-form analysis, the authors simply ignore the short-term interest rate data at the ZLB, arguing that the short-term rate in this period might distort their inference on the trends. However, this choice makes the model internally inconsistent. They discard the short-term rate and pretend the ZLB does not exist. At the same time, agents are forward looking, and they factor the future ZLB into yields at longer maturities. The same lower bound should constrain the nominal trend and $r^{*}$. Moreover, discarding information leads to less accurate estimations. In the DSGE model, they linearize the equilibrium conditions without considering the ZLB, and then assume the ZLB is driven by some exogenous shocks. This solution method leads to the implausibly negative nominal $r^{*}$.

One potential treatment for the ZLB that is commonly adopted in the term structure literature is the shadow rate concept proposed by Fischer Black (1995):

$$
r_{t}=\max \left(s_{t}, \underline{r}\right)
$$

where $r_{t}$ is the observed nominal short-term interest rate, $s_{t}$ is the shadow interest rate that is not subject to a lower bound, and $\underline{r} \approx 0$ is the underlying lower bound. ${ }^{2}$ Imposing a structure like my equation 1 makes the model

1. For a discussion of the eurozone's negative interest rates, see Wu and Xia (2017).

2. See Christensen and Rudebusch (2015), Wu and Xia (2016, 2017), Bauer and Rudebusch (2016), and Lombardi and Zhu (2014) for implementations in the term structure literature. See Wu and Zhang (2016) for a DSGE model. 
Figure 1. Nominal $r^{*}$ and the Shadow Rate, 1960-2016

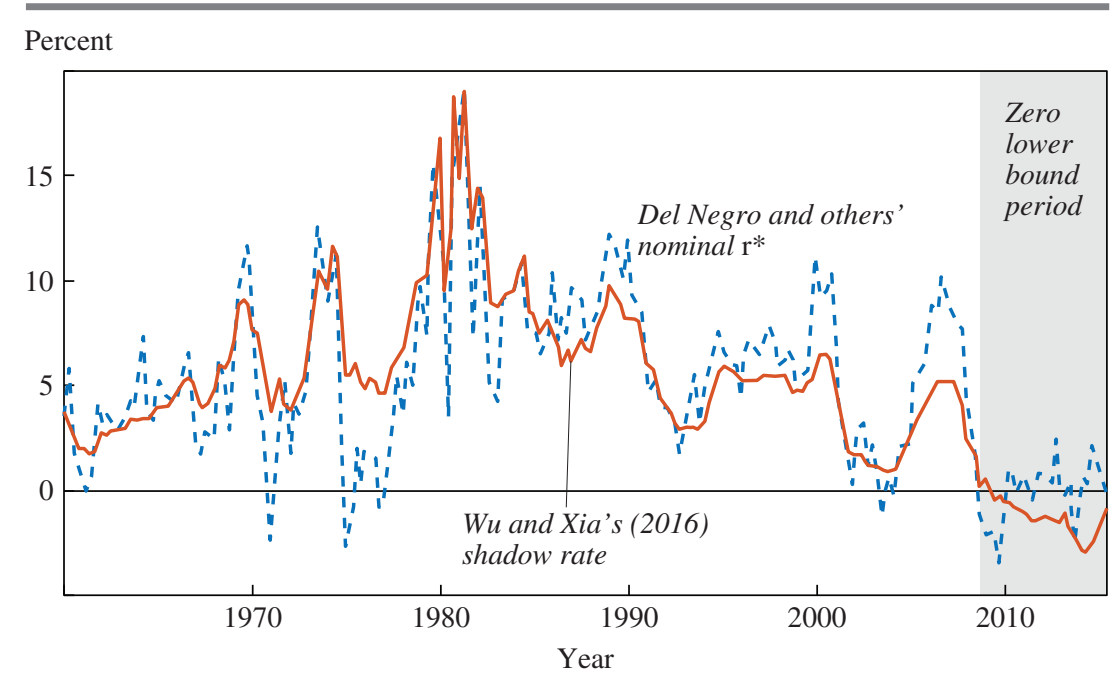

Sources: Del Negro and others; Wu and Xia (2016).

and its implications internally consistent. For example, the short-term rate, the trend in nominal rates, and the expectations for longer rates are all subject to the same lower bound.

This modification also speaks to the overly negative natural rate of interest implied by the DSGE model. The potential consolidation could be that it is really the nominal natural shadow rate $s^{*}$ that is negative at the ZLB. The nominal natural rate of interest, conversely, still remains nonnegative, due to the restriction in my equation 1 . Furthermore, the extended downward trend at the ZLB is about $s^{*}$ instead of $r^{*}$, as both real and nominal $r^{*}$ should essentially be constant.

My figure 1 compares the nominal natural rate of interest $r^{*}$ of Del Negro and his colleagues (dashed line) with Wu and Fan Dora Xia's (2016) shadow rate (solid line). The resemblance of the levels of the two series at the ZLB can be explained within the content of Wu and Zhang's (2016) DSGE model. Both the present paper and Wu and Zhang (2016) use a linearized DSGE model. The key difference is that the former model is linear in the nominal short-term interest rate $r_{t}$, whereas the latter model is linear in the shadow rate $s_{t}$, which relates to the short-term rate through my equation 1. In Wu and Zhang's (2016) specification, although the nominal short-term rate is bounded by the lower bound $\underline{r}$ as observed in the data, the shadow rate is not constrained, and the negative shadow rate explains 
unconventional monetary policy. Therefore, the shadow rate is a natural interpretation for the negative nominal rates found by Del Negro and his colleagues.

THE TREND IN THE CONVENIENCE YIELD Although I agree with the conclusion of a declining trend of interest rates since the late 1990s, whether the premium for safety and liquidity is the source for this decline is questionable. The evidence supporting this conclusion is the increase in the convenience yield, shown in the top-right panel of the authors' figure 3, which is informed by the Baa-Treasury spread. To focus on the trend highlighted in their paper since the very end of the 1990s, the top panel of my figure 2 plots their preferred corporate spread starting from the year 2000. There is no obvious trend except for a peak during the Great Recession.

The bottom panel of my figure 2 plots alternative corporate spreads with different risk characteristics: a high-yield spread, a BBB spread, an overall master spread, and an AAA spread. All of them comove with each other and with the series preferred by Del Negro and his colleagues. The most prominent pattern is a much higher peak during the Great Recession. Otherwise, all the series seem to fluctuate around their unconditional means. However, none of them display an obvious upward trend as extracted from the authors' model. Therefore, although the downward trend in interest rates seems to be there, the main contributing factor claimed in the paper is open to debate.

MODEL-DEPENDENT RESULTS The trend-cycle decomposition is sensitive to model specifications. My figure 3 plots the two trends extracted from the authors' reduced-form analyses in their subsections II.A and II.B. The two lines display distinct trends up to the year 2000. For the first 70 percent of the sample, the correlation is very low, at .37. They differ in the following dimensions. First, the gap between the trends was very wide at the beginning of the sample, nearly 0.8 percentage point. Second, the broad trends are significantly different. For instance, the solid line shows an increase until the early 1980s, then a flattening out until 2000. In contrast, the dotted line was flat until the mid-1980s; then it increased and peaked in the mid1990s. Third, they do not share the same cyclical behaviors. For example, during the recession in the early 1970s, the solid line increased whereas the dotted line decreased.

These contrasts are striking, given the fact that the analyses are based on similar model specifications and data. The only difference is that the authors introduce the Baa corporate bonds in subsection II.B, which in principle should not change the trend on the real interest rate much, but rather provide some inference about the convenience yield. The difference 
Figure 2. Corporate Bond Spreads, 2000-16

\section{Baa spread}

Percent

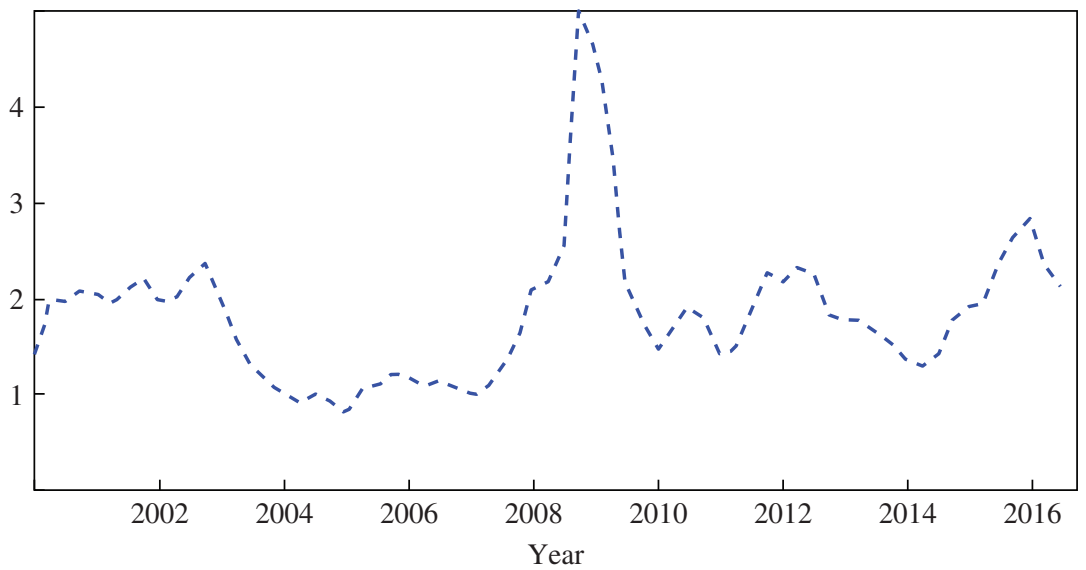

Alternative spreads

Percent

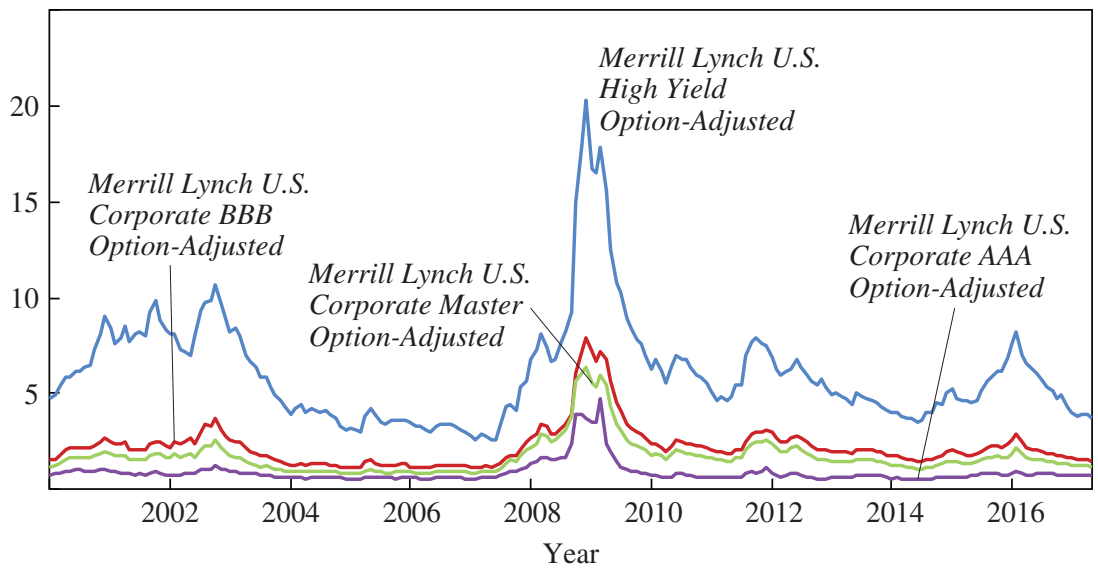

Sources: Del Negro and others; Federal Reserve Economic Data. 
Figure 3. Trends in Two Versions of the Reduced-Form Model, 1960-2016

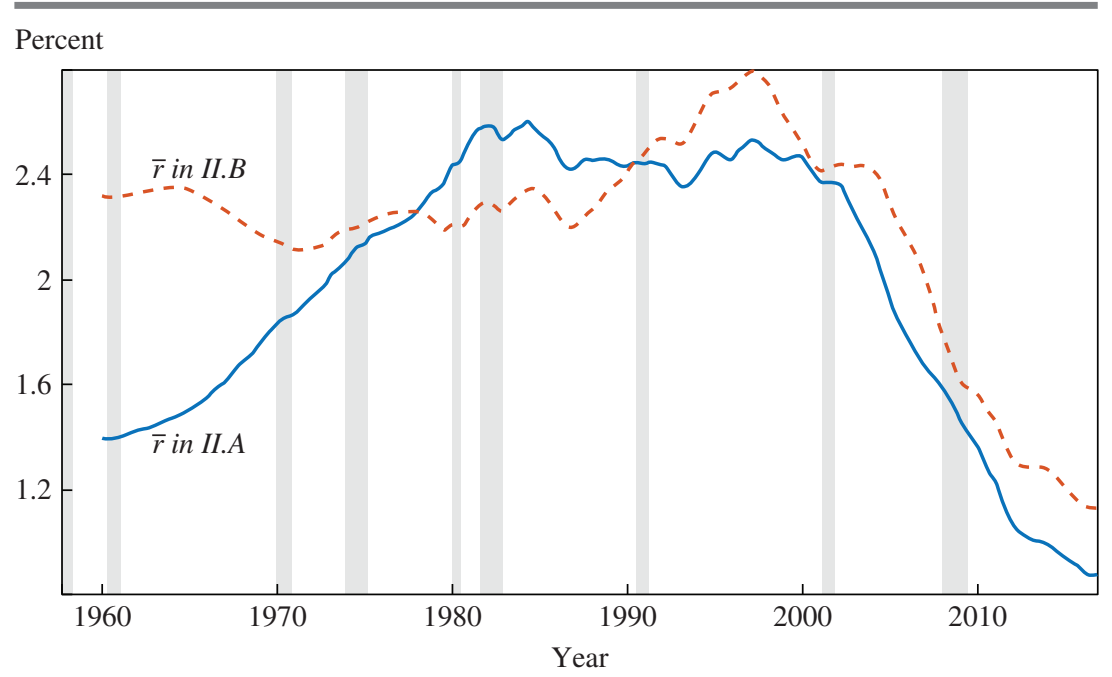

Source: Del Negro and others.

is more dramatic when compared with the findings of Thomas Laubach and John Williams (2003) (see Del Negro and his colleagues' figure 12). For 70 percent of the sample before 2000, the correlation between the two series is -.21 , meaning the two versions of the natural rate of interest are moving in opposite directions. Moreover, the biggest gap is more than 4 percentage points.

\section{REFERENCES FOR THE WU COMMENT}

Bauer, Michael D., and Glenn D. Rudebusch. 2016. "Monetary Policy Expectations at the Zero Lower Bound." Journal of Money, Credit and Banking 48, no. 7: 1439-65.

Bauer, Michael D., Glenn D. Rudebusch, and Jing Cynthia Wu. 2012. "Correcting Estimation Bias in Dynamic Term Structure Models." Journal of Business \& Economic Statistics 30, no. 3: 454-67.

2014. "Term Premia and Inflation Uncertainty: Empirical Evidence from an International Panel Dataset: Comment." American Economic Review 104, no. 1: 323-37.

Black, Fischer. 1995. "Interest Rates as Options." Journal of Finance 50, no. 5: 1371-76.

Christensen, Jens H.E., and Glenn D. Rudebusch. 2015. "Estimating Shadow-Rate Term Structure Models with Near-Zero Yields." Journal of Financial Econometrics 13, no. 2: 226-59. 
Creal, Drew D., and Jing Cynthia Wu. 2016. "Bond Risk Premia in ConsumptionBased Models." Working paper. http://faculty.chicagobooth.edu/drew.creal/ research/papers/crealWu2016_cons.pdf

Duffee, Gregory R. 2002. "Term Premia and Interest Rate Forecasts in Affine Models." Journal of Finance 57, no. 1: 405-43.

Krishnamurthy, Arvind, and Annette Vissing-Jorgensen. 2012. "The Aggregate Demand for Treasury Debt." Journal of Political Economy 120, no. 2: 233-67.

Laubach, Thomas, and John C. Williams. 2003. "Measuring the Natural Rate of Interest." Review of Economics and Statistics 85, no. 4: 1063-70.

Lombardi, Marco, and Feng Zhu. 2014. "A Shadow Policy Rate to Calibrate US Monetary Policy at the Zero Lower Bound." Working Paper no. 452. Basel: Bank for International Settlements.

Wright, Jonathan H. 2011. "Term Premia and Inflation Uncertainty: Empirical Evidence from an International Panel Dataset." American Economic Review 101, no. 4: $1514-34$.

Wu, Jing Cynthia, and Fan Dora Xia. 2016. "Measuring the Macroeconomic Impact of Monetary Policy at the Zero Lower Bound." Journal of Money, Credit and Banking 48, nos. 2-3: 253-91.

. 2017. "Time-Varying Lower Bound of Interest Rates in Europe." Research Paper no. 17-06. Chicago: University of Chicago, Booth School of Business.

Wu, Jing Cynthia, and Ji Zhang. 2016. "A Shadow Rate New Keynesian Model." Working Paper no. 22856. Cambridge, Mass.: National Bureau of Economic Research.

GENERAL DISCUSSION When thinking about safety and liquidity premiums, Jonathan Wright stressed the importance of asking, safety and liquidity relative to what? In theory, the baseline scenario assumes a risk-free rate equal to the inverse of the expectation of the stochastic discount factor. But this assumption, he pointed out, does not take default risk into account. Such an exercise, therefore, could produce a measure of the liquidity premium but not the safety premium. Wright was wary of the authors' approach to defining the convenience yield relative to the Baa interest rate spread because that approach incorporates both default risk and the pricing of default risk, that is, the credit risk premium. He preferred to think of the natural rate of interest in terms of a benchmark, risk-free, short-term rate, such as the return on Treasury bills or the federal funds rate. Within this framework, there are still liquidity premiums, which arguably have risen in recent years; but these increases could only be basis points, not full percentage points. Wright suggested that the authors' large estimates for convenience yields resulted from conflating the liquidity premium with a credit spread. The paper seems to treat the 
Baa spread as some kind of constant of nature, such that when the credit spread rises, the natural rate of interest is mechanically forced down. The credit spread and the liquidity premium should be treated separately, he concluded.

Emi Nakamura was sympathetic to discussant John Williams's perspective that the crucial question is not just whether the natural rate of interest has fallen but also why, and she suspected that the time series could have something to say. The first thing to notice in the time series is that there are large declines in the risk-free rate and large increases in the risk premiums associated with crises, most notably the Great Recession and the Great Depression. This observation struck Nakamura as very supportive of the view that something about risk premiums, liquidity premiums, or something else is involved in certain periods of low interest rates.

Was it an accident that the natural rate of interest fell steeply during the Great Recession, Nakamura wondered. If not, then what does this tell us about which explanation is correct? Certain explanations, such as demographic shifts, would not change discontinuously during the financial crisis. But perhaps large declines in productivity were caused by something that happened during the financial crisis-or there could have been changes in people's expectations about growth or uncertainty. Maybe nothing real about the world changed during the financial crisis, but just people's views of the world; perhaps they realized the world was riskier than they had previously thought.

Eric Swanson stated that there seems to be a debate about whether the decline in the natural rate of interest is due to (i) safety and liquidity factors, the view of the authors and of Arvind Krishnamurthy and Annette VissingJorgensen; or (ii) changes in real factors, the view of Williams and of Larry Summers. ${ }^{1}$ Swanson presented two additional cases that he believed supported the authors' safety and liquidity argument. The first is the observation that some major arbitrages in financial markets are no longer occurring to the extent that they used to, which seems to suggest a greater premium on financial capital since the financial crisis and presumably

1. Arvind Krishnamurthy and Annette Vissing-Jorgensen, "The Aggregate Demand for Treasury Debt," Journal of Political Economy 120, no. 2 (2012): 233-67; Kathryn Holston, Thomas Laubach, and John C. Williams, "Measuring the Natural Rate of Interest: Trends and Determinants," Journal of International Economics (forthcoming); Lawrence H. Summers, "Economic Forum: Policy Responses to Crises," speech given at the 14th Annual Jacques Polak Research Conference, International Monetary Fund, Washington, November 8, 2013; Lawrence H. Summers, "U.S. Economic Prospects: Secular Stagnation, Hysteresis, and the Zero Lower Bound," Business Economics 49, no. 2 (2014): 65-73. 
also on safer and more liquid assets. (A recent paper by Wenxin Du, Alexander Tepper, and Adrien Verdelhan documents this lack of arbitrage very rigorously. ${ }^{2}$ ) The second argument against the real factors explanation is that it would seem to imply that not only has the marginal product of capital in the United States fallen during the past 10 to 15 years, but it has also fallen more or less for the whole world, given the international mobility of capital. Swanson argued that a global decline in the marginal product of capital seemed implausible, given the economic diversity of countries around the world.

Michael Kiley asserted that a number of factors clearly suggest that the natural rate of interest has fallen. But he pushed the authors on how strong their empirical evidence really was. The authors' one-sided estimates of the natural rate of interest are high and relatively constant, at about 2 percent, and then drop in the years 2009-11, which is consistent with other work by Kiley. ${ }^{3} \mathrm{He}$ finds, using a Bayesian analysis, that the data are essentially completely uninformative regarding key parameters governing the evolution of the natural rate of interest: The posterior distribution on the properties of the natural rate of interest process-for example, the variance of the innovation to the natural rate of interest-essentially equals the prior distribution. Kiley wondered if this was also true in the authors' analysis. Are their data telling them anything about the process that the natural rate of interest follows, or is it all driven by their prior distribution? He noted that the authors' robustness tests did not illustrate this point, and he suspected that the authors had a prior distribution in which the innovations to the natural rate of interest had small variances, implying that a slowly declining trend would emerge from their filtering of the data, but that the data did not actually inform the statistical process, and hence the degree of smoothing by the filter, in a meaningful way.

Edward Lazear noted that credit spreads fell dramatically during the loose-money period of 2003-05, but that in 2009, during a similar period of loose-money policy, credit spreads were very large. As Kiley also noted, the authors' model assumes a fairly continuous process; but all the action, Lazear contended, occurs in deviations from the trend. He asked the authors to elaborate on how their model could explain low credit spreads in one loose-money regime and very high spreads in another.

2. Wenxin Du, Alexander Tepper, and Adrien Verdelhan, "Deviations from Covered Interest Rate Parity,” Working Paper no. 23170 (Cambridge, Mass.: National Bureau of Economic Research, 2017).

3. Michael T. Kiley, "What Can the Data Tell Us about the Equilibrium Real Interest Rate?" Finance and Economics Discussion Series no. 2015-077 (Washington: Board of Governors of the Federal Reserve System, 2015). 
Christopher Carroll sought to sharpen a point that had been implicit in several of the previous comments. He did not think it very useful to try to combine two fundamentally different questions - the first being Why have real interest rates of all kinds declined over the last 20 to 30 years compared with their historical norms? and the second being How should one explain short-term deviations? He argued for completely separate treatments of those two questions. We have a reasonably good handle on the first, he noted; Ben Bernanke called it the "global saving glut" in 2005, and Carroll believed this explained a great deal of the decline. ${ }^{4}$ The global saving glut is also a useful way of thinking about where the long-term real interest rate is likely to go in the future. Data on savings rates in different countries show that they tend to be slow moving and stable. To the extent that this is the right story about the long-term decline in interest rates, it is useful to know, because one should anticipate that interest rates will likely be low for quite a long time into the future. Michael Klein agreed with Carroll that the international dimension might be quite important. The dollar actually appreciated during the financial crisis, which is a bit of a conundrum. In terms of convenience yield, there seems to have been increasing demand for U.S. Treasury bills, he noted.

Markus Brunnermeier wondered why the authors decided to use the Baa spread and the on-the-run/off-the-run liquidity spread-among many other potential candidates-as their preferred liquidity measures. More important, he noted that if uninsurable credit risk is increasing, this would naturally result in a lower risk-free rate, which has nothing to do with any risk premium and would not show up in the Baa-Aaa spread or in the onthe-run/off-the-run spread. Furthermore, this uninsurable credit risk could come from emerging markets abroad.

Athanasios Orphanides was curious about the role of quantitative easing in this debate. During the financial crisis, the Federal Reserve appropriately used its authority to purchase massive amounts of Treasury debt, which brought down yields and premiums, but it did not have the same authority to purchase corporate bonds. If the Federal Reserve had also purchased corporate bonds, corporate yields would also have fallen, Orphanides presumed. He wondered how this would have affected the authors' estimates. Relatedly, in thinking about real factors versus financial factors, he posited that one way to summarize some of the financial factors that are driven by government policy—not the market—is to refer

4. Ben S. Bernanke, "The Global Saving Glut and the U.S. Current Account Deficit," remarks given at the Sandridge Lecture, Virginia Association of Economists, Richmond, March 10, 2005. 
to them as constituting financial repression. Policies can effectively change the relative demand for safe assets-which, in the context of the authors' model, would bring down the estimate of the natural rate of interest. $\mathrm{He}$ wondered how the authors might clean out these policy-related factors from their estimates.

Narayana Kocherlakota reiterated why one should care about what is driving down the natural rate of interest-if it is actually falling. He posited that the reason one should care is that one set of explanations does not involve a role for governmental policy, whereas another set does. If one thinks this is because of a demand for safety, that could be fulfilled by increasing the supply of safe assets held by governments such as the United States and the United Kingdom. This really matters, he noted, and points one in a different direction for modeling than what the authors do in their paper. This approach would try to build models that explicitly include the supply and demand for safety. He believed the discussion would be enriched by being more explicit about the relative supply of and demand for safety, and that some of the identification issues might be enhanced as well.

Kocherlakota also followed up on comments made by discussant Cynthia $\mathrm{Wu}$ about the zero lower bound. He suggested that the authors take into account various measures of the natural rate of interest that depend on whether one thinks the zero lower bound is going to be binding in the future. The typical way of estimating the natural rate of interest, as he understood it, assumes that the economy will be at full potential for the foreseeable future. But if the central bank is going to be running into the zero lower bound fairly frequently, there is no reason why that is going to be the right measure, he concluded.

James Stock pushed back on a comment made by Swanson about the international dimension. Another aspect of this dimension, along with declining global real rates, is the global slowdown in growth. This slowdown would seem to argue for real factors rather than only the financial market to explain the decline in the real rate.

Many stories have been proposed to explain the decline in interest rates, especially during the 1990s. The point of the present paper-one of its authors, Marc Giannoni, argued - is not to rule out some of the stories but to emphasize that the convenience yield has played a role in explaining part of the decline in yields over time. In their comments on the paper, both Williams and Wu raised issues about this trend in the last part of the sample, but Giannoni noted that what is important to keep in mind is that they only focused on the trend from 2000 onward. The authors use data from Krishnamurthy and Vissing-Jorgensen, both because this is an established 
approach in the literature but also because their data go back to the early 1960s. These data, and also data from Simon Gilchrist and Egon Zakrajšek, clearly show the rising trend in the convenience yield between the early 1990s and the current period. ${ }^{5}$ Cutting the data from 2000 onward does not show this trend as clearly.

With regard to the comments on the zero lower bound, Giannoni noted that in the time series model, the authors omit data on the short-term rates during the zero lower bound period. This omission could cause a loss of efficiency, but it is not clear that the authors bias the result one way or the other. In the dynamic stochastic general equilibrium setup, the authors formally account for the zero lower bound, using actual data for both the short-term rate and expected future short-term rates to capture the effects of forward guidance or large-scale asset purchases. They capture the counterfactual natural rate of interest as the rate where monetary policy does not have an effect on the economy, so that the natural rate of interest does not need to account for the zero lower bound.

Nakamura and Klein, in their remarks, raised concerns about the drivers of interest rates and their relationship to the convenience yield. Giannoni noted that in the present paper, the authors emphasize the long-run factors that drive interest rates, which have much to do with the long-term factors in convenience. But many other factors also affect rates in the short term. In particular, during recessions, shocks to the marginal efficiency of investment, to productivity, and monetary shocks have played an important role in explaining the behavior of short-term rates. But the effects of these shocks tend to die out, so what are left in the long run are convenience yields.

Andrea Tambalotti believed that he and the paper's other authors were quite careful in their estimates to account for statistical uncertainty. Although this uncertainty is especially relevant when estimating the level of the natural rate of interest, the decline since the 1990s is clear across different models. This decline is what the authors try to emphasize, rather than the exact level at any given point in time. He also noted that there are many ways of looking at the data, but the point of the paper is measurement. The literature is clear that spreads between some assets, and not others, are a useful way to think about safety and liquidity. There are many other ways of measuring spreads; the authors used a measurement approach that they thought was reasonably standard in the literature. They were especially

5. Simon Gilchrist and Egon Zakrajšek, "Credit Spreads and Business Cycle Fluctuations," American Economic Review 102, no. 4 (2012): 1692-720. 
careful about the decomposition between cycle and trend, a concern raised by Carroll and Nakamura. Tambalotti concluded by saying that the authors tried to separate the cycle from the trend as carefully as they could statistically, and that the debate on the features of the data is going to be about how to explain them theoretically.

Marco Del Negro thought it would be interesting to look at the international data to see whether the decline in the convenience yield is important. However, he noted that the authors' story already has an international dimension that is very consistent with the global saving glut hypothesis, and in particular with Bernanke's work on international capital flows and the return to safe assets. ${ }^{6}$ This work documents foreign central banks' and foreign investors' strong demand for safe and liquid securities, such as U.S. Treasury bonds, during the 2000s. This finding is consistent with the authors' trend for the convenience yield.

He also addressed Kiley's remark on the extent to which the data are informative in regard to the key parameters governing the evolution of the natural rate of interest, especially the standard deviation of innovations to the trend. He pointed out that a figure in the online appendix shows the prior and posterior distributions of these parameters, and documents that for important parameters - namely, the standard deviations or trends to the convenience yield - the posterior is quite different from the prior, suggesting that the data are informative. He also pointed out that in the robustness section of the paper, the authors performed their analysis using very uninformative priors, and obtained similar secular movements in the natural rate of interest and the convenience yield.

6. Ben S. Bernanke, Carol Bertaut, Laurie Pounder DeMarco, and Steven Kamin, "International Capital Flows and the Returns to Safe Assets in the United States, 2003-2007," International Finance Discussion Paper no. 1014 (Washington: Board of Governors of the Federal Reserve System, 2011). 